\title{
Toward an integrated clinical, molecular and serological classification of inflammatory bowel disease: Report of a Working Party of the 2005 Montreal World Congress of Gastroenterology
}

\author{
Mark S Silverberg MD PhD FRCPC ${ }^{1 *}$, Jack Satsangi DPhil FRCP FRCPE ${ }^{2 *}$, Tariq Ahmad MRCP, DPhil ${ }^{3}$, \\ Ian DR Arnott BSc MBChB MRCP MD², Charles N Bernstein $\mathrm{MD}^{4}$, Steven R Brant $M D^{5}$, Renzo Caprilli $M D^{6}$, \\ Jean-Frédéric Colombel $\mathrm{MD}^{7}$, Christoph Gasche $\mathrm{MD}^{8}$, Karel Geboes $M D \mathrm{PhD}^{9}$, Derek P Jewell DPhil FRCP10, \\ Amir Karban $\mathrm{MD}^{11}$, Edward V Loftus Jr MD ${ }^{12}$, A Salvador Peña MD PhD FRCP ${ }^{13}$, Robert H Riddell MD FRCPC FRCPath ${ }^{14}$, \\ David B Sachar MD FACP MACG ${ }^{15}$, Stefan Schreiber MD ${ }^{16}$, A Hillary Steinhart MD ${ }^{1}$, Stephan R Targan MD ${ }^{17}$, \\ Severine Vermeire $M D P^{2} D^{18}$, Bryan F Warren MB ChB FRCPath ${ }^{19}$
}

\begin{abstract}
MS Silverberg, J Satsangi, T Ahmad, et al. Toward an integrated clinical, molecular and serological classifcation of inflammatory bowel disease: Report of a Working Party of the 2005 Montreal World Congress of Gastroenterology. Can J Gastroenterol 2005;19(Suppl A):5A-36A.
\end{abstract}

The discovery of a series of genetic and serological markers associated with disease susceptibility and phenotype in inflammatory bowel disease has led to the prospect of an integrated classification system involving clinical, serological and genetic parameters. The Working Party has reviewed current clinical classification systems in Crohn's disease, ulcerative colitis and indeterminate colitis, and provided recommendations for clinical classification in practice. Progress with respect to integrating serological and genetic markers has been examined in detail, and the implications are discussed. While an integrated system is not proposed for clinical use at present, the introduction of a widely acceptable clinical subclassification is strongly advocated, which would allow detailed correlations among serotype, genotype and clinical phenotype to be examined and confirmed in independent cohorts of patients and, thereby, provide a vital foundation for future work.

Key Words: Anti-Saccharomyces cerevisiae antibodies; Crohn's disease; HLA complex; Indeterminate colitis; NOD2/CARD15; Ulcerative colitis
Vers une classification clinique, moléculaire et sérologique intégrée des maladies inflammatoires de l'intestin : Rapport d'un groupe de travail du World Congress of Gastroenterology de 2005 à Montréal

La découverte d'une série de marqueurs génétiques sérologiques associés à la susceptibilité à la maladie et au phénotype dans les maladies inflammatoires de l'intestin a donné lieu à la perspective d'un système de classification intégré mettant en cause des paramètres cliniques, sérologiques et génétiques. Le groupe de travail a analysé les systèmes de classification clinique courants de la maladie de Crohn, de la colite ulcéreuse et de la colite indéterminée et a fourni des recommandations de classification clinique dans la pratique. Les progrès réalisés dans l'intégration des marqueurs sérologiques et génétiques ont été examinés à fond, et les conséquences sont exposées. Aucun système intégré n'est proposé en vue d'un usage clinique pour l'instant, mais l'adoption d'une sous-classification clinique acceptable est fortement recommandée, ce qui permettrait d'examiner et de confirmer les corrélations détaillées entre le sérotype, le génotype et le phénotype clinique dans des cohortes indépendantes de patients et, par conséquent, de fournir les fondements essentiels à de futurs travaux.

*These authors contributed equally to this work. ${ }^{1}$ Department of Medicine, Mount Sinai Hospital IBD Centre, University of Toronto, Toronto, Ontario; ${ }^{2}$ Department of Gastroenterology, Western General Hospital, University of Edinburgh, Edinburgh; ${ }^{3}$ Gastroenterology Unit, University of Oxford, Gibson Laboratories, Radcliffe Infirmary, Oxford, United Kingdom; ${ }^{4}$ Department of Medicine, Section of Gastroenterology, University of Manitoba IBD Clinical and Research Centre, Winnipeg, Manitoba; ${ }^{5}$ The Harvey M and Lyn P Meyerhoff Inflammatory Bowel Disease Center, Department of Medicine, John Hopkins University School of Medicine, and Department of Epidemiology, Johns Hopkins Bloomberg School of Public Health, Baltimore, Maryland, USA; ${ }^{2}$ Department of Clinical Sciences, University of Rome "La Sapienza", Rome, Italy; ${ }^{7}$ Department of Hepatogastroenterology and Registre EPIMAD, Hôpital HURIEZ, CH et U Lille, France;

${ }^{8}$ Division of Gastroenterology and Hepatology, Medical University of Vienna, Vienna, Austria; ${ }^{9}$ Department of Pathology, University Hospital, Leuven, Belgium; ${ }^{10}$ Department of Gastroenterology, University of Oxford, Oxford, United Kingdom; ${ }^{11}$ Department of Gastroenterology, Rambam Medical Center, Bruce Rappaport Faculty of Medicine, Technion, Haifa, Israel; ${ }^{2}$ Division of Gastroenterology and Hepatology, Mayo Clinic College of Medicine, Rochester, Minnesota, USA; ${ }^{13}$ Department of Pathology, VU University Medical Centre, Amsterdam, The Netherlands; ${ }^{14}$ Department of Pathology, Mount Sinai Hospital, University of Toronto, Toronto, Ontario; ${ }^{15}$ Mount Sinai School of Medicine, New York, New York, USA; ${ }^{6}$ Institute for Clinical Molecular Biology, Christian-Albrechts-University, Kiel, Germany; ${ }^{17}$ Cedars-Sinai Division of Gastroenterology, Inflammatory Bowel Disease Center and Immunobiology Institute, UCLA School of Medicine, Los Angeles, California, USA; ${ }^{18}$ Division of Gastroenterology, University Hospital Gasthuisberg, Leuven, Belgium; ${ }^{19}$ Department of Cellular Pathology, John Radcliffe Hospital, University of Oxford, Oxford, United Kingdom

Correspondence and reprints: Dr Mark S Silverberg, Mount Sinai Hospital, 441-600 University Avenue, Toronto, Ontario M5G 1X5.

Telephone 416-586-8236, fax 416-586-4878, e-mail msilverberg@mtsinai.on.ca 
$\mathrm{C}^{-1}$ rohn's disease (CD) and ulcerative colitis (UC) afflict individuals in many parts of the world and have long been accepted as heterogeneous disorders with a wide variety of clinical presentations and manifestations. Falling under the general term idiopathic inflammatory bowel disease (IBD), these disorders clearly represent a constellation of diseases with both common and unique characteristics.

As a result of this significant clinical heterogeneity, efforts have been made to classify IBD using recognizable clinical and epidemiological features. Most recent attention has focused on CD. An international working team that issued its report in Rome in 1991 proposed a classification scheme in which $\mathrm{CD}$ is divided into numerous subgroups based upon anatomical distribution, operative history and predominant clinical 'behaviour', that is, inflammatory, fistulizing or stenotic. Subsequently, the international working group, commissioned for the 1998 World Congress of Gastroenterology in Vienna, Austria, refined the clinical classification of CD. The Vienna group classified $\mathrm{CD}$ according to three critical phenotypic characteristics (age at diagnosis, location and clinical behaviour), thereby developing a system that is more practicable for clinical use. These classification systems have since been applied to numerous clinical trials and studies of the pathogenesis and natural history of CD.

Since 1998, significant advances have been made in the discovery of molecular and serological markers related to IBD. Evaluation of these markers and of their importance to IBD diagnosis and phenotypic categorization is the subject of intense investigation. Moreover, limitations in the existing clinical CD classification scheme have become evident, as described by the original authors. It is also noteworthy that there remains a need for a similar reassessment of the classification of UC. The appropriate use of the term indeterminate colitis (IC) is another thorny issue in clinical and research settings. This Working Party has taken on the ambitious task of addressing these individual issues.

Individual teams have taken on the tasks of developing an updated CD classification system, proposing a clinical classification for UC and clarifying the clinical context in which the term IC should be used. The role of geography and ethnicity is discussed, but not of specific environmental influences. At the present time, the classification of IBD is based on predominantly clinical parameters, whereas molecular and serological markers largely remain in the research arena. The Working Party has evaluated currently available data with the goal of integrating clinical features of IBD with genetic and serological markers. Our findings are presented, together with recommendations for clinical classification systems. We hope that these data will catalyze progress over the next decade, with benefits for both clinicians and research investigators.

\section{Crohn's disease clinical classification}

\section{Key points}

Modification of the Vienna classification as follows:

- Introduction of an early age of onset category (diagnosis at 16 years or younger);

- Allow for the co-classification of location L4 (upper gastrointestinal [GI] involvement) with L1 to L3 (Table 1); and

- Inclusion of a modifier for perianal disease.

\section{Significant references}

Cosnes J, Cattan S, Blain A, et al. Long-term evolution of disease behavior of Crohn's disease. Inflamm Bowel Dis 2002;8:244-50.

Louis E, Collard A, Oger AF, Degroote E, Aboul Nasr El Yafi FA, Belaiche J. Behaviour of Crohn's disease according to the Vienna classification: Changing pattern over the course of the disease. Gut 2001;49:777-82.

Sachar DB, Bodian CS, Goldstein ES, et al. Is perianal Crohn's disease associated with intestinal fistulization? Am J Gastroenterol 2005;100:1547-9.

$\mathrm{CD}$ is a clinically heterogeneous disorder with a variety of demographic, clinical and phenotypic features. There have been attempts to use these characteristics to identify subgroups of CD patients who differ in their natural history, complications or response to therapy.

\section{Existing classification systems}

Greenstein et al (1) proposed classifying patients who require surgery for $\mathrm{CD}$ into those with perforating and nonperforating disease. They found that the indications for subsequent surgery tended to be the same as those for the first or previous operation. Moreover, patients with perforation tended to have earlier recurrence of $\mathrm{CD}$ following surgery, regardless of disease location. This categorization of $\mathrm{CD}$ into perforating and nonperforating subtypes has since been adapted to include patients managed with or without surgery and has been incorporated in the Vienna classification (2).

The Vienna classification of CD considers age of onset (A), disease location (L) and disease behaviour (B), resulting in 24 possible subgroups (2). However, because disease location and disease behaviour have been found to be highly correlated $(3,4)$, the majority of patients fall into a much smaller number of categories. Furthermore, the distribution of patients within the subcategories is not even. In a review of 877 patients from a single practice, it was found that less than $1 \%$ had only upper GI involvement and only $15.6 \%$ were diagnosed after 40 years of age (5). In another series, $21.1 \%$ of patients were diagnosed after 40 years of age (6). This uneven distribution may be an accurate reflection of the relative rarity of some subtypes, but it can produce some practical problems when applying statistical analysis to patient datasets.

Despite some of these concerns, a number of studies have demonstrated correlations between the Vienna classification system and other aspects of disease presentation, genetic susceptibility and natural history. It has been shown that certain disease location and behaviour variables in the Vienna classification system are associated with anti-Saccharomyces cerevisiae antibody (ASCA) profiles $(7,8)$, and with the presence of one of the nucleotide-binding oligomerization domain 2/caspase recruitment domain-containing protein 15 (NOD2/CARD15) gene mutations (8-10). The Vienna classification also appears to predict the need for immunosuppressants and surgery (11).

It has been well recognized that disease behaviour, however, has a tendency to progress from one category to another during prolonged follow-up (12-14). It has also been suggested that perianal disease should not be regarded as a manifestation of penetrating disease behaviour (B3) because its occurrence has been found to be independent of intestinal penetrating disease $(15,16)$. In addition, the upper GI disease location 
(L4) variable is said to be present when there is any disease proximal to the terminal ileum, even if the ileum and/or colon are involved. This potentially creates an artificial distinction that, although useful for its relative ease of use and simplicity, may obscure the importance of the occurrence of disease at two or more sites.

There are certain aspects of disease course and prognosis that are not included in existing classification systems. The severity and aggressiveness of the disease are features that are difficult to reliably define and evaluate, even though they are potentially relevant to studies of natural history and as prognostic variables for therapeutic trials. Potential corollaries of the severity and aggressiveness of disease are the responsiveness to different classes of medical therapies and the need for surgical therapy.

\section{Age of onset}

Age of onset is a variable that is likely to predict a greater genetic predisposition to disease or, alternatively, an earlier or heavier exposure to some, as of yet undetermined, environmental causative or permissive factor. There is evidence that the phenotype of disease at diagnosis varies according to the age of onset and may relate to some extent to genotype $(17,18)$. Small intestinal and upper GI disease is more common in individuals diagnosed with CD before 20 years of age, whereas colonic disease is diagnosed more frequently in patients older than 60 years of age (19-24). Heyman et al (25) analyzed data from 1370 pediatric-onset IBD cases, with some striking findings. Colonic disease was present in almost all children diagnosed before the age of eight years, including those with CD, but in only $46 \%$ of those diagnosed thereafter. The older children were more likely to have small intestinal or upper GI disease (25-27). The male to female ratio also decreases with increasing age of onset of CD (25). Family history of IBD is also more likely to be elicited in patients with an earlier age of onset (22). Given the fact that children have different presentations and genotypes from those seen in adults, we propose the introduction of a new early-onset category. The revised age breakdown would now be $\mathrm{A} 1$, with age at diagnosis of 16 or younger; A2, with age of diagnosis 17 to 40 years; and A3, with age of diagnosis older than 40 years (Table 1 ).

\section{Disease location}

The major divisions of disease site that are agreed upon by most experts are ileum (distal small intestine), colon and ileocolonic. These are recognized and well-defined within the context of the Vienna classification system. As already discussed, however, the application of the definition of upper GI involvement essentially disregards any disease involvement distal to the jejunum. When the Vienna classification system was developed and existing databases were examined it appeared that the presence of disease distal to the jejunum was unusual in patients with upper GI involvement. Because these data were derived before the availability of sensitive techniques, such as wireless video capsule endoscopy, subtle disease in the small intestine might have been missed. We suggest that the issue of distal disease in patients with upper GI involvement should be re-examined using more sensitive techniques and, if necessary, modifications of the Vienna classification should be considered. To resolve this issue, we propose that, if proximal disease is found in conjunction with distal disease (categories L1 to L3), a category of L4 be added and not be
TABLE 1

Summary of revised 'Montreal classification' of Crohn's disease

\begin{tabular}{ll}
\hline Age at diagnosis $(\mathbf{A})$ \\
\hline A1 & 16 years or younger \\
A2 & $17-40$ years \\
A3 & Over 40 years
\end{tabular}

\begin{tabular}{llcr} 
Location (L) & $\begin{array}{c}\text { Upper GI } \\
\text { modifier (L4) }\end{array}$ & \\
\hline L1 & Terminal ileum & $\mathrm{L} 1+\mathrm{L} 4$ & Terminal ileum + Upper GI \\
L2 & Colon & $\mathrm{L} 2+\mathrm{L} 4$ & Colon + Upper GI \\
L3 & lleocolon & $\mathrm{L} 3+\mathrm{L} 4$ & lleocolon + Upper GI \\
L4 & Upper GI & - & - \\
& & Perianal disease & \\
Behaviour (B) & modifier (p) & \\
\hline B1* & Nonstricturing, & B1p & Nonstricturing, \\
& nonpenetrating & & nonpenetrating \\
& & & + perianal \\
B2 & Stricturing & B2p & Stricturing + perianal \\
B3 & Penetrating & B3p & Penetrating + perianal
\end{tabular}

*B1 category should be considered 'interim' until a prespecified time has elapsed from the time of diagnosis. Such a time period may vary from study to study (eg, 5-10 years is suggested) but should be defined in order for B1 behaviour to be considered 'definitive'. GI Gastrointestinal

considered a mutually exclusive category. For example, a patient with both distal ileal and jejunal disease would be given the designation L1 as well as L4. This would enable the analysis of patients with ileal and/or colonic involvement with concomitant proximal involvement (Table 1).

Although disease site tends to be relatively stable over time (16), there are patients in whom new sites of disease appear only years after the original diagnosis of CD. Regression of disease can also occur, so that previously affected areas can be completely healed by treatment. In some cases, surgical resection appears to have precipitated the extension of disease location. Although it would be virtually impossible to arbitrarily define a specific point in the disease course at which time disease location can be determined with reasonable validity, it would seem reasonable to continue to regard the maximum extent of disease before the first resection as the 'true' disease location for the purposes of the classification scheme.

\section{Disease behaviour}

The classification of disease behaviour, as based on the definitions provided in the Vienna classification system, may be problematic for a number of reasons. First, disease categories are not necessarily independent. It has been shown, for example, that the relatively well-defined category of disease site tends to be correlated with disease behaviour (eg, ileal with fibrostenotic disease). Second, a number of factors might lead to interobserver disagreement in the assignment of a behaviour $(28,29)$. Various disease behaviours can coexist, making it difficult to determine which feature is 'primary'. For example, internal fistulas almost always coexist with some degree of stenosis or obstruction distal to the origin of the fistula (30). Additionally, disease behaviour has been shown to change or progress over the course of the disease in some patients, typically from nonpenetrating, nonstricturing disease (B1) to stricturing (B2) or penetrating (B3) $(5,16)$. Therefore, any future attempts at classifying disease behaviour should incorporate some aspect of time course or, at a 
minimum, require a certain amount of time to have elapsed before assigning a disease behaviour designation. Data from several studies suggest five years as a reasonable interval because many, but not all, patients that are destined to develop stricturing or penetrating disease will have done so by that time (Table 1).

Although a five-year time period following diagnosis might seem somewhat arbitrary, it is based in part on the rate and incidence of disease progression reported by Louis et al (14). In that study, $26.3 \%$ of patients had stricturing or penetrating disease behaviour at diagnosis and, by five years after diagnosis, the percentage had increased to $48 \%$ and, by 10 years, to almost $70 \%$. These individuals would be considered to have varying degrees of more progressive or active disease. In a population-based study from Olmsted County, development of a fistula (perianal or enteroenteric) was observed in $26 \%$ of patients by five years (31). Approximately one-half of these patients had one or more fistulas before, or within 30 days after, diagnosis. In that study, the initial disease behaviour at diagnosis for the remaining patients and the rates of progression to stricturing disease were not reported. Based upon the Louis data (14), if one were to use the 10 -year point to determine the presence of progressive or aggressive disease, fully $70 \%$ of patients would fall into this category. This is probably an overestimate; therefore, the five-year cut-off was suggested as a reasonable compromise. It should be remembered that a requirement for a minimum five-year follow-up would mean that a significant proportion of patients could not be classified early in the course of their disease. This has important implications depending on the way in which the behaviour classification is used. For clinical trials, the disease behaviour at the time of intervention is probably more important than the possible disease behaviour at 10 or 20 years. In such cases, it might be reasonable to classify disease behaviour before the five-year point. On the other hand, for studies of genotype-phenotype correlations, it is important to have a well-defined and stable phenotype that does not change over time; thus, a minimum of 10 years or more follow-up might be more appropriate. It is suggested that investigators using the disease behaviour classification determine what is appropriate for their purposes, because it will almost certainly vary from study to study.

Another concern with the existing Vienna classification definition of penetrating disease behaviour (B3) is the inclusion of patients with only perianal fistula. Smith et al (14) studied the Vienna classification, disease progression and outcome, serology and genetic markers in 231 well-characterized CD patients and found that patients with perianal fistulas or abscesses differed from those with intestinal penetrating disease. The International Organization for Inflammatory Bowel Diseases Task Force on Disease Classification (16) examined the database records of $5491 \mathrm{CD}$ patients from six centres and found that, in patients with colonic disease but not in those with ileal disease, there was an association between intestinal fistulas and perianal fistulas. In addition, data from a populationbased research registry have shown that almost $80 \%$ of patients with perianal fistula have no enteric fistula (32). These observations suggest that the presence of perianal and enteric fistula describes two different phenotypes.

We suggest that the Vienna classification be modified so that perianal fistulas are no longer included in the penetrating disease category. The wording of the definition of this category would be changed to "the occurrence of intra-abdominal fistulas, inflammatory masses and/or abscesses at any time in the course of disease". We suggest the inclusion of perianal fistulas and abscesses as modifiers of the disease behaviour variable. This would be indicated by a 'p' (for perianal) appended to B1, $\mathrm{B} 2$ or $\mathrm{B} 3$, resulting in $\mathrm{B} 1 \mathrm{p}, \mathrm{B} 2 \mathrm{p}$ or B3p (Table 1 ).

\section{CONCLUSIONS}

The recommendations outlined above are based, as much as possible, on existing clinical and natural history data, as well as expert opinions. The additions to the Vienna classification require further validation studies in the ongoing process of developing a robust scheme that incorporates the most recent clinical, serological and genetic information.

\section{REFERENCES}

1. Greenstein AJ, Lachman P, Sachar DB, et al. Perforating and nonperforating indications for repeated operations in Crohn's disease: Evidence for two clinical forms. Gut 1988;29:588-92.

2. Gasche C, Scholmerich J, Brynskov J, et al. A simple classification of Crohn's disease: Report of the Working Party for the World Congresses of Gastroenterology, Vienna 1998. Inflamm Bowel Dis 2000;6:8-15.

3. Cosnes J, Cattan S, Blain A, et al. Long-term evolution of disease behavior of Crohn's disease. Inflamm Bowel Dis 2002;8:244-50.

4. Marion JF, Lachman P, Greenstein AJ, Sachar DB. Rarity of fistulas in Crohn's disease of the jejunum. Inflamm Bowel Dis 1995;1:34-6.

5. Freeman HJ. Application of the Vienna Classification for Crohn's disease to a single clinician database of 877 patients. Can J Gastroenterol 2001;15:89-93.

6. Dorn SD, Abad JF, Panagopoulos G, Korelitz BI. Clinical characteristics of familial versus sporadic Crohn's disease using the Vienna Classification. Inflamm Bowel Dis 2004;10:201-6.

7. Klebl FH, Bataille F, Bertea CR, et al. Association of perinuclear antineutrophil cytoplasmic antibodies and anti-Saccharomyces cerevisiae antibodies with Vienna classification subtypes of Crohn's disease. Inflamm Bowel Dis 2003;9:302-7.

8. Linskens RK, Mallant-Hent RC, Murillo LS, von Blomberg BM, Alizadeh BZ, Pena AS. Genetic and serological markers to identify phenotypic subgroups in a Dutch Crohn's disease population. Dig Liver Dis 2004;36:29-34.

9. Heresbach D, Gicquel-Douabin V, Birebent B, et al. NOD2/CARD15 gene polymorphisms in Crohn's disease: A genotype-phenotype analysis. Eur J Gastroenterol Hepatol 2004;16:55-62.

10. Newman B, Silverberg MS, Gu X, et al. CARD15 and HLA DRB1 alleles influence susceptibility and disease localization in Crohn's disease. Am J Gastroenterol 2004;99:306-15.

11. Veloso FT, Ferreira JT, Barros L, Almeida S. Clinical outcome of Crohn's disease: Analysis according to the vienna classification and clinical activity. Inflamm Bowel Dis 2001;7:306-13.

12. Cosnes J, de Parades V, Carbonnel F, et al. Classification of the sequelae of bowel resection for Crohn's disease. Br J Surg 1994;81:1627-31.

13. Freeman HJ. Natural history and clinical behavior of Crohn's disease extending beyond two decades. J Clin Gastroenterol 2003;37:216-9.

14. Louis E, Collard A, Oger AF, Degroote E, Aboul Nasr El Yafi FA, Belaiche J. Behaviour of Crohn's disease according to the Vienna classification: Changing pattern over the course of the disease. Gut 2001;49:777-82.

15. Smith BR, Arnott ID, Drummond HE, Nimmo ER, Satsangi J. Disease location, anti-Saccharomyces cerevisiae antibody, and NOD2/CARD15 genotype influence the progression of disease behavior in Crohn's disease. Inflamm Bowel Dis 2004;10:521-8.

16. Sachar DB, Bodian CS, Goldstein ES, et al. Is perianal Crohn's disease associated with intestinal fistulization? Am J Gastroenterol 2005;100:1547-9.

17. Levine A, Karban A, Eliakim R, et al. A polymorphism in the TNF-alpha promoter gene is associated with pediatric onset and colonic location of Crohn's disease. Am J Gastroenterol 2005;100:407-13.

18. Idestrom M, Rubio C, Granath F, Finkel Y, Hugot JP. CARD15 mutations are rare in Swedish pediatric Crohn disease. J Pediatr Gastroenterol Nutr 2005;40:456-60. 
19. Brant SR, Picco MF, Achkar JP, et al. Defining complex contributions of NOD2/CARD15 gene mutations, age at onset, and tobacco use on Crohn's disease phenotypes. Inflamm Bowel Dis 2003;9:281-9.

20. Fellows IW, Freeman JG, Holmes GK. Crohn's disease in the city of Derby, 1951-85. Gut 1990;31:1262-5.

21 Lee FI, Nguyen-Van-Tam JS. Prospective study of incidence of Crohn's Disease in Northwest England: No increase since the late 1970's. Eur J Gastroenterol Hepatol 1994;6:27-31.

22. Polito JM, Childs B, Mellits ED, Tokayer AZ, Harris ML, Bayless TM. Crohn's disease: Influence of age at diagnosis on site and clinical type of disease. Gastroenterology 1996;111:580-6.

23. Meinzer $\mathrm{U}$, Idestrom $\mathrm{M}$, Alberti $\mathrm{C}$, et al. Ileal involvement is age dependent in pediatric Crohn's disease. Inflamm Bowel Dis 2005;11:639-44.

24. Cuffari C, Bayless TM. Crohn's disease: Age of onset determines clinical phenotype. Gastroenterol Int 1997;10:89.

25. Heyman MB, Kirschner BS, Gold BD, et al. Children with earlyonset inflammatory bowel disease (IBD): Analysis of a pediatric IBD consortium registry. J Pediatr 2005;146:35-40.

26. Kugathasan S, Judd RH, Hoffmann RG, et al. Epidemiologic and clinical characteristics of children with newly diagnosed inflammatory bowel disease in Wisconsin:A statewide populationbased study. J Pediatr 2003;143:525-31.

27. Sawczenko A, Sandhu BK. Presenting features of inflammatory bowel disease in Great Britain and Ireland. Arch Dis Child 2003;88:995-1000

28. Steinhart AH, Girgrah N, McLeod RS. Reliability of a Crohn's disease clinical classification scheme based on disease behavior. Inflamm Bowel Dis 1998;4:228-34.

29. Riis L, Munkholm P, Binder V, Skovgaard LT, Candstat LT, Langholz E. Intra- and interobserver variation in the use of the Vienna Classification of Crohn's disease. Inflamm Bowel Dis 2005;11:657-61.

30. Oberhuber G, Stangl PC, Vogelsang H, Schober E, Herbst F, Gasche C. Significant association of strictures and internal fistula formation in Crohn's disease. Virchows Arch 2000;437:293-7.

31. Schwartz DA, Loftus EV Jr, Tremaine WJ, et al. The natural history of fistulizing Crohn's disease in Olmsted County, Minnesota. Gastroenterology 2002;122:875-80.

32. Tang LY, Rawsthorne P, Bernstein CN. In Crohn's disease is there an association between perineal fistulizing disease and luminal fistulizing disease? A population-based study. Gastroenterology 2005;128:A113. (Abst)

\section{Ulcerative colitis clinical classification}

\section{Key points}

A classification system for UC is proposed that incorporates:

- Disease extent; and

- Disease severity of individual acute relapses.

\section{Significant references}

Langholz E, Munkholm P, Davidsen M, Binder V. Course of ulcerative colitis: Analysis of changes in disease activity over years. Gastroenterology 1994;107:3-11.

Langholz E, Munkholm P, Davidsen M, Nielsen OH, Binder V. Changes in extent of ulcerative colitis: A study on the course and prognostic factors. Scand J Gastroenterol 1996;31:260-6.

Ritchie JK, Powell-Tuck J, Lennard-Jones JE. Clinical outcome of the first ten years of ulcerative colitis and proctitis. Lancet 1978;1:1140-3.

With an increasing understanding of the epidemiology and genetics of IBD, it has become evident that UC, like CD, may actually represent several forms of IBD. A formal clinical classification of UC similar to the Vienna classification of CD (1) does not exist. We sought to review the evidence that justifies the existence for a clinical classification of UC.
Theoretically, a clinical classification system for UC would be useful if it had implications for pathogenesis (ie, if it correlated with subclinical or genetic markers), therapy (eg, topical or oral therapy) or prognosis (eg, severity of disease, requirement for colectomy, colorectal cancer risk or mortality). The most commonly used classification systems in UC stratify patients by the extent of colonic involvement or by disease activity. This section reviews the rationale for these classification systems.

\section{Classification by extent}

UC can be defined by the extent of colorectal inflammation at a radiographic, endoscopic or histological level. For the purposes of simplification, we propose that the extent of UC be defined by endoscopic appearance and by maximal extent during follow-up. The three subgroups of UC defined by extent are:

1. Ulcerative proctitis (E1): involvement limited to the rectum (ie, proximal extent of inflammation is distal to the rectosigmoid junction).

2. Left-sided UC (E2) (also known as distal UC): involvement limited to the portion of the colorectum distal to the splenic flexure.

3. Extensive UC (E3) (also known as pancolitis): involvement extends proximal to the splenic flexure.

This three-tiered classification system appears to be useful in distinguishing patients by medical therapy and by prognosis. For example, hydrocortisone or mesalamine suppositories appear to be most useful as primary therapy for patients with ulcerative proctitis $(2,3)$, while these same medications in foam or enema form are most useful as primary therapy in patients with left-sided UC $(2,4,5)$. Oral delivery of sulfasalazine and the 5-aminosalicylate agents is, of course, possible in patients with proctitis and left-sided disease, but may not be necessary. On the other hand, use of topical therapy alone is usually insufficient for the primary therapy of extensive UC.

The extent of colitis has implications for the activity or severity of the condition, whether measured by rates of medication usage, hospitalization or colectomy. A population-based study from southeastern Norway (6) found that patients with extensive colitis were more likely to require 5-aminosalicylate agents or corticosteroids than patients with left-sided disease or proctitis. In a study of 269 recently diagnosed UC patients evaluated at St Mark's Hospital, United Kingdom, between 1966 and 1975 (7,8), crude hospitalization rates were significantly higher among those with extensive colitis $(70 \%)$ than proctosigmoiditis $(25 \%)$ or proctitis $(13 \%)$. A review of selected referral centre-based $(7,9)$ and population-based $(6,10)$ cohorts shows that the actuarial risk of colectomy is influenced by the extent of UC (Table 2). The risk of colectomy among proctitis patients ranged from $2 \%$ to $9 \%$ after five years, while patients with extensive colitis had five-year colectomy rates of $30 \%$ to $44 \%$.

It has been recognized for years that, in UC, the risk of colorectal cancer is correlated with disease extent. This correlation has been established in studies from referral centres $(11,12)$ or population surveys $(13-16)$ (Table 3$)$. The cumulative risk of colorectal cancer in patients with ulcerative proctitis ranges from $0 \%$ to $12 \%$ after 30 years of disease, compared with a cumulative risk of $4 \%$ to $47 \%$ after 30 years in those with extensive or pancolonic disease. 
TABLE 2

Risk of colectomy stratified by disease extent in selected cohorts of ulcerative colitis patients*

\begin{tabular}{|c|c|c|c|c|c|}
\hline Setting (reference) & Proctitis & Proctosigmoiditis & Left-sided colitis & Extensive colitis & Pancolitis \\
\hline St Mark's Hospital, UK $(7,8)$ & $2 \%$ at five years & $6 \%$ at five years & & $21 \%$ at five years & $30 \%$ at five years \\
\hline Copenhagen County, Denmark (10) & $9 \%$ at five years & & $19 \%$ at five years & & $35 \%$ at five years \\
\hline Cleveland Clinic, USA (9) & & $14 \% \dagger ; 7 \%$ at five years & $52 \%^{\dagger}$ & & $61 \%^{\dagger} ; 44 \%$ at five years \\
\hline Southeastern Norway (IBSEN) (6) & $2 \%$ at one year & & $2 \%$ at one year & $9 \%$ at one year & \\
\hline
\end{tabular}

${ }^{*}$ Rates are actuarial unless otherwise specified; ${ }^{\dagger}$ Crude rate, mean follow-up of 12.7 years (minimum five-year follow-up in 100\%). IBSEN Inflammatory Bowel South-Eastern Norway Study Group; UK United Kingdom; USA United States of America

TABLE 3

Risk of colorectal cancer stratified by disease extent in selected cohorts of ulcerative colitis patients*

\begin{tabular}{lcccc}
\hline Setting (reference) & Proctitis & Left-sided colitis & Extensive colitis \\
\hline Mayo Clinic, USA (11) & $12 \%$ at 30 years & $30 \%$ at 30 years & $47 \%$ at 30 years \\
Cleveland Clinic, USA (12) & & $4 \%$ at 30 years & $25 \%$ at 30 years & Pancolitis \\
Stockholm County, Sweden (13) & & $<5 \%$ at 25 years & $13 \%$ at 25 years \\
Central Israel (14) & $0 \%$ at 20 years & & $4 \%$ at 20 years & $14 \%$ at 20 years \\
Uppsala, Sweden (15) & $1.1 \%{ }^{\dagger}$ & $<5 \%$ at 30 years & $12-32 \%$ at 30 years & $5.3 \%{ }^{\dagger}$ \\
Malmo, Sweden (16) & $0.6 \%^{\dagger}$ & & \\
\hline
\end{tabular}

${ }^{*}$ Rates are actuarial unless otherwise specified; ${ }^{\dagger}$ Crude rate, mean follow-up of 13.9 years. USA United States of America

TABLE 4

Standardized mortality ratio (SMR; observed deaths/expected deaths) and $95 \%$ Cls stratified by disease extent in selected cohorts of ulcerative colitis patients

\begin{tabular}{|c|c|c|c|c|c|}
\hline Setting (reference) & $\begin{array}{c}\text { Proctitis } \\
\text { SMR }(95 \% \mathrm{Cl})\end{array}$ & $\begin{array}{l}\text { Proctosigmoiditis } \\
\text { SMR }(95 \% \mathrm{CI})\end{array}$ & $\begin{array}{l}\text { Left-sided colitis } \\
\text { SMR }(95 \% \mathrm{Cl})\end{array}$ & $\begin{array}{l}\text { Extensive colitis } \\
\text { SMR }(95 \% \mathrm{Cl})\end{array}$ & $\begin{array}{c}\text { Pancolitis SMR } \\
(95 \% \mathrm{CI})\end{array}$ \\
\hline Uppsala, Sweden (17) & $1.4(1.2-1.5)$ & & $1.2(1.0-1.4)$ & & $1.9(1.7-2.2)$ \\
\hline Copenhagen County, Denmark (10) & & & & & $1.68(\mathrm{P}<0.02)$ \\
\hline Leicestershire, UK (19) & $0.8(0.52-1.17)$ & & $0.93(0.55-1.47)$ & $0.84(0.42-1.49)$ & $0.85(0.54-1.27)$ \\
\hline Wolverhampton, Salisbury and Swindon, UK (20) & $0.64(0.23-1.40)$ & $0.9(0.46-1.57)$ & $1.56(0.89-2.52)$ & $1.01(0.40-2.08)$ & \\
\hline Copenhagen County, Denmark (1997 update) (18) & $0.87(0.72-1.07)$ & & & $1.23(1.04-1.44)$ & \\
\hline
\end{tabular}

UK United Kingdom

Population-based studies suggest that mortality in UC patients may also correlate with increasing extent of colitis $(10,17,18)$ (Table 4). In the updated examination of mortality in the Copenhagen County, Denmark, cohort (18), extensive colonic involvement at diagnosis remained a significant predictor of mortality after adjusting for age, sex and calendar period of diagnosis. Other studies, however, have not shown a consistent relationship $(19,20)$.

It is important to note that most of the aforementioned studies based the extent of colitis on radiographic or endoscopic, not histological, criteria. With the advent of total colonoscopy in the 1970s, it became evident the previous methods of evaluation for UC (ie, proctoscopy or sigmoidoscopy plus double contrast barium enema) were relatively insensitive and could frequently underestimate the extent of involvement or even miss a diagnosis (21). The significance of histological evidence of chronic colitis in an endoscopically normal proximal colon remains unclear in terms of the risk of colectomy, cancer, proximal progression of the disease, or mortality.

One drawback of the extent-based classification system is its instability over time, especially in the proctitis and left-sided colitis subgroups. Most longitudinal studies of UC cohorts that have specifically examined the problem report both progression and regression of the proximal extent of inflammation $(9,22-25)$ (Table 5). The actuarial risk of proximal extension of proctitis after 10 years of disease is between $41 \%$ and $54 \%$. For left-sided colitis, the likelihood of later progression to extensive colitis may be even higher. Although not as extensively studied, a diagnosis of extensive colitis may not necessarily be stable $(9,23,26)$ (Table 5). The regression rate ranges from a crude rate of $1.6 \%$ (9) to an actuarial rate of $71 \%$ after 10 years (23). We therefore propose that the maximum extent of involvement be used in the clinical classification system.

It is not clear that additional terms that are occasionally used to classify UC by extent actually identify clinically important subgroups. For example, the term 'proctosigmoiditis' is sometimes used to describe patients with rectal and sigmoid colonic inflammation without descending colonic involvement. The clinical course and prognosis of these patients is quite similar to those deemed to have left-sided colitis. Another strategy occasionally used is to separate 'extensive UC' (involving the transverse colon but not the ascending 
TABLE 5

Rate of disease extent progression and regression in selected cohorts of ulcerative colitis patients*

\begin{tabular}{|c|c|c|c|c|c|c|c|}
\hline Setting (reference) & $\begin{array}{l}\text { Proctitis to } \\
\text { left-sided }\end{array}$ & $\begin{array}{l}\text { Proctitis to } \\
\text { extensive }\end{array}$ & $\begin{array}{c}\text { Proctitis to } \\
\text { any progression }\end{array}$ & $\begin{array}{l}\text { Left-sided to } \\
\text { extensive }\end{array}$ & $\begin{array}{l}\text { Left-sided to } \\
\text { proctitis }\end{array}$ & $\begin{array}{l}\text { Extensive colitis } \\
\text { to any regression }\end{array}$ & $\begin{array}{l}\text { Pancolitis to } \\
\text { any regression }\end{array}$ \\
\hline St Mark's Hospital, UK (22) & $12 \%$ at 10 years & $7 \%$ at 10 years & & & & & \\
\hline Cleveland Clinic, USA (9) & $11.9 \%^{\dagger}$ & $34.0 \%^{\dagger}$ & $45.9 \%^{\dagger}$ & $70.4 \%^{\dagger}$ & $3.9 \%^{\dagger}$ & & $1.6 \%^{\dagger}$ \\
\hline Birmingham, UK (24) & & & $49 \%$ at 10 years & $31 \%$ at 10 years & & & \\
\hline Southeastern Norway (IBSEN) (26) & & & $22 \%$ at 1 year & $16 \%$ to $24 \%$ & $23 \%$ to $25 \%$ & $70 \%$ at 1 year & $39 \%$ at 1 year \\
\hline
\end{tabular}

${ }^{*}$ Rates are actuarial unless otherwise specified; ${ }^{\dagger}$ Crude rate, mean follow-up of 12.7 years (minimum of five years in $\left.100 \%\right)$. IBSEN Inflammatory Bowel SouthEastern Norway Study Group; UK United Kingdom; USA United States of America

colon or cecum) from 'pancolitis'. Again, the clinical courses and prognoses of these two groups are quite similar. There is little or no evidence that these terms enable us to differentiate UC patients by pathogenesis, therapy or prognosis any more precisely than is possible with the three-tiered classification system described above.

Classification by severity

UC can be classified broadly into four disease activity/severity categories:

1. UC in clinical remission (SO): No symptoms of UC.

2. Mild UC (S1): in the classic description of disease activity by Truelove and Witts (27), this was defined as four or fewer bloody stools daily, lack of fever, pulse of less than 90 beats/min, hemoglobin of $105 \mathrm{~g} / \mathrm{L}$ or greater and erythrocyte sedimentation rate (ESR) of less than $30 \mathrm{~mm} / \mathrm{h}$. A similar definition was given in the practice guidelines for management of UC recently published by the American College of Gastroenterology (ACG) (28): four or fewer stools daily (with or without blood), no systemic signs of toxicity and a normal ESR.

3. Moderate UC (S2): Truelove and Witts (27) defined this as the state between mild and severe. The ACG guidelines defined moderate disease as more than four stools daily but with minimal signs of systemic toxicity (28).

4. Severe UC (S3): This was defined as the passage of at least six bloody stools daily, pulse of at least 90 beats/min, temperature of at least $37.5^{\circ} \mathrm{C}$, hemoglobin of less than $105 \mathrm{~g} / \mathrm{L}$ and ESR of at least $30 \mathrm{~mm} / \mathrm{h}$ (27). The ACG guidelines defined severe colitis as at least six bloody stools daily and evidence of toxicity (fever, tachycardia, anemia or elevated ESR) (28). The latter guidelines separated 'fulminant colitis' from 'severe'. Fulminant patients were those with at least 10 stools daily, continuous bleeding, toxicity, abdominal tenderness and distension, requirement for blood transfusion and colonic dilation on plain abdominal films (28).

One of the limitations of the present disease activity classification systems is that they are useful only for predicting clinical course in the short term. As in $\mathrm{CD}$, there are no longitudinal disease severity indices (ie, incorporating disease severity over time). One of the few studies to address this comes from Copenhagen County, where UC patients could be classified into those with prolonged remission, those with intermittent symptoms and those with continuous activity (29). Disease activity over the first three years of diagnosis predicted the clinical course over the next five years (29). Another issue that needs to be addressed is whether the term 'fulminant colitis' adds any additional value to a three-tiered activity classification system. In most series, fulminant colitis has typically been defined retrospectively to describe patients who failed medical therapy and required colectomy. A small subset of patients with fulminant colitis develop multiple organ dysfunction (30).

Should age at diagnosis be used to classify UC?

The possible existence of a bimodal distribution in age at onset of UC continues to be debated. Some studies found a unimodal distribution, with a peak incidence in the third or fourth decade of life $(31,32)$, while others demonstrated a large peak in the third decade of life and a smaller peak in the elderly (33). Regardless of the pattern, age-related differences in incidence suggest that $\mathrm{UC}$ is a heterogeneous entity that varies by the age at diagnosis.

Early studies indicate that, compared with those diagnosed after 16 years of age, patients who are diagnosed in childhood present more often with sudden onset of severe symptoms rather than an insidious onset, experience more complications, are more likely to develop colorectal cancer and are more likely to die of disease-related complications $(11,34)$. In the population-based Copenhagen County cohort, children diagnosed with UC before the age of 15 years had higher rates of extensive colitis, proximal progression of disease and mortality rates than those diagnosed in adulthood (35). On the other hand, that study found no difference in colectomy rates between the two groups. There are conflicting data about whether younger age at onset of UC is a risk factor for IBDrelated colorectal cancer, independent of increased duration $(15,36)$.

At the other end of the age spectrum, some investigators have reported that elderly patients with UC have a milder form of the disease. In a 1935 paper from the Mayo Clinic (37) describing 25 patients diagnosed with UC after the age of 60 years, most patients had mild, even intermittent, symptoms and responded promptly to treatment. Later reports $(38,39)$ stated that the prognosis of UC in the elderly was significantly worse than that of the average patient, but were based on very small numbers of patients. Finally, other studies (40-42) suggest that elderly patients with IBD do no worse than expected for the average patient. Therefore, at this juncture, there is 
insufficient information to warrant using age at diagnosis of UC in a clinical classification system for the disease. Nevertheless, it should be recorded as part of a minimal data set.

\section{SPECIAL SITUATIONS}

\section{Primary sclerosing cholangitis-associated IBD}

The characteristics of IBD associated with primary sclerosing cholangitis (PSC) deserve additional comment. While only $5 \%$ of UC patients have evidence of sclerosing cholangitis, approximately $70 \%$ to $80 \%$ of sclerosing cholangitis patients have IBD, with predominantly colonic involvement (43). The bowel disease is often quite mild and insidious in onset. A high proportion of newly diagnosed PSC patients, even those without GI complaints, prove to have chronic colitis when they undergo colonoscopy with biopsy (44). One such patient was even found to have colorectal dysplasia at the time of UC diagnosis, suggesting that some PSC patients may have had undiagnosed IBD for years. Several Mayo Clinic studies (45-47) found that PSC-IBD patients were more likely than patients with UC alone to have extensive colitis with rectal sparing and 'backwash ileitis' without other typical findings of CD, such as granulomas, skip areas, fistulas or strictures. PSC-IBD patients are less likely than matched UC controls to require colectomy (47). If they undergo proctocolectomy with ileal pouch-anal anastomosis (IPAA), however, PSC-IBD patients are more likely than UC patients without PSC to develop pouchitis (48). Furthermore, the risk of colorectal dysplasia and cancer seems to be higher in PSC-IBD patients than UC patients without PSC, even after accounting for differences in disease extent and duration $(47,49,50)$. Because of this increased risk of neoplasia, some authorities have advocated initiating annual surveillance colonoscopy immediately after the diagnosis of PSC-IBD. The differences in clinicopathological features (rectal sparing and backwash ileitis) and prognosis (pouchitis and increased risk of colorectal neoplasia) suggest that PSC-IBD may be an IBD phenotype distinct from both $\mathrm{UC}$ and CD (47).

\section{Right-sided colonic or periappendiceal inflammation in left-sided colitis}

Several studies $(51-55)$ in the past 15 years have revealed endoscopic evidence of right-sided colonic and/or periappendiceal inflammation in patients with left-sided UC. The prevalence of this finding ranges from $19 \%$ to $75 \%$, but its clinical significance is debatable. There is no indication that these patients are more likely to later be diagnosed with CD. One recent pathological study of colon resection specimens suggested that patients with appendiceal inflammation were more likely to develop pouchitis (56), but this finding needs to be confirmed. At this time, there is insufficient evidence to incorporate periappendiceal inflammation into a clinical classification scheme.

\section{CONCLUSIONS}

UC can be classified by extent of disease into proctitis (E1), leftsided disease (E2) or extensive disease (E3), and can be classified by disease severity into mild (S1), moderate (S2) or severe (S3). We suggest avoidance of the terms 'proctosigmoiditis' and 'fulminant colitis' in classification systems, because they do not appear to further differentiate patients into clinically useful categories. PSC-IBD may represent a unique phenotype of bowel inflammation. Periappendiceal inflammation in the setting of left-sided colitis is not uncommon, but the clinical significance of this finding remains unclear.

\section{REFERENCES}

1. Gasche C, Scholmerich J, Brynskov J, et al. A simple classification of Crohn's disease: Report of the Working Party for the World Congress of Gastroenterology, Vienna 1998. Inflamm Bowel Dis 2000;6:8-15.

2. Cohen RD, Woseth DM, Thisted RA, Hanauer SB. A meta-analysis and overview of the literature on treatment options for left-sided ulcerative colitis and ulcerative proctitis. Am J Gastroenterol 2000;95:1263-76.

3. Regueiro MD. Diagnosis and treatment of ulcerative proctitis. J Clin Gastroenterol 2004;38:733-40.

4. Marshall JK, Irvine EJ. Putting rectal 5-aminosalicylic acid in its place: The role in distal ulcerative colitis. Am J Gastroenterol 2000;95:1628-36.

5. Marshall JK, Irvine EJ. Rectal corticosteroids versus alternative treatments in ulcerative colitis: A meta-analysis. Gut 1997;40:775-81.

6. Moum B, Ekbom A, Vatn MH, et al. Clinical course during the 1st year after diagnosis in ulcerative colitis and Crohn's disease - results of a large, prospective population-based study in southeastern Norway, 1990-93. Scand J Gastroenterol 1997;32:1005-12.

7. Ritchie JK, Powell-Tuck J, Lennard-Jones JE. Clinical outcome of the first ten years of ulcerative colitis and proctitis. Lancet 1978;1:1140-3

8. Lennard-Jones JE. The clinical outcome of ulcerative colitis depends on how much of the colonic mucosa is involved. Scand J Gastroenterol Suppl 1983;88:48-53.

9. Farmer RG, Easley KA, Rankin GB. Clinical patterns, natural history, and progression of ulcerative colitis. A long-term follow-up of 1116 patients. Dig Dis Sci 1993;38:1137-46.

10. Langholz E, Munkholm P, Davidsen M, Binder V. Colorectal cancer risk and mortality in patients with ulcerative colitis. Gastroenterology 1992;103:1444-51.

11. Devroede GJ, Taylor WF, Sauer WG, Jackman RJ, Stickler GB. Cancer risk and life expectancy of children with ulcerative colitis. N Engl J Med 1971;285:17-21.

12. Mir-Madjlessi SH, Farmer RG, Easley KA, Beck GJ. Colorectal and extracolonic malignancy in ulcerative colitis. Cancer 1986;58:1569-74

13. Brostrom O, Monsen U, Nordenwall B, Sorstad J, Hellers G. Prognosis and mortality of ulcerative colitis in Stockholm County, 1955-1979. Scand J Gastroenterol 1987;22:907-13.

14. Gilat T, Fireman Z, Grossman A, et al. Colorectal cancer in patients with ulcerative colitis. A population study in central Israel. Gastroenterology 1988;94:870-7.

15. Ekbom A, Helmick C, Zack M, Adami HO. Ulcerative colitis and colorectal cancer. A population-based study. N Engl J Med 1990;323:1228-33.

16. Stewenius J, Adnerhill I, Anderson H, et al. Incidence of colorectal cancer and all cause mortality in non-selected patients with ulcerative colitis and indeterminate colitis in Malmo, Sweden. Int J Colorectal Dis 1995;10:117-22

17. Ekbom A, Helmick CG, Zack M, Holmberg L, Adami HO. Survival and causes of death in patients with inflammatory bowel disease: A population-based study. Gastroenterology 1992;103:954-60.

18. Winther KV, Jess T, Langholz E, Munkholm P, Binder V. Survival and cause-specific mortality in ulcerative colitis: Follow-up of a population-based cohort in Copenhagen County. Gastroenterology 2003;125:1576-82.

19. Probert CS, Jayanthi V, Wicks AC, Mayberry JF. Mortality in patients with ulcerative colitis in Leicestershire, 1972-1989. An epidemiological study. Dig Dis Sci 1993;38:538-41.

20. Farrokhyar F, Swarbrick ET, Grace RH, Hellier MD, Gent AE, Irvine EJ. Low mortality in ulcerative colitis and Crohn's disease in three regional centers in England. Am J Gastroenterol 2001;96:501-7.

21. Elliott PR, Williams CB, Lennard-Jones JE, et al. Colonoscopic diagnosis of minimal change colitis in patients with a normal sigmoidoscopy and normal air-contrast barium enema. Lancet 1982;1:650-1

22. Powell-Tuck J, Ritchie JK, Lennard-Jones JE. The prognosis of idiopathic proctitis. Scand J Gastroenterol 1977;12:727-32. 
23. Langholz E, Munkholm P, Davidsen M, Nielsen $\mathrm{OH}$, Binder V. Changes in extent of ulcerative colitis: A study on the course and prognostic factors. Scand J Gastroenterol 1996;31:260-6.

24. Ayres RC, Gillen CD, Walmsley RS, Allan RN. Progression of ulcerative proctosigmoiditis: Incidence and factors influencing progression. Eur J Gastroenterol Hepatol 1996;8:555-8.

25. Meucci G, Vecchi M, Astegiano M, et al. The natural history of ulcerative proctitis: A multicenter, retrospective study. Am J Gastroenterol 2000;95:469-73.

26. Moum B, Ekbom A, Vatn MH, Elgjo K. Change in the extent of colonoscopic and histological involvement in ulcerative colitis over time. Am J Gastroenterol 1999;94:1564-9.

27. Truelove SC, Witts LJ. Cortisone in ulcerative colitis: Final report on a therapeutic trial. Br Med J 1955;2:1041-8.

28. Kornbluth A, Sachar DB. Ulcerative colitis practice guidelines in adults (update): American College of Gastroenterology, Practice Parameters Committee. Am J Gastroenterol 2004;99:1371-85.

29. Langholz E, Munkholm P, Davidsen M, Binder V. Course of ulcerative colitis: Analysis of changes in disease activity over years. Gastroenterology 1994;107:3-11

30. Caprilli R, Latella G, Vernia P, Frieri G. Multiple organ dysfunction in ulcerative colitis. Am J Gastroenterol 2000;95:1258-62.

31. Loftus EV Jr, Silverstein MD, Sandborn WJ, Tremaine WJ, Harmsen WS, Zinsmeister AR. Ulcerative colitis in Olmsted County, Minnesota, 1940-1993: Incidence, prevalence, and survival. Gut 2000;46:336-43

32. Shivananda S, Lennard-Jones J, Logan R, et al. Incidence of inflammatory bowel disease across Europe: Is there a difference between north and south? Results of the European Collaborative Study on Inflammatory Bowel Disease (EC-IBD). Gut 1996:39:690-7.

33. Langholz E, Munkholm P, Nielsen OH, Kreiner S, Binder V. Incidence and prevalence of ulcerative colitis in Copenhagen county from 1962 to 1987. Scand J Gastroenterol 1991;26:1247-56.

34. Jackman RJ, Bargen JA, Heimholz HF. Life histories of 95 children with chronic ulcerative colitis, a statistical study based on comparison with a whole group of 871 patients. Am J Dis Child 1940;59:459-67.

35. Langholz E, Munkholm P, Krasilnikoff PA, Binder V. Inflammatory bowel diseases with onset in childhood. Clinical features, morbidity, and mortality in a regional cohort. Scand J Gastroenterol 1997;32:139-47.

36. Lashner BA, Silverstein MD, Hanauer SB. Hazard rates for dysplasia and cancer in ulcerative colitis. Results from a surveillance program. Dig Dis Sci 1989;34:1536-41.

37. Brust JC, Bargen JA. Chronic ulcerative colitis among elderly persons. Minnesota Med 1935;18:583-5.

38. Brandt L, Boley S, Goldberg L, Mitsudo S, Berman A. Colitis in the elderly. A reappraisal. Am J Gastroenterol 1981;76:239-45.

39. Brandt LJ, Boley SJ, Mitsudo S. Clinical characteristics and natural history of colitis in the elderly. Am J Gastroenterol 1982;77:382-6

40. Jones HW, Hoare AM. Does ulcerative colitis behave differently in the elderly? Age Ageing 1988;17:410-4

41. Softley A, Myren J, Clamp SE, Bouchier IA, Watkinson G, de Dombal FT. Inflammatory bowel disease in the elderly patient. Scand J Gastroenterol Suppl 1988;144:27-30.

42. Triantafillidis JK, Emmanouilidis A, Pomonis E, et al. Ulcerative colitis in the elderly: Clinical patterns and outcome in 51 Greek patients. J Gastroenterol 2001;36:312-6.

43. LaRusso NF, Wiesner RH, Ludwig J, MacCarty RL. Current concepts. Primary sclerosing cholangitis. N Engl J Med 1984;310:899-903.

44. Broome U, Lofberg R, Lundqvist K, Veress B. Subclinical time span of inflammatory bowel disease in patients with primary sclerosing cholangitis. Dis Colon Rectum 1995;38:1301-5.

45. Perdigoto R, Wiesner RH, LaRusso NF, Dozois R. Inflammatory bowel disease associated with primary sclerosing cholangitis: Incidence, severity and relationship to liver disease. Gastroenterology 1991;100:A238. (Abst)

46. Faubion WA, Loftus EV, Sandborn WJ, Freese DK, Perrault J. Pediatric "PSC-IBD": A descriptive report of associated inflammatory bowel disease among pediatric patients with PSC. J Pediatr Gastroenterol Nutr 2001;33:296-300.
47. Loftus EV Jr, Harewood GC, Loftus CG, et al. PSC-IBD: A unique form of inflammatory bowel disease associated with primary sclerosing cholangitis. Gut 2005;54:91-6.

48. Penna C, Dozois R, Tremaine W, et al. Pouchitis after ileal pouchanal anastomosis for ulcerative colitis occurs with increased frequency in patients with associated primary sclerosing cholangitis. Gut 1996;38:234-39.

49. Broome U, Lindberg G, Lofberg R. Primary sclerosing cholangitis in ulcerative colitis - a risk factor for the development of dysplasia and DNA aneuploidy? Gastroenterology 1992;102:1877-80.

50. Jayaram H, Satsangi J, Chapman RW. Increased colorectal neoplasia in chronic ulcerative colitis complicated by primary sclerosing cholangitis: Fact or fiction? Gut 2001;48:430-4.

51. D'Haens G, Geboes K, Peeters M, Baert F, Ectors N, Rutgeerts P. Patchy cecal inflammation associated with distal ulcerative colitis: A prospective endoscopic study. Am J Gastroenterol 1998;92:1275-9.

52. Okawa K, Aoki T, Sano K, Harihara S, Kitano A, Kuroki T. Ulcerative colitis with skip lesions at the mouth of the appendix: A clinical study. Am J Gastroenterol 1998;93:2405-10.

53. Yang SK, Jung HY, Kang GH, et al. Appendiceal orifice inflammation as a skip lesion in ulcerative colitis: An analysis in relation to medical therapy and disease extent. Gastrointest Endosc 1999;49:743-7

54. Matsumoto T, Nakamura S, Shimizu M, Iida M. Significance of appendiceal involvement in patients with ulcerative colitis. Gastrointest Endosc 2002:55:180-5.

55. Yamagishi N, Iizuka B, Nakamura T, Suzuki S, Hayashi N. Clinical and colonoscopic investigation of skipped periappendiceal lesions in ulcerative colitis. Scand J Gastroenterol 2002;37:177-82.

56. Yantiss RK, Sapp HL, Farraye FA, et al. Histologic predictors of pouchitis in patients with chronic ulcerative colitis. Am J Surg Pathol 2004:28:999-1006.

\section{Indeterminate colitis}

\section{Key points}

- The diagnosis of IC should be made only after colectomy.

- The term colonic IBD type unclassified (IBDU) should be used in all other cases where definitive features of $\mathrm{CD}$ and $\mathrm{UC}$ are absent.

\section{Significant references}

Joossens S, Reinisch W, Vermeire S, et al. The value of antiSaccharomyces cerevisiae (ASCA) and perinuclear antineutrophil cytoplasmic antibodies (pANCA) in indeterminate colitis (IC): A prospective follow-up study. Gastroenterology 2002;122:1242-7.

Price AB. Overlap in the spectrum of non-specific inflammatory bowel disease - 'colitis indeterminate'. J Clin Pathol 1978;31:567-77.

Moum B, Ekbom A, Vatn H, et al. Inflammatory bowel disease: Re-evaluation of the diagnosis in a prospective population based study in southeastern Norway. Gut 1997;40:328-32.

IC is a well-recognized term but there is a great deal of confusion about its exact meaning. In this section, we will discuss this problem and propose a new classification system for chronic inflammatory colitis. Population-based studies from Scandinavia (1-9) have shown that $5 \%$ to $20 \%$ of IBD patients with colonic inflammation only cannot be definitively diagnosed with CD or UC using available diagnostic tools, including clinical examination, radiology, endoscopy and histology. These patients have been placed in the category of IC, according to the original publication by Price (10). The incidence of 
IC is estimated to be $1.6 / 100,000$ to $2.4 / 100,000$ in adults and at $0.2 / 100.000$ in children $(8,9)$.

\section{Definition of IC: Evolution of diagnostic criteria}

The term 'indeterminate colitis' was first introduced at St Mark's Hospital, United Kingdom, in 1978 by the pathologist Ashley Price and was based on examination of surgical specimens that displayed overlapping features of both $\mathrm{CD}$ and UC (10). Originally, IC was considered to be a temporary diagnosis because it was believed that the majority of patients would eventually prove to have either CD or UC during follow-up $(2,3,11)$.

In the following years, the introduction of colonoscopy led to the development of an integrated diagnosis based on clinical features and endoscopy with biopsies. The disease is chronic and restricted to the colon. Typically, endoscopy is inconclusive and microscopic features of crypt architectural distortion (more than 10\% of crypts) and patchy acute and chronic inflammation are described, with no particular diagnostic features of either CD or UC. Infectious colitis and other causes of colitis have to be excluded by stool cultures and histological examination (12-16). This change in definition supports the concept that IC is really a distinct disease instead of merely a temporary diagnosis.

\section{CD, UC or IC: Does it matter?}

One could argue that it does not really matter if chronic colitis is further classified as IC, CD or UC, because most treatments (5-aminosalicylic acid, corticosteroids, azathioprine and infliximab) are effective for all. But this is not entirely true. It has been shown that the clinical course and the prognosis of patients with IC is worse than that of UC, and several studies $(17-22)$ have documented a worse outcome of surgery and greater risk of chronic pouchitis. However, these findings have not been confirmed by all investigators (22-24). A recent study from Toronto (22) found that patients with IC have a greater risk of pouchitis than those with UC (43\% versus $22 \%$; $\mathrm{P}<0.05)$, but the risk of pouch failure with excision was not significantly different (10\% versus $6 \%)$. In the series of IC patients who underwent surgery at St Mark's Hospital in London between 1960 and 1983, patients who continued to have a diagnosis of IC after careful preoperative and postoperative assessment did well and were unlikely to later develop CD (23). So far, it is still unclear whether a total colectomy with IPAA should be recommended in these patients, and prospective studies will be required to answer this clinically important question.

\section{Research agenda}

- There is a need for prospective studies investigating the outcome of surgery and of IPAA in patients with IC.

Toward a molecular classification of IC - A role for serological markers?

A multicentre prospective study (25) from Leuven, Belgium, Vienna, Austria and Lille, France identified 97 patients who could not be classified as having either CD or UC. Serological markers ASCA and atypical antineutrophil cytoplasmic antibody with a perinuclear staining pattern at indirect immunofluoresence (pANCA) were determined in all patients. A definitive diagnosis of $\mathrm{CD}$ was made when there were characteristic small bowel lesions, fistulas or granulomas. A definitive diagnosis of UC was based on the finding in surgical specimens of diffuse involvement, starting distally, with a lack of transmural inflammation and, if applicable, more severe lesions distally. For the cases where only endoscopic samples were available, the diagnosis was based on examination of multiple biopsies, obtained during repeated endoscopies, that verified that the ileum was uninvolved and that colonic inflammation was more severe in the distal than the proximal colon. Further microscopic features included the presence of widespread and diffuse mucosal distortion, diffuse transmucosal lymphocytic inflammation, cryptitis and crypt abscesses. After a mean follow-up of six years, 31 of 97 patients (32\%) acquired a definitive diagnosis of CD (17 cases) or UC (14 cases). Interestingly, almost one-half of the patients (48.5\%) had neither ASCA nor pANCA, and the majority of these patients $(85 \%)$ remained with the diagnosis of IC. In contrast, $61 \%$ of patients who eventually were given a definitive diagnosis of either CD or UC had one or both antibodies $(\mathrm{P}<0.001)$ (25). A follow-up study in 90 of the 97 patients in the original cohort (mean duration of follow-up 14.5 years, minimum of 2.5 years) confirmed that these seronegative patients more often continued to have a diagnosis of IC even after other antimicrobial antibodies (anti-OmpC and anti-I2) were sought (26). Using this panel of four antibodies, approximately onequarter $(26.4 \%)$ of the patients were seronegative and, in $74 \%$ of these patients, the exact diagnosis remained indeterminate, in contrast to only $50 \%$ of patients with positive antibodies $(\mathrm{P}=0.04)$.

It has been hypothesized that the higher incidence of chronic pouchitis in patients with IC and IPAA represent persistent immune reactivity to microbial antigens (27). In a prospective study, preoperative serological responses to ASCA, I2 and OmpC were assessed in 28 IC patients undergoing IPAA. With a median follow-up of 38 months (range three to 75 months), $61 \%$ of patients developed pouchitis, of whom $25 \%$ were acute and $75 \%$ chronic. Chronic pouchitis developed in 10 of 16 patients $(63 \%)$ who had a positive antibody reactivity profile compared with only two of 12 patients $(17 \%)$ with a negative profile $(\mathrm{P}=0.015)$. Therefore, IC patients who have a positive antibody reactivity profile before IPAA are at significantly higher risk of developing continuous pouch inflammation after surgery than are those with a negative profile.

\section{Research agenda}

- There is a need for studies on the value of novel (eg, Cbir) antimicrobial antibodies in patients with IC.

- There is a need for studies investigating which combination of serological markers provide the best specificity and positive predictive value for specific forms of IBD, including IC.

Toward a molecular classification of IC - A role for genetic markers?

At present, no full papers have been published examining the role of genetic markers in the further classification of patients with IC. DNA was available from a subgroup of the patients studied by Joossens et al (25) (68 of 97) and was genotyped for the three main CD-associated NOD2/CARD15 variants (28). Overall, 14 (20.6\%) carried at least one NOD2/CARD15 variant and 15 patients were given a definitive diagnosis (10 CD 
and five UC). Only one of the 10 patients with CD carried NOD2 mutations, compared with none of those with a final diagnosis of UC and 13 of the remaining 53 IC patients. There was one compound heterozygous patient, who is still currently categorized as having IC. These data do not suggest a role for NOD2 testing in the further classification of IC patients, but more studies of genetic markers are required.

\section{Research agenda}

- There is a need for genetic markers to help in the classification of IC patients.

\section{Toward a novel classification of IC?}

Advances in medical diagnostics as well as results from recent studies suggest that the concept of IC as a temporary diagnosis should be reconsidered. We believe that IC, as currently defined, is an ambiguous term that is applied to a heterogeneous group of patients with chronic inflammatory colitis. We therefore propose a revision of the concept, based on how the initial diagnosis is made (Figure 1).

In the cases in which the diagnosis is based on findings at surgical resection, in which features of both CD and UC are detected, we propose that the term 'IC' be retained, because this was also the setting in which the term was originally described by Price (10). Follow-up studies (24) have shown that, unless transmural lymphoid hyperplasia or granulomas are found, these patients usually prove not to have CD. The transmural polymorphous inflammation that is seen in these patients is a feature of severe colitis per se, and is not indicative of either CD or UC. On the other hand, we believe that studies investigating the serological markers ASCA, pANCA, antiflagellin, anti-OmpC and 12 might be helpful in further differentiating these conditions, especially when IPAA is envisaged (29-31).

The situation is different when the diagnosis is based on clinical features and endoscopy with biopsies. The clinical features consist of chronic IBD with inflammation restricted to the colon and without small bowel involvement. The endoscopy is inconclusive and histology reveals chronic inflammation with absence of diagnostic features of either CD or UC. In such cases, we propose that the term colonic IBDU be applied. A careful upper GI evaluation including gastroscopy and, if normal, novel endoscopic methods (such as video capsule endoscopy or double-balloon enteroscopy) may be useful. In general, we believe that more research, including the study of novel antimicrobial and genetic markers, is needed to further characterize this subgroup of patients. It is likely that international collaborations will be required to achieve this goal.

\section{REFERENCES}

1. Lee KS, Medline A, Shockey Q. Indeterminate colitis in the spectrum of inflammatory bowel disease. Arch Path Lab Med 1979;103:173-6.

2. Hildebrand H, Fredrickzon B, Homlquist L, Kristiansson B, Lindquist B. Chronic inflammatory bowel disease in children and adolescents in Sweden. J Pediatr Gastroenterol Nutr 1991;13:293-7.

3. Moum B, Ekbom A, Vatn HN, et al. Inflammatory bowel disease: Re-evaluation of the diagnosis in a prospective population based study in southeastern Norway. Gut 1997;40:328-32.

4. Ekbom A. Indeterminate IBD: The magnitude of the problem. Inflamm Bowel Dis 2000;6:S14-S15.

5. Geboes K, De Hertogh G. Indeterminate colitis. Inflamm Bowel Dis 2003;9:324-31

6. Guindi M, Riddell RH. Indeterminate colitis. J Clin Pathol 2004;57:1233-44

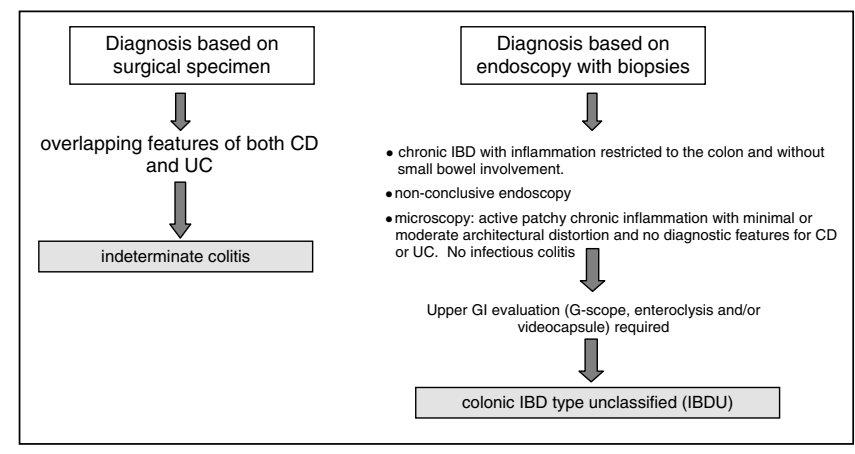

Figure 1) Flow chart illustrating proposed classification for patients with chronic inflammatory colitis. CD Crohn's disease; GI Gastrointestinal; G-scope Gastroscope; IBD Inflammatory bowel disease; UC Ulcerative colitis

7. Hale W, Floch M, Burakoff R, Itzkowitz S, Warren B, Plevy S. Indeterminate colitis. J Clin Gastroenterol 2004;38:S57.

8. Hildebrand H, Finkel Y, Grahnquist L, Lindholm J, Ekbom A, Askling J. Changing pattern of paediatric inflammatory bowel disease in northern Stockholm 1990-2001. Gut 2003;52:1432-4.

9. Stewenius J, Adnerhill I, Anderson H, et al. Incidence of colorectal cancer and all cause mortality in non-selected patients with ulcerative colitis and indeterminate colitis in Malmo, Sweden. Int J Colorect Dis 1995;10:117-20.

10. Price AB. Overlap in the spectrum of non-specific inflammatory bowel disease - 'colitis indeterminate'. J Clin Pathol 1978;31:567-77.

11. Meucci G, Bortoli A, Albini Riccioli F, et al; on behalf of the GMIl (Gruppo di Studio per le Malattie Infiammatorie Intestinali). Frequency and clinical evolution of indeterminate colitis: A retrospective multi-center study in northern Italy. Eur J Gastroenterol Hepatol 1999;11:909-13.

12. Le Berre N, Heresbach D, Kerbaol M, et al. Histological discrimination of idiopathic inflammatory bowel disease from other types of colitis. J Clin Pathol 1995;48:749-53.

13. Riddell RH. Pathology of idiopathic inflammatory bowel disease. In: Kirsner JB, ed. Inflammatory Bowel Disease, 5th edn. Philadelphia: WB Saunders Company, 2000:427-50.

14. Tsang P, Rotterdam H. Biopsy diagnosis of ulcerative colitis. Possibilities and pitfalls. Am J Surg Pathol 1999;23:423-30.

15. Nostrant TT, Kumar NB, Appelmann HD. Histopathology differentiates acute self-limited colitis from ulcerative colitis. Gastroenterology 1987;92:318-28.

16. Mottet NK. Intestinal histopathology of ulcerative colitis. In: Mottet NK, ed. Histopathologic Spectrum of Regional Enteritis and Ulcerative Colitis, Vol 2. Philadelphia: WB Saunders Company, 1971:108-54

17. Koltun WA, Schoetz DJ Jr, Roberts PL, Murray JJ, Coller JA, Veidenheimer MC. Indeterminate colitis predisposes to perineal complications after ileal pouch-anal anastomosis. Dis Colon Rectum 1991;34:857-60.

18. Stewenius J, Adnerhill I, Ekelund G, et al. Operations in unselected patients with ulcerative colitis and indeterminate colitis: A longterm follow-up study. Eur J Surg 1996;162:131-7.

19. McIntyre BP, Pemberton JH, Wolff BG, Dozois RR, Beart RW. Indeterminate colitis: Long-term outcome in patients after ileal pouch-anal anastomosis. Dis Colon Rectum 1995;38:51-4.

20. Atkinson KG, Owen DA, Wankling G. Restorative proctocolectomy and indeterminate colitis. Am J Surg 1994;167:516-8.

21. Stewenius J, Adnerhill I, Ekelund G, et al. Risk of relapse in new cases of ulcerative colitis and indeterminate colitis. Dis Colon Rectum 1996;39:1019-25.

22. Brown CJ, Maclean AR, Cohen Z, MacRae HM, O'Connor BI, McLeod RS. Crohn's disease and indeterminate colitis and the ileal pouch-anal anastomosis: Outcomes and patterns of failure. Dis Colon Rectum 2005 May 23; [Epub ahead of print]

23. Dayton MT, Larsen KR, Christiansen DD. Similar functional results and complications after ileal pouch-anal anastomosis in patients with indeterminate vs. ulcerative colitis. Arch Surg 2002;137:690-5. 
24. Wells AD, McMillan I, Price AB, Ritchie JK, Nicholls RJ. Natural history of indeterminate colitis. Br J Surg 1991;78:179-81.

25. Joossens S, Reinisch W, Vermeire S, et al. The value of antiSaccharomyces cerevisiae (ASCA) and perinuclear anti-neutrophil cytoplasmic antibodies (pANCA) in indeterminate colitis (IC): A prospective follow-up study. Gastroenterology 2002;122:1242-7.

26. Joossens S, Colombel JF, Vermeire S, et al. Panel of serologic antibodies in patients with indeterminate colitis. Gastroenterology 2003;124:A419. (Abst)

27. Hui T, Landers C, Vasiliauskas E, et al. Serologic responses in indeterminate colitis patients before ileal pouch-anal anastomosis may determine those at risk for continuous pouch inflammation. Dis Colon Rectum 2005;48:1254-62

28. Vermeire S, Reinisch W, Joossens S, et al. NOD2/CARD15 genotyping in patients with indeterminate colitis (IC): Helpful towards definitive diagnosis? Gastroenterology 2002;122:AM1416.

29. Targan SR, Landers CJ, Yang H, et al. Antibodies to CBir1 flagellin define a unique response that is associated independently with complicated Crohn's disease. Gastroenterology 2005;128:2020-8.

30. Ahmad T, Armuzzi A, Bunce M, et al. The molecular classification of the clinical manifestations of Crohn's disease. Gastroenterology 2002;122:854-66.

31. Peeters M, Joossens S, Vermeire S, Vlietinck R, Bossuyt X, Rutgeerts P. Diagnostic value of anti-Saccharomyces cerevisiae and antineutrophil cytoplasmic autoantibodies in inflammatory bowel disease. Am J Gastroenterol 2001;96:730-4.

\section{Geographic and ethnic factors associated with IBD}

\section{Key points}

- Wide variations exist in the incidence and prevalence of IBD worldwide.

- A minimal dataset to be used in genetic and environmental research must involve details of ethnicity and residency.

\section{Significant references}

Ekbom A, Helmick C, Zack M, Adami HO. The epidemiology of inflammatory bowel disease: A large, population-based study in Sweden. Gastroenterology 1991;100:350-8.

Bernstein CN, Blanchard JF, Rawsthorne P, Wajda A. Epidemiology of Crohn's disease and ulcerative colitis in a central Canadian province: A population-based study. Am J Epidemiol 1999;149:916-24.

Roth MP, Petersen GM, McElree C, Feldman E, Rotter JI. Geographic origins of Jewish patients with inflammatory bowel disease. Gastroenterology 1989;97:900-4.

Current knowledge suggests that both genetic and environmental influences are important in the etiopathogenesis of IBD. In this section of the Working Party report, we assess the geographical and ethnic contributions to the patterns of IBD and make suggestions about how the disease should be classified to aid further research. Incidence rates are quoted as number of cases per 100,000 population.

\section{Geographical variations in the incidence and prevalence of $\mathrm{CD}$ and $\mathrm{UC}$}

A global north-south variation in the incidence of IBD has been documented. Standardized incidence rates of 10.9 to 12.8 for UC and 6.0 to 7.0 for CD have been reported from northern California (1) and Scandinavia (2). Rates of 2.0 to 6.3 for UC and 0.9 to 3.1 for CD have been observed in the southern hemisphere (3). Direct comparisons can be misleading, because IBD is less prevalent in the developing world. For example, the incidence of $\mathrm{UC}$ and $\mathrm{CD}$ are 1.9 and 0.5 , respectively, in Asia (4), 2.3 and 1.6, respectively in Africa (5), and 2.2 and 0.03 , respectively, in Latin America (6). Studies from within Europe also suggest a north-south incidence gradient but, again, direct comparison of studies is confounded by differences in case ascertainment and data analysis. Raw data suggest that the incidence in northern areas is four to five times greater than those in southern areas (7-17).

Data from North America confirmed this observation in a single study (18) with higher hospitalization and mortality rates from IBD observed in the northern United States compared with southern states. This pattern was seen for AfricanAmericans and Caucasians, males and females, and UC and CD. A prospective collaborative European study (EC-IBD) (19) found that UC was $40 \%$ more common in northern centres, and that CD was $80 \%$ more common. Differences were not as large as expected, which might be due to a rising incidence in southern Europe $(14,19)$. More recent data examining the incidence of juvenile-onset CD in Scotland (20) found age-specific incidence rates for $\mathrm{CD}$ in northern Scotland (3.1) to be higher that those in the south (2.1). The absolute difference was relatively modest, with CD detected $47 \%$ more frequently in the north. This difference was not seen for UC.

There are a number of 'hot spots' for the incidence of IBD. The highest reported incidence and prevalence rates are from Manitoba, Canada (21,22); Scandinavia (2,13); Iceland (12); and the United Kingdom, especially Scotland (20,23,24). High incidence rates from other provinces in Canada, similar to that of Manitoba, support the notion of northern geographical areas having the highest incidence rates (25).

\section{Variations according to ethnic background}

Historical data suggest that African-Americans have a lower incidence of IBD than Caucasians. This pattern was seen in data from South Africa, but the blacks that did develop IBD were urbanized and had at least a partially Westernized diet (5). More recent data suggest that incidence rates in blacks may actually be closer to those in Caucasians. Kurata et al (26) found that hospitalization rates for CD were similar in African-Americans and Caucasians, and a tertiary referral centre study from Georgia, United States, identified a crude incidence rate of 5.3 for UC and 8.8 for CD in black children (27). A prospective United Kingdom survey of childhood IBD found that the incidence of both CD and UC in black children was similar to that in white populations (23). Furthermore, retrospective data from the United Kingdom found a nonsignificant difference in the incidence of CD in Afro-Caribbean and white populations in Derby (4.5 to 5.6 versus 7.0) (28). Southern Asian populations have been thought to have a low incidence of IBD but United Kingdom studies have found that Asians born in the United Kingdom have a higher incidence of $\mathrm{UC}$ and proctitis than white populations $(29,30)$. A three-year prospective study from Leicester, United Kingdom found the incidence of UC to be higher in second-generation than first-generation Asians. Moreover, the incidence of UC in second-generation Asians exceeds that in Caucasians (31). Available data suggest that IBD remains uncommon in Hispanics, Asian Americans 
TABLE 6

The prevalence of Crohn's disease in the Jewish Israeli population - stratification by birthplace of patients

\begin{tabular}{llccccc}
\hline & & & \multicolumn{4}{c}{ Prevalence* $^{*}$ Reference } \\
\cline { 3 - 7 } & Population & Years & Total & $\begin{array}{c}\text { Europel } \\
\text { N Am }\end{array}$ & $\begin{array}{c}\text { Asial } \\
\text { Africa }\end{array}$ & Israel \\
\hline 42 & Beer-Sheva & $1961-1980$ & 14.0 & 24.6 & 19.4 & 6.9 \\
43 & Central Israel & $1970-1980$ & 19.4 & 30.0 & 12.2 & 12.6 \\
44 & Kibbutz & 1987 & 25.5 & 17.4 & 41.8 & 38.9 \\
45 & Kinneret & $1960-1990$ & 45.9 & 80.1 & 41.8 & 41.1 \\
36 & Beer-Sheva & $1968-1992$ & 50.6 & 58.7 & 55.0 & 46.3 \\
46 & Kibbutz & 1997 & 65.1 & 79.2 & 11.9 & 78.3 \\
\hline
\end{tabular}

${ }^{\star}$ Figures are quoted per 100,000 population. N Am North America

and aboriginal North Americans (32). Aboriginal Canadians and First Nations persons from Manitoba are also less likely to develop IBD, especially CD (22).

Epidemiological data have consistently documented a higher incidence of IBD in Ashkenazi Jewish than in nonJewish populations (33). One study suggested that the incidence of IBD within Jewish populations might be related to the country of origin (34), but more recent data from Israel found that the incidence (4.2) and prevalence (50.6) of CD were independent of country of origin, and comparable with those in many Caucasian populations $(35,36)$ (Table 6$)$. The incidence and prevalence of CD among non-Ashkenazi Jews approach those of Ashkenazi Jews in North America and Europe, and prevalence rates in Israel are lower than those reported from Manitoba and Rochester, Minnesota $(21,37)$.

Variations in the incidence of IBD between rural and urban populations

Higher incidences of both CD and UC have been identified in urban than rural populations in the United States (18), Manitoba (22), Uppsala, Sweden (16), the Faroe Islands (38), Scotland (9) and Rochester, Minnesota (37,39). Data from Alberta, Canada identified an urban predominance for CD but not UC (40). Few studies have found no difference (41). The availability of health care resources is frequently cited as a confounding factor. Canada and Sweden $(16,22)$ provide universal health care, thereby minimizing the ascertainment bias, and the observed differences for both CD and UC between urban and rural populations were confirmed.

\section{Association between the incidence of IBD with}

socioeconomic status

Blanchard et al (22) found that a higher average household income was associated with a higher incidence of CD but not UC. This finding has been confirmed by recent data from Scotland, which showed an inverse association between the deprivation score and incidence of juvenileonset CD (20).

\section{CONCLUSIONS}

There are a number of geographical and ethnic influences on the incidence of IBD. The most prominent are Ashkenazi Jewish ethnicity and living within an urban, high prevalence area (North America and western Europe, especially). Many of
TABLE 7

Recommendations for geographical and ethnic data to be collected in a research minimal data set

\begin{tabular}{ll}
\hline Ethnicity & $\begin{array}{l}\text { White/black/Asian/other } \\
\text { Jewish: yes/no } \\
\text { Country of birth }\end{array}$ \\
Family history of IBD & $\begin{array}{l}\text { Froband/parents/grandparents } \\
\text { Second-degree relative } \\
\text { Multiple affected family members/other }\end{array}$ \\
Place of residence & $\begin{array}{l}\text { Postal codes } \\
\text { Environment }\end{array}$ \\
\hline
\end{tabular}

IBD Inflammatory bowel disease the other identified variables suggest a prominent environmental influence. Although many of these factors are too variable to be incorporated into a classification of IBD, it would be appropriate to collect data to enable population stratification for research purposes. We therefore suggest that a minimal data set include parameters shown in Table 7 .

\section{REFERENCES}

1. Hiatt RA, Kaufman L. Epidemiology of inflammatory bowel disease in a defined northern California population. West J Med 1988;149:541-6.

2. Moum B, Ekbom A, Vatn MH, et al. Inflammatory bowel disease: Re-evaluation of the diagnosis in a prospective population based study in south eastern Norway. Gut 1997;40:328-32.

3. Andres PG, Friedman LS. Epidemiology and the natural course of inflammatory bowel disease. Gastroenterol Clin North Am 1999;28:255-81.

4. Morita N, Toki S, Hirohashi T, et al. Incidence and prevalence of inflammatory bowel disease in Japan: Nationwide epidemiological survey during the year 1991. J Gastroenterol 1995;30 (Suppl 8):1-4.

5. Wright JP, Froggatt J, O'Keefe EA, et al. The epidemiology of inflammatory bowel disease in Cape Town 1980-1984. S Afr Med J $1986 ; 70: 10-5$

6. Linares de la Cal JA, Canton C, Pajares JM, Mate-Jimenez J. Inflammatory bowel disease in Argentina and Panama (1987-1993). Eur J Gastroenterol Hepatol 1997;9:1129.

7. Orholm M, Munkholm P, Langholz E, Nielsen OH, Sorensen IA, Binder V. Familial occurrence of inflammatory bowel disease. N Engl J Med 1991;324:84-8.

8. Binder V, Both H, Hansen PK, Hendriksen C, Kreiner S, Torp-Pedersen K. Incidence and prevalence of ulcerative colitis and Crohn's disease in the County of Copenhagen, 1962 to 1978. Gastroenterology 1982;83:563-8.

9. Sinclair TS, Brunt PW, Mowat NA. Nonspecific proctocolitis in northeastern Scotland: A community study. Gastroenterology 1983;85:1-11.

10. Shivananda S, Pena AS, Nap M, Weterman IT, Mayberry JF, Ruitenberg EJ, Hoedemaeker PJ. Epidemiology of Crohn's disease in Regio Leiden, The Netherlands. A population study from 1979 to 1983. Gastroenterology 1987;93:966-74.

11. Shivananda S, Pena AS, Mayberry JF, Ruitenberg EJ, Hoedemaeker PJ. Epidemiology of proctocolitis in the region of Leiden, The Netherlands. A population study from 1979 to 1983 . Scand J Gastroenterol 1987;22:993-1002.

12. Bjornsson S, Johannsson JH. Inflammatory bowel disease in Iceland, 1990-1994: A prospective, nationwide, epidemiological study. Eur J Gastroenterol Hepatol 2000;12:31-8.

13. Roin F, Roin J. Inflammatory bowel disease of the Faroe Islands, 1981-1988. A prospective epidemiologic study: Primary report. Scand J Gastroenterol Suppl 1989;170:44-6.

14. Trallori G, Palli D, Saieva C, et al. A population-based study of inflammatory bowel disease in Florence over 15 years (1978-92). Scand J Gastroenterol 1996;31:892-9. 
15. Cottone M, Cipolla C, Orlando A, Oliva L, Aiala R, Puleo A. Epidemiology of Crohn's disease in Sicily: A hospital incidence study from 1987 to 1989. "The Sicilian Study Group of Inflammatory Bowel Disease”. Eur J Epidemiol 1991;7:636-40.

16. Ekbom A, Helmick C, Zack M, Adami HO. The epidemiology of inflammatory bowel disease: A large, population-based study in Sweden. Gastroenterology 1991;100:350-8.

17. Kyle J. Crohn's disease in the northeastern and northern Isles of Scotland: An epidemiological review. Gastroenterology 1992;103:392-9.

18. Sonnenberg A, McCarty DJ, Jacobsen SJ. Geographic variation of inflammatory bowel disease within the United States. Gastroenterology 1991;100:143-9.

19. Shivananda S, Lennard-Jones J, Logan R, et al. Incidence of inflammatory bowel disease across Europe: Is there a difference between north and south? Results of the European Collaborative Study on Inflammatory Bowel Disease (EC-IBD). Gut 1996;39:690-7.

20. Armitage EL, Aldhous MC, Anderson N, et al. Incidence of juvenile-onset Crohn's disease in Scotland: Association with northern latitude and affluence. Gastroenterology 2004;127:1051-7.

21. Bernstein CN, Blanchard JF, Rawsthorne P, Wajda A. Epidemiology of Crohn's disease and ulcerative colitis in a central Canadian province: A population-based study. Am J Epidemiol 1999;149:916-24.

22. Blanchard JF, Bernstein CN, Wajda A, Rawsthorne P. Small-area variations and sociodemographic correlates for the incidence of Crohn's disease and ulcerative colitis. Am J Epidemiol 2001;154:328-35.

23. Sawczenko A, Sandhu BK, Logan RF, et al. Prospective survey of childhood inflammatory bowel disease in the British Isles. Lancet 2001;357:1093-4.

24. Rubin GP, Hungin AP, Kelly PJ, Ling J. Inflammatory bowel disease: Epidemiology and management in an English general practice population. Aliment Pharmacol Ther 2000;14:1553-9.

25. Bernstein CN, Wajda A, Blanchard JF, et al. The Burden Of IBD in Canada: A Population-Based Study. Gastroenterology 2005; DDW.

26. Kurata JH, Kantor-Fish S, Frankl H, Godby P, Vadheim CM. Crohn's disease among ethnic groups in a large health maintenance organization. Gastroenterology 1992;102:1940-8.

27. Ogunbi SO, Ransom JA, Sullivan K, Schoen BT, Gold BD. Inflammatory bowel disease in African-American children living in Georgia. J Pediatr 1998;133:103-7.

28. Fellows IW, Mayberry JF, Holmes GK. Crohn's disease in West Indians. Am J Gastroenterol 1988;83:752-5.

29 Probert CS, Jayanthi V, Pinder D, Wicks AC, Mayberry JF. Epidemiological study of ulcerative proctocolitis in Indian migrants and the indigenous population of Leicestershire. Gut 1992;33:687-93.

30. Montgomery SM, Morris DL, Pounder RE, Wakefield AJ. Asian ethnic origin and the risk of inflammatory bowel disease. Eur J Gastroenterol Hepatol 1999;11:543-6.

31. Carr I, Mayberry JF. The effects of migration on ulcerative colitis: A three-year prospective study among Europeans and first- and second-generation South Asians in Leicester (1991-1994). Am J Gastroenterol 1999;94:2918-22

32. Loftus EV Jr. Clinical epidemiology of inflammatory bowel disease: Incidence, prevalence, and environmental influences. Gastroenterology 2004;126:1504-17.

33. Yang H, Taylor KD, Rotter JI. Inflammatory bowel disease. I. Genetic epidemiology. Mol Genet Metab 2001;74:1-21.

34. Roth MP, Petersen GM, McElree C, Feldman E, Rotter JI. Geographic origins of Jewish patients with inflammatory bowel disease. Gastroenterology 1989;97:900-4.

35. Ekbom A. The epidemiology of IBD: A lot of data but little knowledge. How shall we proceed? Inflamm Bowel Dis 2004;10(Suppl 1):S32-4.

36. Odes HS, Locker C, Neumann L, et al. Epidemiology of Crohn's disease in southern Israel. Am J Gastroenterol 1994;89:1859-62.

37. Loftus EV Jr, Silverstein MD, Sandborn WJ, Tremaine WJ, Harmsen WS, Zinsmeister AR. Ulcerative colitis in Olmsted County, Minnesota, 1940-1993: Incidence, prevalence, and survival. Gut 2000;46:336-43.

38. Berner J, Kiaer T. Ulcerative colitis and Crohn's disease on the Faroe Islands 1964-83. A retrospective epidemiological survey. Scand J Gastroenterol 1986;21:188-92.

39. Gollop JH, Phillips SF, Melton LJ, III, Zinsmeister AR. Epidemiologic aspects of Crohn's disease: a population based study in Olmsted County, Minnesota, 1943-1982. Gut 1988;29:49-56.
40. Pinchbeck BR, Kirdeikis J, Thomson AB. Inflammatory bowel disease in northern Alberta. An epidemiologic study. J Clin Gastroenterol 1988;10:505-15.

41. Evans JG, Acheson ED. An epidemiological study of ulcerative colitis and regional enteritis in the Oxford area. Gut 1965;6:311-24.

42. Krawiec J, Odes HS, Lasry Y, Krugliak P, Weitzman S. Aspects of the epidemiology of Crohn's disease in the Jewish population in Beer Sheva, Israel. Isr J Med Sci 1984;20:16-21.

43. Fireman Z, Grossman A, Lilos P, Eshchar Y, Theodor E, Gilat T. Epidemiology of Crohn's disease in the Jewish population of central Israel, 1970-1980. Am J Gastroenterol 1989;84:255-8.

44. Niv Y. The prevalence of Crohn's disease in the Israeli Kibbutz population. Can J Gastroenterol 1991;5:91-3.

45. Shapira M, Tamir A. Crohn's disease in the Kinneret sub-district, Israel, 1960-1990. Incidence and prevalence in different ethnic subgroups. Eur J Epidemiol 1994;10:231-3.

46. Niv Y, Abuksis G, Fraser GM. Epidemiology of Crohn's disease in Israel: a survey of Israeli kibbutz settlements. Am J Gastroenterol 1999;94:2961-5.

\section{Serological studies in IBD - Implications for classification}

\section{Key points}

Serological markers:

- Serological markers should not be the only determinant for clinical decision making.

- Novel markers show promise and panels of markers may prove useful in differential diagnosis and prognosis.

- The IBD serological panel (Table 8).

\section{Significant references}

Joossens S, Reinisch W, Vermeire S, et al. The value of serologic markers in indeterminate colitis: A prospective follow-up study. Gastroenterology 2002;122:1242-7.

Mow WS, Vasiliauskas EA, Lin YC, et al. Association of antibody responses to microbial antigens and complications of small bowel Crohn's disease. Gastroenterology 2004;126:414-24.

Targan S, Landers CJ, Yang H, et al. Antibodies to CBir1 flagellin define a unique response that is associated independently with complicated Crohn's disease. Gastroenterology 2005;128:2020-8.

The two most widely studied serological tests are for the presence of pANCA (reviewed in [1,2]) and ASCA. The seroprevalence of these markers among different studies has been quite variable, likely in part due to the lack of standardization of the techniques used for these assays (3).

Immune responsiveness to several specific microbial antigens in patients with $\mathrm{CD}$ and $\mathrm{UC}$ has been described by Targan et al (4). OmpC is the outer membrane porin $\mathrm{C}$ of Escherichia coli. I2 is a fragment of bacterial DNA that has been cloned from lamina propria mononuclear cells in patients with active $\mathrm{CD}$. This sequence has been shown to be associated with Pseudomonas fluorescens. In patients with $\mathrm{CD}$, reported seroprevalence is $55 \%$ for anti-OmpC and $50 \%$ for anti-I2 (5). Linskens et al (6) used several strains of Gram-positive anaerobic coccoid rods in an agglutination test. The agglutinating antibodies to coccoid rods were mostly of immunoglobulin $G$ isotype. A sensitivity of $52 \%$ for $\mathrm{CD}$ was reported. More recently, Lodes et al (7) used serological expression cloning in colitic $\mathrm{C} 3 \mathrm{H} / \mathrm{HeJBir}$ mice to identify commensal bacterial 
TABLE 8

Prevalence of antibodies in inflammatory bowel disease

\begin{tabular}{lcccccc}
\hline & pANCA & ASCA & PAB & $\begin{array}{c}\text { Anti- } \\
\text { OmpC }\end{array}$ & Anti-12 & $\begin{array}{c}\text { Anti-CBir1 } \\
\text { flagellin }\end{array}$ \\
\hline CD & $2-28$ & $48-69$ & $27-39$ & 55 & 50 & 50 \\
UC & $45-82$ & $5-15$ & $3-23$ & 2 & 10 & 6 \\
Healthy controls & 2.5 & 5 & 0 & 1.3 & 10 & 8 \\
\hline
\end{tabular}

Data from references 1,2,4,7,23 and 41. ASCA Anti-Saccharomyces cerevisiae antibody; $C D$ Crohn's disease; OmpC Outer membrane porin $C$ of Escherichia coli; PAB Antipancreatic antibody; pANCA Antineutrophil cytoplasmic antibody with a perinuclear staining pattern at indirect immunofluoresence; UC Ulcerative colitis

\section{TABLE 9}

Results of anti-Saccharomyces cerevisiae antibody (ASCA) and antineutrophil cytoplasmic antibody (ANCA) in a prospective study of patients with indeterminate colitis

\begin{tabular}{lcccc}
\hline & $\mathbf{n}(\%)$ & $\begin{array}{c}\text { Ulcerative } \\
\text { colitis n (\%) }\end{array}$ & $\begin{array}{c}\text { Crohn's } \\
\text { disease } \mathbf{n}(\%)\end{array}$ & $\begin{array}{c}\text { Indeterminate } \\
\text { colitis n (\%) }\end{array}$ \\
\hline ASCA+/ANCA- & $26(26.8)$ & $8(30.8)$ & $2(7.7)$ & $16(61.5)$ \\
ASCA-/ANCA+ & $20(20.6)$ & $4(20)$ & $7(35)$ & $9(45)$ \\
ASCA+/ANCA+ & $4(4.1)$ & $2(50)$ & $1(25)$ & $1(25)$ \\
ASCA-/ANCA- & $47(48.5)$ & $3(6.4)$ & $4(8.5)$ & $40(85.1)$ \\
Total & $97(100)$ & $17(17.5)$ & $14(14.4)$ & $66(68.1)$ \\
\hline
\end{tabular}

Data from reference 15 proteins that could contribute to the pathogenesis of IBD. The dominant antigens identified were flagellins. A T cell line specific for one of those flagellins (CBir1) induced colitis when transferred into naive mice with severe combined immunodeficiency. A serum response to flagellin CBir1 was detected in $50 \%$ of CD patients, $6 \%$ of UC patients and $8 \%$ of controls (8).

\section{Serological markers and IBD diagnosis}

The clinical value of pANCA or ASCA testing in patients presenting with nonspecific GI symptoms is limited because of inadequate sensitivity. ANCA positivity has been observed in other inflammatory disorders of the colon, such as eosinophilic and collagenous colitis. The specificity of ASCA seems to be higher for CD, but ASCA positivity has been observed in patients with Behcet's disease, primary biliary cirrhosis, autoimmune hepatitis and celiac disease, in which positive results have been reported in up to $43 \%$ of patients (9). Although the use of serological markers in routine screening is not recommended in adults (10), the situation may be different in children (11). Two recent studies $(12,13)$ in children came to the conclusion that, as in adults, the low sensitivity of serological markers limits their value in screening and evaluation of patients with suspected IBD.

\section{Indeterminate colitis}

The most specific serological test to distinguish CD from UC is the combination of ASCA and pANCA. The CD-associated serological pattern is ASCA+/pANCA-; conversely, the UCassociated pattern is pANCA+/ASCA-. Several independent studies have found that these combinations had positive predictive values of $77 \%$ to $96 \%$ for differentiating CD from UC $(1,2)$. Using likelihood ratios, patients who are pANCA+ and ASCA- are 19 times more likely to have UC, whereas patients who are ASCA + and pANCA- are 16 times more likely to have CD (14). It should be remembered, however, that these estimates are based on retrospective studies performed mostly in referral centre populations.

The results of the only prospective study that assessed the usefulness of serological markers in IC provided further evidence for the theory that $\mathrm{IC}$, rather than being merely undiagnosed UC or CD, is rather a distinct clinical entity (15). ASCA and pANCA tests were performed for 97 patients with an initial diagnosis of IC. After a mean of one-year follow-up, a definitive diagnosis was reached in 31 of 97 patients (32\%) (Table 9). ASCA+/ANCA- results predicted CD in $80 \%$ of IC patients, whereas ASCA-/ANCA+ results were predictive of

\begin{abstract}
TABLE 10
Sensitivity, specificity, positive predictive value (PPV) and negative predictive value (NPV) of the combination of antiSaccharomyces cerevisiae antibody (ASCA) and antineutrophil cytoplasmic antibody (ANCA) in a prospective study of patients with indeterminate colitis

\begin{tabular}{lcccc}
\hline \multicolumn{1}{c}{ Diagnosis } & $\begin{array}{c}\text { Sensitivity } \\
(\mathbf{\%})\end{array}$ & $\begin{array}{c}\text { Specificity } \\
(\mathbf{\%})\end{array}$ & $\begin{array}{c}\text { PPV } \\
(\mathbf{\%})\end{array}$ & $\begin{array}{c}\text { NPV } \\
\mathbf{( \% )}\end{array}$ \\
\hline ASCA+/ANCA- CD & $8 / 12(66.7)$ & $7 / 9(77.8)$ & $8 / 10(80)$ & $7 / 11(63.6)$ \\
ASCA-/ANCA+ UC & $7 / 9(77.8)$ & $8 / 12(66.7)$ & $7 / 11(63.6)$ & $8 / 10(80)$ \\
\hline
\end{tabular}
\end{abstract}

Data from reference 15. CD Crohn's disease; UC Ulcerative colitis

UC in 64\% (Table 10). Nevertheless, $48.5 \%$ of IC patients did not have antibodies against either ASCA or ANCA, perhaps limiting the clinical utility of serological testing. In summary, the serological tests may serve as an adjunct to the clinical workup in IC. Although it may be too early to suggest they be used alone to determine the appropriateness of restorative proctocolectomy in patients needing surgery (16), the addition of new markers may improve overall diagnostic accuracy.

In a study incorporating additional serological markers, the addition of anti-OmpC and anti-I2 to ASCA and pANCA was of no value in the diagnosis of IC (17); whereas the ASCA2 test allowed the reclassification of three CD patients (18). The new anti-CBir1 flagellin antibodies could be relevant in IC because they are associated with colonic CD, independent of ASCA, and may allow differentiation of CD from UC in patients who are positive for pANCA (4).

Serological markers and IBD stratification

Serological markers have been further used to categorize subgroups of patients with IBD. In patients with CD, pANCA positivity has been associated with a UC-like phenotype $(19,20)$, and a recent analysis found that it is associated with late-onset disease and inflammatory disease type according to the Vienna classification (21). In general, these types of studies are very difficult to compare, and seemingly contradictory results could depend on the specific technique employed. For example, the use of indirect immunofluorescence alone allows only the detection of the antibody, but the ELISA technique provides an assessment of the amount of antibody present.

The strongest phenotypic association of ASCA is with $\mathrm{CD}$ involving the small bowel rather than the colon. The group from Edinburgh (22) described a strong association between ASCA positivity and progression type from purely 


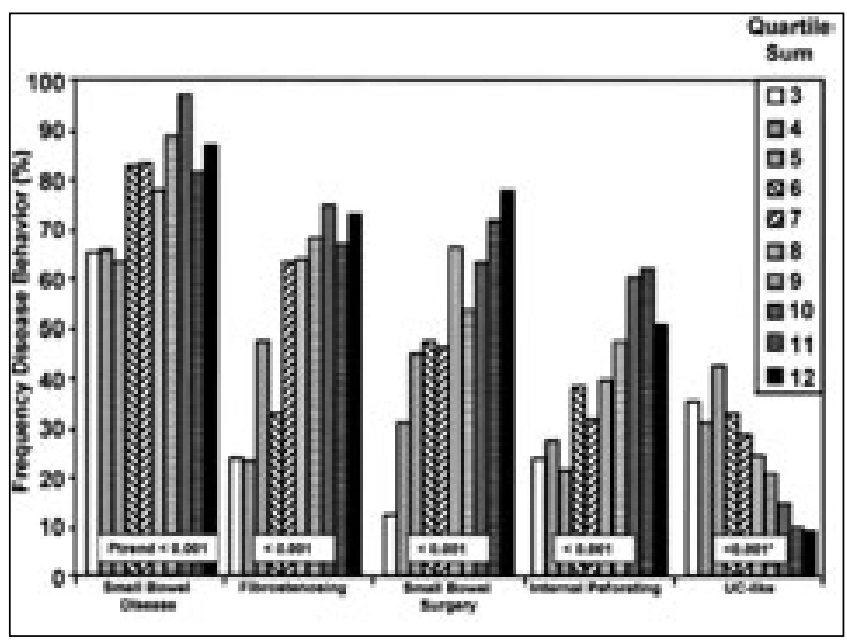

Figure 2) Frequency of Crohn's disease behaviour according to antibody reactivity. Quartile sum analysis (sum of quartile scores for anti-I2, anti-OmpC and anti-Saccharomyces cerevisiae antibodies) was performed to evaluate the association between the combination of the level of antibodies and disease characteristics for any individual patient. By adding individual quartile scores for each antibody, a quartile sum score (range three to 12) was obtained that represented the cumulative immune response toward all three microbial antigens. Patients with high scores had a high likelihood of small bowel, fibrostenotic and perforating disease, were likely to need small bowel surgery, and had a low frequency of ulcerative colitis (UC)-like phenotype. Data from reference 23

inflammatory to stricturing and penetrating disease with a more severe phenotype and requirement for surgery. Using cluster analysis, Landers et al (5) have shown that CD patients can exhibit a lack of tolerance to specific bacterial antigens and autoantigens, and can be separated into four groups depending on their antibody response patterns: ASCA, OmpC/I2, pANCA or no/low response. The same group was able to stratify patients based on the presence of the markers and levels of the antibody responses (23). Antibodies to I2 were associated with fibrostenotic disease and the need for small bowel surgery, while those to OmpC predicted internal penetrating behaviour. ASCA positivity was associated with small bowel disease, fibrostenosis, internal perforating disease and the need for small bowel surgery, and was negatively associated with UC-like behaviour. Conversely, the presence of pANCA predicted UC-like behaviour and was negatively associated with small bowel disease, fibrostenosis and small bowel surgery. They also found that $72 \%$ of patients positive for I2, OmpC and ASCA had undergone small bowel surgery compared with $23 \%$ of patients who lacked these antibodies. An association with the level of antibody production was also demonstrated. Levels of ASCA, I2 and OmpC were grouped by quartile. By adding individual quartile scores for each serological marker, a quartile sum score was then calculated. As shown in Figure 2, patients with high quartile sum scores were more likely to have small bowel disease, fibrostenotic and internal perforating disease with an increasing need for small bowel surgery and a decreasing frequency of UC-like phenotype.
Complementary data from an independent European population, using the same methodology, confirmed that the presence and magnitude of serological responses correlated with $\mathrm{CD}$ phenotype and severity (24). Multivariate analysis demonstrated independent associations between anti-OmpC and progression of disease type $(\mathrm{P}=0.005)$ and long disease duration $(\mathrm{P}=0.002)$, and between anti-I2 and long disease duration $(\mathrm{P}=0.002)$ and the need for surgery $(\mathrm{P}=0.033)$. ASCA positivity was also associated with disease progression $(\mathrm{P}<0.001)$. When the presence and magnitude of all antibody responses were considered, reactivity to microbial components was associated with long disease duration $(\mathrm{P}<0.001)$, progression of disease type $(P<0.001)$, penetrating disease $(P=0.008)$, small bowel disease $(\mathrm{P}<0.02)$, and the need for surgery $(\mathrm{P}<0.001)$. However, antibody status was not associated with NOD2/CARD15 genotype. A recent twin study (25) showed a strong correlation between ASCA titres and concordance for $\mathrm{CD}$ within monozygotic twin pairs, suggesting that the level of increase is genetically determined but independent of NOD2/CARD15. ASCA may thus be a marker of a response to an environmental antigen. Moreover, specific gene(s) other than NOD2/CARD15 could determine the level of response and perhaps also specific phenotypic characteristics (25).

Serum responses to CBir1 flagellin have been recently shown to independently identify a unique subset of patients with complicated CD: anti-CBir1 expression is independently associated with the presence of internal-penetrating and fibrostenosing disease involving the small bowel (4). There is evidence that patients with abnormalities in both innate and adaptive immunity may develop severe CD (26). Allelic variants of CARD8, which generate a nonfunctioning protein, were associated with internal penetrating $\mathrm{CD}$ only among patients who were also OmpC-positive. These data suggest that the combination of abnormalities in the innate and adaptive immune responses in the same individual could result in a severe form of CD.

Serological markers and IBD monitoring and management Most studies do not support a relationship between UC activity and either the presence of ANCA or their titres. Hence, in contrast with systemic vasculitides, serial measurement of ANCA titres in IBD is not useful for follow-up of disease activity or the prediction of relapses.

The presence of ASCA in CD is generally stable over time and is independent of $\mathrm{CD}$ activity and duration. A follow-up study (27) in 25 patients with active CD showed that mesalamine had no influence on ASCA status, and that ASCA levels were decreased but not eliminated by prednisolone therapy. In one pediatric study (28), ASCA titres correlated significantly with disease activity, and a significant reduction of ASCA was observed when clinical remission was achieved. However, Desir et al (29) could not confirm this finding in a study of 61 children with $\mathrm{CD}$ that found that changes in ASCA titres over time were unable to predict clinical outcomes.

The association between responses to microbial antigens and $\mathrm{CD}$ severity and need for early surgery makes these markers potentially valuable prognostic indicators, but these findings must be confirmed by prospective studies (23). More aggressive medical therapy may be indicated for patients whose serology indicates an increased susceptibility to disease progression. 
Another promising field of development for serological markers may be the prediction of response to therapy. Higher clinical response to infliximab has been associated with the presence of 'speckled' ANCA, while lack of response was associated with pANCA (30). Esters et al (31) found no overall relationship between ASCA or ANCA positivity and response to infliximab in 279 patients with CD. Numerically lower response rates were observed in patients with refractory disease with the ANCA+/ASCA- profile, but statistical significance was not achieved. These observations need to be confirmed by other investigators. In a study (32) of 27 patients with CD needing either an ileostomy or a colostomy for refractory proctocolitis or perianal disease, the presence of anti-I2 antibodies predicted a favourable clinical response to fecal diversion. This observation supports the hypothesis that patients who react to particular microbial antigens might respond to manipulation of bacterial flora.

In a prospective study, Fleshner et al (33) found an association between the level of pANCA expression and chronic pouchitis. A long-term follow-up study of 102 UC patients, however, showed no association between pANCA positivity and pouchitis (34). Divergent definitions of pouchitis and differences in data collection methodology (ie, retrospective versus prospective) likely account for these contradictory findings. Furthermore, the fact that only one patient in the retrospective study had a pANCA level above 100 prevents meaningful comparison, and suggests that the population studied had, overall, much less severe disease. A recent study (35) suggested that serological responses in IC patients before IPAA identifies patients who are at risk for developing continuous pouchitis. In that study, the serological expression of any marker alone did not predict the development of continuous pouch inflammation; however, continuous pouch inflammation developed in 10 of 16 patients (63\%) who had a positive antibody reactivity profile compared with only two of 12 patients $(17 \%)$ with a negative profile $(\mathrm{P}=0.015)$.

\section{Serological markers and prediction of IBD}

Serum autoantibodies, which appear long before onset of clinical disease, are a characteristic feature of autoimmune diseases (36) as emphasized by two recent studies. In a study of patients with rheumatoid arthritis, Nielen et al (37) found antibodies for immunoglobulin $\mathrm{M}$ rheumatoid factor or anticyclic-citrullinatedpeptide in serum samples taken a median of 4.5 years before disease onset. Arbuckle et al (38), using the United States Armed Serum Repository, identified 132 military personnel diagnosed with systematic lupus erythematosus in whom antinuclear antibodies and anti-Ro appeared as early as 10 years before the onset of the disease. It may thus be possible to identify patients with subclinical disease or a predisposition to its development. Studies have consistently shown an increased frequency of ASCA in first-degree relatives of patients with $\operatorname{IBD}(1,2)$. Very interestingly, a recent study by Israeli et al $(39)$ showed for the first time that ASCA may precede by several months the clinical diagnosis of CD.

Recently, anti-OmpC was demonstrated to also have a strong familial aggregation. Mei et al (40) showed that antiOmpC is detected in $18 \%$ of unaffected family members of probands with $\mathrm{CD}$ as compared with $6 \%$ of control subjects. Whether the expression of anti-OmpC proves to be a preand/or subclinical marker of disease will be assessed in ongoing evaluation of these families.

\section{CONCLUSIONS AND RECOMMENDATIONS}

Relying exclusively on serum indicators for diagnosis in the clinical setting is not justified. The available serological markers are not sensitive enough to be used for IBD screening in the general population; however, the addition of more markers improves the overall sensitivity. Therapeutic decisions in patients with IC must not rely solely on serological testing, although it might be possible to predict the development of chronic pouchitis. High titres of pANCA in UC patients and of antibodies against microbial antigens in $\mathrm{CD}$ patients are associated with worse outcomes, but larger prospective studies are necessary before serology can be used to guide clinical decisions. Recent observations have reinforced the potential utility of serological markers for identifying more homogeneous clusters of CD patients. Ongoing study correlations between serological markers (either individual tests or panels) and genotypes, pathophysiological abnormalities, clinical phenotypes (including natural history) and response to treatment would lead to a clearer understanding of the pathophysiology of different types of IBD. Finally, a key role for these markers is their potential to immunotype clinical cohorts so that results of different, independently executed studies can be compared. Such analysis might shed light on differences in pathophysiology, disease severity and response to treatment.

\section{REFERENCES}

1. Reumaux D, Sendid B, Poulain D, Duthilleul P, Dewit O, Colombel JF. Serological markers in inflammatory bowel diseases. Best Pract Res Clin Gastroenterol 2003;17:19-35

2. Colombel JF, Reumaux D, Sendid B, Duthilleul P, Poulain D. Serodiagnostics in IBD. In: Bernstein CN, ed. The Inflammatory Bowel Disease Yearbook 2003. London: Remedica, 2003:63-78.

3. Sandborn WJ, Loftus EV Jr, Colombel JF, et al. Evaluation of serologic disease markers in a population-based cohort of patients with ulcerative colitis and Crohn's disease. Inflamm Bowel Dis 2001;7:192-201.

4. Targan S, Landers CJ, Yang H, et al. Antibodies to CBir1 flagellin define a unique response that is associated independently with complicated Crohn's disease. Gastroenterology 2005;128:2020-8.

5. Landers CJ, Cohavy O, Misra R, et al. Selected loss of tolerance evidenced by Crohn's disease-associated immune responses to autoand microbial antigens. Gastroenterology 2002;123:689-99.

6. Linskens RK, Mallant-Hent RC, Groothuismink ZMA,et al. Evaluation of serological markers to differentiate between ulcerative colitis and Crohn's disaese: pANCA, ASCA and agglutinating antibodies to anaerobic coccoid rods. Eur J Gastroenterol Hepatol 2002;14:1013-8.

7. Lodes MJ, Cong Y, Elson CO, et al. Bacterial flagellin is a dominant antigen in Crohn disease. J Clin Invest 2004;113:1296-306.

8. Targan S, Landers CJ, Lodes M, Cong Y, Elson CO, Hershberg R. Antibodies to a novel flagellin (CBir1) define a unique serologic response in Crohn's disease. Gastroenterology 2004;126:A112. (Abst)

9. Damoiseaux JG, Bouten B, Linders AM, et al. Diagnostic value of anti-Saccharomyces cerevisiae and antineutrophil cytoplasmic antibodies for inflammatory bowel disease: High prevalence in patients with celiac disease. J Clin Immunol 2002;22:281-8.

10. Present DH. Serologic tests are not helpful in managing inflammatory bowel disease. Inflamm Bowel Dis 2002;8:227-9; discussion 223, 230-1.

11. Dubinsky MC, Ofman JJ, Urman M, Targan SR, Seidman EG. Clinical utility of serodiagnostic testing in suspected pediatric inflammatory bowel disease. Am J Gastroenterol 2001;96:758-65.

12. Khan K, Schwarzenberg SJ, Sharp H, Greenwood D, Weisdorf-Schindele S. Role of serology and routine laboratory tests in childhood inflammatory bowel disease. Inflamm Bowel Dis 2002;8:325-9

13. Gupta SK, Fitzgerald JF, Croffie JM, Pfefferkon MD, Molleston JP, Corkins MR. Comparison of serological markers of inflammatory bowel disease with clinical diagnosis in children. Inflamm Bowel Dis 2004;10:240-4. 
14. Panaccione R, Sandborn WJ. Is antibody testing for inflammatory bowel disease clinically useful? Gastroenterology 1999; 116:1001-3.

15. Joossens S, Reinisch W, Vermeire S, et al. The value of serologic markers in indeterminate colitis: A prospective follow-up study. Gastroenterology 2002;122:1242-7.

16. Plevy S. Do serological markers and cytokines determine the indeterminate? J Clin Gastroenterol 2004;38:S51-6.

17. Joosens S, Colombel JF, Vermeire S, et al. Panel of serologic antibodies in patients with indeterminate colitis. Gastroenterology 2003;124:A19. (Abst)

18. Vandewalle P, Standaert A, Seddik M, et al. A new ASCA test based on synthetic oligomannosides epitopes complements ASCA detection in Both Crohn's disease and indeterminate colitis. Gastroenterology 2004;126:A112. (Abst)

19. Vasiliauskas EA, Plevy SE, Landers CJ, et al. Perinuclear antineutrophil cytoplasmic antibodies in patients with Crohn's disease define a clinical subgroup. Gastroenterology 1996;110:1810-9.

20. Vasiliauskas EA, Kam LY, Karp LC, Gaiennie J, Yang H, Targan SR. Marker antibody expression stratifies Crohn's disease into immunologically homogeneous subgroups with distinct clinical characteristics. Gut 2000;47:487-96.

21. Klebl FH, Bataille F, Bertea CR, et al. Association of perinuclear antineutrophil cytoplasmic antibodies and anti-Saccharomyces cerevisiae antibodies with Vienna classification subtypes of Crohn's disease. Inflamm Bowel Dis 2003;9:302-7.

22. Walker LJ, Aldhous MC, Drummond HE, et al. Anti-Saccharomyces cerevisiae antibodies (ASCA) in Crohn's disease are associated with disease severity but not NOD2/CARD15 mutations. Clin Exp Immunol 2004;135:490-6.

23. Mow WS, Vasiliauskas EA, Lin YC, et al. Association of antibody responses to microbial antigens and complications of small bowel Crohn's disease. Gastroenterology 2004;126:414-24.

24. Arnott ID, Landers CJ, Nimmo EJ, et al. Sero-reactivity to microbial components in Crohn's disease is associated with disease severity and progression, but not NOD2/CARD15 genotype. Am J Gastroenterol 2004;99:2376-84

25. Halfvarson J, Standaert-Vitse A, Jarnerot G, et al. ASCA in twins with inflammatory bowel disease. Gut 2005; in press.

26. Picornell MT, Abreu MT, Ippoliti A, et al. Card8 variant and the expression of anti-Ompc are synergistically associated with internal penetrating Crohn's disease. Gastroenterology 2005;128(Suppl 2). (Abst)

27. Teml A, Kratzer V, Schneider B, et al. Anti-Saccharomyces cerevisiae antibodies: A stable marker for Crohn's disease during steroid and 5-aminosalicylic acid treatment. Am J Gastroenterol 2003;98:2226-31.

28. Canani RB, Romano MT, Greco L, et al. Effects of disease activity on anti-Saccharomyces cerevisiae antibodies. Implications for diagnosis and follow-up of children with Crohn's disease. Inflamm Bowel Dis 2004:10:234-9

29. Desir B, Amre DK, Lu SE, et al. Utility of serum antibodies in determining clinical course in pediatric Crohn's disease. Clin Gastroenterol Hepatol 2004;2:139-46.

30. Taylor KD, Plevy SE, Yang H, et al. ANCA pattern and LTA haplotype relationship to clinical responses to anti-TNF antibody treatment in Crohn's disease. Gastroenterology 2001;120:1347-55.

31. Esters N, Vermeire S, Joossens S, et al. Serological markers for prediction of response to anti-tumor necrosis factor treatment in Crohn's disease. Am J Gastroenterol 2002;97:1458-62.

32. Spivak J, Targan S, Vasiliauskas E, et al. Antibodies to I2 predict clinical response to fecal diversion in Crohn's disease. Gastroenterology 2004;126:A69. (Abst)

33. Fleshner PR, Vasiliauskas EA, Kam LY, et al. High level perinuclear antineutrophil cytoplasmic antibody (pANCA) in ulcerative colitis patients before colectomy predicts the development of chronic pouchitis after ileal pouch-anal anastomosis. Gut 2001;49:671-7.

34. Aisenberg J, Legnani PE, Nilubol N, et al. Are pANCA, ASCA, or cytokine gene polymorphisms associated with pouchitis? Long-term follow-up in 102 ulcerative colitis patients. Am J Gastroenterol 2004;99:432-41.

35. Hui T, Landers C, Vasiliauskas E, et al. Serologic responses in indeterminate colitis patients before ileal pouch-anal anastomosis may determine those at risk for continuous pouch inflammation. Dis Colon Rectum 2005; in press.

36. Scofield RH. Autoantibodies as predictors of disease. Lancet 2004;363:1544-6.
37. Nielen MM, van Schaardenburg D, Reesink HW, et al. Specific autoantibodies precede the symptoms of rheumatoid arthritis: A study of serial measurements in blood donors. Arthritis Rheum 2004;50:380-6.

38. Arbuckle MR, McClain MT, Rubertone MV, et al. Development of autoantibodies before the clinical onset of systemic lupus erythematosus. N Engl J Med 2003;349:1526-33.

39. Israeli E, Grotto I, Gilburd B, et al. Anti-Saccharomyces cerevisiae and antineutrophil cytoplasmic antibodies as predictors of inflammatory bowel disease. Gut 2005; in press.

40. Mei L, Landers CJ, Dutridge D, et al. Familial expression of antiEscherichia coli outer membrane porin $\mathrm{C}(\mathrm{OmpC})$ in relatives of patients with Crohn's disease. Gastroenterology 2005;128(4S):A2.

41. Joossens S, Vermeire S, Van Steen C, et al. Pancreatic autoantibodies in inflammatory bowel disease. Inflamm Bowel Dis 2004;10:771-7.

\section{NOD2/CARD15 and IBD}

\section{Key points 1}

- Three NOD2/CARD15 mutations that predispose to the development of CD are established: Cins1007fs, G908R and R702W.

- NOD2/CARD15 variation shows a significant gene-dosage effect, OR genotype MM 17, OR genotype MW 2.4.

- All three mutations show in vitro impairment of muramyl dipeptide (MDP)-driven nuclear factor-kappaB activation.

- The risk of CD with Cins1007fs > G908R R702W.

- Population attributable risk is less for the most northern European populations.

- CD NOD2/CARD15 risk in non-Jewish Caucasians is greater than in Ashkenazi Jews.

- NOD2/CARD15 variants are not present in Pacific Asian populations and are rare in African-Americans.

- Private mutations are increased in CD patients; those with impaired nuclear factor-kappaB activation are likely to predispose to $\mathrm{CD}$.

\section{Significant references}

Economou M, Trikalinos TA, Loizou KT, Tsianos EV, Ioannidis JP. Differential effects of NOD2 variants on Crohn's disease risk and phenotype in diverse populations: A metaanalysis. Am J Gastroenterol 2004;99:2393-404.

Arnott ID, Nimmo ER, Drummond HE, et al. NOD2/CARD15, TLR4 and CD14 mutations in Scottish and Irish Crohn's disease patients: Evidence for genetic heterogeneity within Europe? Genes Immun 2004;5:417-25.

Brant SR, Picco MF, Achkar JP, et al. Defining complex contributions of NOD2/CARD15 gene mutations, age at onset, and tobacco use on Crohn's disease phenotypes. Inflamm Bowel Dis 2003;9:281-9.

Overview of NOD2/CARD15 mutations associated with $\mathrm{CD}$ risk and population differences Three independent NOD2/CARD15-coding mutations (R702W [Arg702Trp], G908R [Gly908Arg] and Cins1007fs [Leu1007fsinsC]) are consistently more common in Caucasian CD patients (30\% to $40 \%$ of whom are carriers) than healthy Caucasian controls (in whom $10 \%$ to $20 \%$ are carriers), and therefore these mutations are established genetic risk factors for CD (1). These mutations are absent (2-5) or very rare (6) 
in Asians (eg, Japanese, Chinese and Koreans), Arabs $(7,8)$, Africans and African Americans (9,10). The relative risks for developing $C D$ vary widely. In a meta-analysis (11) of 37 studies of NOD2/CARD15 in Caucasian subjects, the overall risk for developing $\mathrm{CD}$ in simple heterozygotes (genotype MW, in which there is one normal and one mutant chromosome) was 2.4 (95\% CI 2.0 to 2.9), and risk for persons with two mutant chromosomes (genotype MM, simple homozygotes or compound heterozygotes) was 17.1 (95\% CI 10.7 to 27.2). The markedly increased risk of CD for MM compared with MW carriers has raised the possibility that NOD2/CARD15 might be recessive and that the risk from the MW genotype might be due to a significant proportion of MW carriers containing a rare mutation of the seemingly wild-type (W) allele. Lesage et al (12) screened for rare coding variants, called private mutations (PM), in $453 \mathrm{CD}$ patients and 103 healthy controls and still found a greater risk of CD in 28 proven MW simple heterozygotes (ie, having one proven wild type allele). The PM allele frequency $(f)$ in CD patients $\left(f_{\mathrm{PM}-\mathrm{CD}}\right)$ was 0.13 , while that in healthy controls $\left(f_{\mathrm{PM}-\mathrm{HC}}\right)$ was $0.06(\mathrm{P}<0.01)$. Promoter or splice risk mutations have not been demonstrated in patients with CD.

An intronic variant IVS8+158C/T (JW-1) on the P268S background, was associated with significant risk of $\mathrm{CD}$ in Ashkenazi Jews $\left(f_{\mathrm{CD}} 20.5 \%, f_{\mathrm{HC}} 6.3 \%\right.$; OR 5.75; 95\% CI 2.0 to $16.4)$ but not in non-Jewish whites $\left(f_{\mathrm{CD}} 15.6 \%, f_{\mathrm{HC}} 15.3 \%\right)$ (13). The risk associated with JW-1 remains to be confirmed $(14,15)$, and a functional effect has not been reported. $\mathrm{R} 702 \mathrm{~W}$ is more prevalent in non-Jewish White patients with $\mathrm{CD}\left(f_{\mathrm{CD}-\mathrm{NJ}} 10.7, f_{\mathrm{CD}-\mathrm{AJ}} 2.6 ; \mathrm{P}=0.00001\right)$, while $\mathrm{G} 908 \mathrm{R}$ is more prevalent in Ashkenazi Jews with $\mathrm{CD}\left(f_{\mathrm{CD}-\mathrm{NJ}} 4.3, f_{\mathrm{CD}-\mathrm{AJ}} 8.7\right.$; $\mathrm{P}=0.008)$ (16). In Europeans, population attributable risk of NOD2/CARD15 was observed to be decreased in the most northern European populations (eg, Norwegians, Finns and Scots) compared with those from more southern latitudes. For example, the population attributable risk in Edinburgh, Scotland is $11 \%$, and in Oxford, England is 27\%) (17). This suggests that the risk of developing $\mathrm{CD}$ may depend on the interaction of NOD2 with unknown risk factors that more often present in southern latitudes.

\section{Differences in risks of specific mutations}

The Cins 1007 fs has been observed to have a greater CD risk than the R702W and G908R variants in the majority of studies. A meta-analysis (11) showed that the ORs for developing CD in non-Jewish Caucasians were 4.1 for Cins 1007 fs (95\% CI 3.2 to 5.2), 2.2 for R702W (95\% CI 1.8 to 2.6) and 3.0 for G908R (95\% CI 2.4 to 3.7). Complementing this finding, Cins $1007 \mathrm{fs}$ expressed in vitro in NOD2/CARD15-negative human embryonic kidney 293 cells was unable to activate nuclear factorkappaB upon stimulation with the bacterial cell wall component, muramyl dipeptide (MDP); whereas R702W and G908R exhibit only reduced stimulation compared with wildtype NOD2/CARD15 transfectants (16). The Cins1007fs variant also showed greater reduction in in vivo human defensin expression compared with R702W and G908R (18). In the Lesage et al study (13), none of the PM alone were significantly more prevalent in CD than healthy controls. However, it is expected that an adequately powered study would prove that some of these rare variants indeed increase the risk of $\mathrm{CD}$, because in vitro MDP-stimulated nuclear factor-kappaB activation is decreased with G978E or nearly absent with E778K (19).
Other nonconserved variants, however, have no effect on nuclear factor-kappaB activation (or even have a hyperstimulatory effect, as in the Blau syndrome-associated NOD2 mutations, R334Q and L469F) and are therefore not likely to confer an increased risk of $\mathrm{CD}$. The present literature on the influence of NOD2/CARD15 on CD and its phenotypes is therefore based on incomplete data, because some seemingly wild-type alleles will actually be disease-causing PM alleles. Ultimately, true appreciation of the relevance of NOD2/CARD15 to CD will require large studies of patients whose phenotypes have been carefully assessed and whose genotypes have been examined for rare mutations known for being defective in terms of nuclear factor-kappaB activation.

\section{NOD2/CARD15 and other IBD phenotypes}

In general, the allele frequency of NOD2/CARD15 variants has been similar in UC patients and healthy controls and, thus, NOD2/CARD15 variation does not appear to be a risk factor for developing UC. There is evidence, however, that NOD2/CARD15 may interact with the IBD5 (OCTN1/N2) haplotype to increase the risk of UC $(20,21)$. NOD2/CARD15 has not been examined in an adequately powered sample of IC patients. Before NOD2/CARD15 variation can be used to clinically separate CD from UC and IC, it would be necessary to genotype a very large series of UC and IC patients to determine whether NOD2/CARD15 variation influences changes in phenotype to $\mathrm{CD}$, particularly in children.

\section{NOD2/CARD15 and CD site}

In nearly all phenotype analyses, NOD2/CARD15 mutations are significantly more prevalent in patients with ileal disease than those with CD limited to the colon. A meta-analysis (11) showed that the OR for ileal compared with colon-only disease was 2.5 (95\% CI 2.0 to 3.2). The association between NOD2/CARD15 mutations and ileal disease might be due to the fact that the expression of NOD2 in the intestinal epithelium is localized to Paneth cells, which are numerous in the ileum but not the colon $(22,23)$. This association has important implications for CD phenotype analyses. For example, analysis of $\mathrm{CD}$ phenotype using overlapping site categories, such as 'any ileal disease' or 'any colonic disease', is not recommended because most (24), but not all (25), studies have observed similar patterns of NOD2/CARD15 variation with both ileal and ileal-colonic disease. Furthermore, because NOD2 is an innate host determinant of site, NOD2/CARD15 genotypes should be considered in studies in which disease site either is or influences the outcome being measured. Although most studies yielded only numerical trends that did not reach statistical significance, a meta-analysis (11) has shown that NOD2/CARD15 mutations are indeed (weakly) associated with CD limited to the colon (OR 1.5; 95\% CI 1.2 to 1.9 ).

In summary, carriage of NOD2/CARD15 variants is a risk factor for both 'any-ileal' and for 'colonic-only' disease sites, but there is a significantly greater risk for disease involving the ileum. No studies have genotyped large samples of patients with CD involving either the upper GI tract or the jejunum only to determine if NOD2/CARD15 mutations present a risk for disease at these sites.

\section{NOD2/CARD15 and CD behaviour}

According to a meta-analysis (11), carriage of NOD2/CARD15 variants is a risk factor for developing intestinal strictures (OR 2.0; 
95\% CI 1.6 to 2.3). Most strictures occur in the ileum, and some investigators $(24,26)$, but not others $(27)$, have observed this association independent of ileal disease site. NOD2/CARD15 variants have also been associated with nonperianal (intestinal) fistulas (24). Nearly all studies have used the Vienna classification, in which internal and perianal fistulizing disease are considered together (28). NOD2/CARD15 variation tends to be less common in perianal versus nonperianal sites (24). It is noteworthy that perianal fistulas are more commonly found with colonic disease and that internal fistulas and strictures are often observed together. Evidence that NOD2/CARD15 variants predispose to intestinal, but not perianal fistulizing disease, as well as recent evidence that the IBD5 haplotype is associated with perianal disease (29) suggests that separate examination of intestinal and perianal fistulas is important for disease classification.

A well-recognized complicating factor in disease behaviour correlations is that nearly all patients have inflammatory (nonstricturing/nonfistulizing) disease at diagnosis, with complications accumulating over the course of disease. One approach is to compare patients who have complications with those who continue to have a stable inflammatory phenotype for more than seven years after diagnosis (24). Alternatively, Smith et al (30) examined complications as they developed and observed that NOD2/CARD15 variants were associated with delayed rather than rapid progression of strictures and fistulas in patients with CD.

\section{NOD2/CARD15 and other CD phenotype and demographic characteristics}

NOD2/CARD15 variation has been associated with increased disease severity, including increased risk for surgery $(31,32)$, acute intestinal obstruction (33), lower weight at diagnosis (34) and younger age at diagnosis (24,27). Patients with ileal disease are more likely to require surgery, and some studies have observed that survival without surgery (24), or without a second operation (27), was not independent of ileal site. Surprisingly, few studies have found an increased presence of NOD2/CARD15 mutations in those with familial as opposed to sporadic $\mathrm{CD}$, although meta-analysis $(11,35)$ has shown that, in non-Jewish populations, the presence of NOD2/CARD15 variants is a risk factor for familial CD (OR 1.4; 95\% CI 1.2 to 1.7). It should be noted, however, that ileal disease, young age at onset and family history of CD may all be associated (36). A preliminary population-based report from Manitoba concluded that NOD2/CARD15 variation was a significant risk factor for $\mathrm{CD}$, independent of a family history of IBD (37).

The role of NOD2/CARD15 has been examined for other phenotypes. Two studies have revealed no evidence of a link between NOD2/CARD15 and granulomas in CD patients $(38,39)$, although an earlier study suggested an association between the R702W variant and both stricture formation and granulomas (40). The lack of a clear association is perhaps not surprising given that Blau syndrome is seen with mutations that increase NOD2/CARD15 activity in vitro (19). NOD2/CARD15 has not been shown to be consistently associated with extraintestinal disease manifestations (41). Presently, NOD2/CARD15 has not been shown to influence response to treatment of $\mathrm{CD}$ although only infliximab has been evaluated so far $(42,43)$.

Several studies $(17,24,27)$ have demonstrated that more than $90 \%$ of patients with two mutant alleles (MM genotype) had ileal disease. Prospective studies of patients will be necessary to determine if this seemingly high positive predictive value is clinically useful. One should note that a significant genedosage effect has also been observed for the development of intestinal strictures $(24,26)$.

\section{Conclusions and recommendations from NOD2/CARD15 experience on classification of IBD}

The identification of the importance of the NOD2/CARD15 gene has been a major breakthrough in the understanding of this clinically heterogeneous and complex genetic disorder. Mutation of the NOD2/CARD15 gene is now established as an important host determinant of the risk for CD compared with UC, but only in Caucasian populations, and possibly with different influences in Jewish and non-Jewish populations. It is associated with ileal location of disease, stricturing and perhaps internal fistulizing disease, and early age of onset. On the other hand, it is less common in persons with perianal complications of CD. Although NOD2/CARD15 variants have been correlated with severity of disease, it is not clear whether this is independent of their established association with ileal disease. NOD2/CARD15 shows a significant gene-dosage effect for development of CD as well as the site of disease and its complications. The differences in risks associated with individual alleles is relatively minor, although the Cins1007fs has a more profound effect. Finally, a small but potentially significant number of rare NOD2/CARD15 variants (private mutations) have been ignored in nearly all studies.

The important influence of NOD2/CARD15 on IBD disease heterogeneity demands that a uniform approach be taken regarding disease classification; that the classification is structured so that the influence of NOD2/CARD15 and other IBD susceptibility genes can be observed; and that significantly larger studies, and ideally prospective as well as population studies be performed using the updated disease classification guidelines.

We propose the following specific recommendations for the next classification scheme and for future study designs:

1. Retain the nonoverlapping disease site categories, so that comparisons can be made between any ileal disease and disease limited to the colon, and similarly between any colon disease and disease limited to the ileum.

2. Create categories that include any fistulas, as well as separate categories for internal fistulas and perianal fistulas. In addition, create an additional category of "coexisting internal fistulizing and stricturing complications" for the many cases in whom the two complications cannot be separated.

3. When possible, include in the category of "inflammatory" disease behaviour those patients with stable disease for several years. Ideally, stricturing or fistulizing complications would be subclassified into those occurring early in the disease course (perhaps before eight years), moderate disease course (ie, eight to 19 years) and late disease course (ie, after 20 years). Consideration needs to be made, however, that for many retrospective studies, it might not be possible to ascertain the onset of these complications.

4. Match studies for participants' ethnicities, or adjust for differences between groups.

5. Unlike most current genotype/phenotype and 
genotype/therapy studies, future studies must take into account the strong NOD2/CARD15 gene-dosage effect.

6. Although they would be costly, the projected development of increasingly comprehensive genetic panels for clinical prediction and genetic counselling (44) demands that more genotype/phenotype studies consider private mutations that likely contribute to $\mathrm{CD}$ risk, eg, those that have been shown to decrease NOD2/CARD15 MDPstimulated activity. This is analogous to what is being done for diseases like cystic fibrosis, in which private mutations are, in aggregate, not uncommon. For comparison purposes, studies that include private mutation genotyping should also perform analyses limited to the three major NOD2/CARD15 mutations.

Instituting the above recommendations would help make future studies more comparable and more useful.

\section{Key points 2}

- Germline NOD2/CARD15 variation appears to be a risk factor for CD and not UC.

- NOD2/CARD15 variation is a risk factor for both ileal disease and, to a lesser extent, for CD limited to the colon.

- NOD2/CARD15 variation is a risk factor for stricturing and perhaps intestinal penetrating disease, but more research on disease progression is needed.

- Gene-dosage effects (MM versus MW) need to be considered when assessing overall and disease subtype risks.

- The phenotype and course of UC patients with NOD2/CARD15 variants must be evaluated.

- The overall NOD2/CARD15 risk requires investigation in population-based and community settings, and in prospective studies.

\section{REFERENCES}

1. Brant SR, Okazaki T. Inflammatory bowel disease genetics. In: Bernstein CM, ed. Yearbook in Inflammatory Bowel Disease. London: Remedica, 2004:79-128.

2. Yamazaki K, Takazoe M, Tanaka T, Kazumori T, Nakamura Y. Absence of mutation in the NOD2/CARD15 gene among 483 Japanese patients with Crohn's disease. J Hum Genet 2002;47:469-72.

3. Inoue N, Tamura K, Kinouchi Y, et al. Lack of common NOD2 variants in Japanese patients with Crohn's disease. Gastroenterology 2002;123:86-91.

4. Leong RW, Armuzzi A, Ahmad T, et al. NOD2/CARD15 gene polymorphisms and Crohn's disease in the Chinese population. Aliment Pharmacol Ther 2003;17:1465-70.

5. Croucher PJ, Mascheretti S, Hampe J, et al. Haplotype structure and association to Crohn's disease of CARD15 mutations in two ethnically divergent populations. Eur J Hum Genet 2003;11:6-16.

6. Guo QS, Xia B, Jiang Y, Qu Y, Li J. NOD2 3020insC frameshift mutation is not associated with inflammatory bowel disease in Chinese patients of Han nationality. World J Gastroenterol 2004;10:1069-1071.

7. Zouiten-Mekki L, Zaouali H, Boubaker J, et al. CARD15/NOD2 in a Tunisian population with Crohn's disease. Dig Dis Sci 2005;50:130-135.

8. Karban A, Atia O, Leitersdorf E, et al. The relation between NOD2/CARD15 mutations and the prevalence and phenotypic heterogeneity of Crohn's Disease: Lessons from the Israeli Arab Crohn's disease cohort. Dig Dis Sci 2005;50:1692-7.

9. Stockton JC, Howson JM, Awomoyi AA, et al. Polymorphism in NOD2, Crohn's disease, and susceptibility to pulmonary tuberculosis. FEMS Immunol Med Microbiol 2004:41:157-60.

10. Bonen DK, Nicolae DL, Moran T, et al. Racial differences in NOD2 variation: Characterization of NOD2 in African-Americans with Crohn's disease. Gastroenterology 2002;122:A29 (Abst)

11. Economou M, Trikalinos TA, Loizou KT, Tsianos EV, Ioannidis JP Differential effects of NOD2 variants on Crohn's disease risk and phenotype in diverse populations: A metaanalysis. Am J Gastroenterol 2004;99:2393-404.

12. Lesage S, Zouali H, Cezard JP, et al. CARD15/NOD2 mutational analysis and genotype-phenotype correlation in 612 patients with inflammatory bowel disease. Am J Hum Genet 2002;70:845-57.

13. Sugimura K, Taylor KD, Lin YC, et al. A Novel NOD2/CARD15 haplotype conferring risk for Crohn disease in Ashkenazi Jews. Am J Hum Genet 2003;72:509-18.

14. Karban A, Eliakim R. Failure to replicate the association of the novel NOD2/CARD15 haplotype (S268P-JW1) to Crohn's disease in the Jewish Israeli population. Gastroenterology 2004;126:624-5.

15. Tukel T, Shalata A, Present D, et al. Crohn disease: Frequency and nature of CARD15 mutations in Ashkenazi and Sephardi/Oriental Jewish families. Am J Hum Genet 2004;74:623-36.

16. Bonen DK, Ogura Y, Nicolae DL, et al. Crohn's disease-associated NOD2 variants share a signaling defect in response to lipopolysaccharide and peptidoglycan. Gastroenterology 2003;124:140-6.

17. Arnott ID, Nimmo ER, Drummond HE, et al. NOD2/CARD15, TLR4 and CD14 mutations in Scottish and Irish Crohn's disease patients: Evidence for genetic heterogeneity within Europe? Genes Immun 2004:5:417-25.

18. Wehkamp J, Harder J, Weichenthal M, et al. NOD2 (CARD15) mutations in Crohn's disease are associated with diminished mucosal alpha-defensin expression. Gut 2004;53:1658-64.

19. Tanabe T, Chamaillard M, Ogura Y, et al. Regulatory regions and critical residues of NOD2 involved in muramyl dipeptide recognition. EMBO J 2004;23:1587-97.

20. Giallourakis C, Stoll M, Miller K, et al. IBD5 is a general risk factor for inflammatory bowel disease: Replication of association with Crohn disease and identification of a novel association with ulcerative colitis. Am J Hum Genet 2003;73:205-11.

21. McGovern DP, van Heel DA, Negoro K, Ahmad T, Jewell DP. Further evidence of IBD5/CARD15 (NOD2) epistasis in the susceptibility to ulcerative colitis. Am J Hum Genet 2003;73:1465-6.

22. Lala S, Ogura Y, Osborne C, et al. Crohn's disease and the NOD2 gene: A role for paneth cells. Gastroenterology 2003;125:47-57.

23. Ogura Y, Lala S, Xin W, et al. Expression of NOD2 in Paneth cells: A possible link to Crohn's ileitis. Gut 2003;52:1591-7.

24. Brant SR, Picco MF, Achkar JP, et al. Defining complex contributions of NOD2/CARD15 gene mutations, age at onset, and tobacco use on Crohn's disease phenotypes. Inflamm Bowel Dis 2003;9:281-9

25. Newman B, Silverberg MS, Gu X, et al. CARD15 and HLA DRB1 alleles influence susceptibility and disease localization in Crohn's disease. Am J Gastroenterol 2004;99:306-15.

26. Abreu MT, Taylor KD, Lin YC, et al. Mutations in NOD2 are associated with fibrostenosing disease in patients with Crohn's disease. Gastroenterology 2002;123:679-88.

27. Ahmad T, Armuzzi A, Bunce M, et al. The molecular classification of the clinical manifestations of Crohn's disease. Gastroenterology 2002;122:854-66

28. Gasche C, Scholmerich J, Brynskov J, et al. A simple classification of Crohn's disease: Report of the Working Party for the World Congresses of Gastroenterology, Vienna 1998. Inflamm Bowel Dis 2000;6:8-15.

29. Armuzzi A, Ahmad T, Ling KL, et al. Genotype-phenotype analysis of the Crohn's disease susceptibility haplotype on chromosome $5 \mathrm{q} 31$. Gut 2003;52:1133-9.

30. Smith BR, Arnott ID, Drummond HE, Nimmo ER, Satsangi J. Disease location, anti-Saccharomyces cerevisiae antibody, and NOD2/CARD15 genotype influence the progression of disease behavior in Crohn's disease. Inflamm Bowel Dis 2004;10:521-8.

31. Vermeire S, Wild G, Kocher K, et al. CARD15 Genetic variation in a Quebec population: Prevalence, genotype- phenotype relationship, and haplotype structure. Am J Hum Genet 2002;71:74-83.

32. Ferreira AC, Almeida S, Tavares M, et al. NOD2/CARD15 and TNFA, but not IL1B and IL1RN, are associated with Crohn's disease. Inflamm Bowel Dis 2005;11:331-9.

33. Guagnozzi D, Cossu A, Viscido A, et al. Acute intestinal obstruction and NOD2/CARD15 mutations among Italian Crohn's disease patients. Eur Rev Med Pharmacol Sci 2004;8:179-85. 
34. Tomer G, Ceballos C, Concepcion E, Benkov KJ. NOD2/CARD15 variants are associated with lower weight at diagnosis in children with Crohn's disease. Am J Gastroenterol 2003;98:2479-84.

35. Cuthbert AP, Fisher SA, Mirza MM, et al. The contribution of NOD2 gene mutations to the risk and site of disease in inflammatory bowel disease. Gastroenterology 2002;122:867-74.

36. Polito JM, Childs B, Mellits ED, Tokayer AZ, Harris ML, Bayless TM. Crohn's disease: Influence of age at diagnosis on site and clinical type of disease. Gastroenterology 1996;111:580-6.

37. Wang MH, Shugart YY, Rawsthorne P, et al. A population based assessment of NOD2/CARD15 and risk of developing Crohn's disease. Gastroenterology 2004;126:A46. (Abst)

38. Pierik M, De HG, Vermeire S, et al. Epithelioid granulomas, pattern recognition receptors, and phenotypes of Crohn's disease. Gut 2005;54:223-7.

39. Shaoul R, Karban A. Weiss B, et al. NOD2/CARD15 mutations and presence of granulomas in pediatric and adult Crohn's disease. Inflamm Bowel Dis 2004;10:709-14

40. Heresbach D, Gicquel-Douabin V, Birebent B, et al. NOD2/CARD15 gene polymorphisms in Crohn's disease: A genotype-phenotype analysis. Eur J Gastroenterol Hepatol 2004;16:55-62.

41. Lakatos PL, Lakatos L, Szalay F, et al, for the Hungarian IBD Study Group. Toll-like receptor 4 and NOD2/CARD15 mutations in Hungarian patients with Crohn's disease: Phenotype-genotype correlations. World J Gastroenterol 2005;11:1489-11.

42. Vermeire S, Louis E, Rutgeerts P, et al. NOD2/CARD15 does not influence response to infliximab in Crohn's disease. Gastroenterology 2002;123:106-11.

43. Mascheretti S, Hampe J, Croucher PJ, et al. Response to infliximab treatment in Crohn's disease is not associated with mutations in the CARD15 (NOD2) gene: An analysis in 534 patients from two multicenter, prospective GCP-level trials. Pharmacogenetics 2002;12:509-15.

44. McGovern DP, van Heel D, Ahmad T, Negoro K, Travis S, Jewell D. Evaluation of a genetic panel in the diagnosis of Crohn's disease. Gastroenterology 2005;128:A445. (Abst)

\section{Role of human leukocyte antigen genes}

\section{Key points}

- The IBD susceptibility gene(s) within the human leukocyte antigen (HLA) complex remain undiscovered. Strong linkage disequilibrium, extensive polymorphism and high gene density continue to hamper their identification.

- The most consistently replicated associations are with the classical class II gene, HLA-DR. Some HLA-DRB1 alleles are associated with susceptibility while others offer protection. The specific associations with $\mathrm{CD}$ and $\mathrm{UC}$ are different, with the notable exception that HLA-

DRB1*0103 is shared by UC and colonic CD. A hierarchy of association is observed, with HLA-DRB1*0103 conferring the greatest risk (RR two to 10).

- Most HLA associations are population-specific, reflecting ethnic differences in allele frequency and patterns of linkage disequilibrium.

- In $\mathrm{CD}$, the strongest associations are with specific phenotypes defined by the location of disease. DRB1*0103 is a risk factor for CD limited to the colon. DRB1*0701 is a risk factor for ileal (ileal and ileocolonic) CD in Caucasians who lack the common disease-associated NOD2/CARD15 mutations.

- In UC, the strongest associations are seen with overall disease susceptibility, and consistent associations are observed with DRB1*0103 and DRB1*1502. Fewer subgroup associations have been identified than with CD, but the association with DRB1*0103 is particularly strong in patients with extensive or severe disease;

- Specific associations have been described with the extraintestinal manifestations of $\mathrm{CD}$, but the findings must be replicated by additional studies.

- Stratification of HLA association data by other IBDassociated variants (eg, NOD2/CARD15) reduces genetic heterogeneity and facilitates the identification of important gene-gene interactions.

- The HLA region is likely to harbour more than one IBD susceptibility gene, and recent studies suggest that the second locus is likely to be in the class III region.

- The low sensitivity and specificity of the diseaseassociated alleles currently limits their use alone in the diagnosis and classification of IBD.

\section{Significant references}

Satsangi J, Welsh KI, Bunce M, et al. Contribution of genes of the major histocompatibility complex to susceptibility and disease phenotype in inflammatory bowel disease. Lancet 1996;347:1212-7.

Stokkers PC, Reitsma PH, Tytgat GN, van Deventer SJ. HLA-DR and -DQ phenotypes in inflammatory bowel disease: A meta-analysis. Gut 1999;45:395-401.

Ahmad T, Armuzzi A, Bunce M, et al. The molecular classification of the clinical manifestations of Crohn's disease. Gastroenterology 2002;122:854-66.

The HLA complex is a highly polymorphic, gene-dense region on chromosome $6 \mathrm{p}$ encompassing at least 130 expressed genes, many of which have immunoregulatory roles $(1,2)$. Several independent studies have provided consistent evidence that both UC $(3,4)$ and $\mathrm{CD}(3-7)$ are linked to IBD3 (6p21.1-23), an area which encompasses the HLA complex. These findings have subsequently been confirmed by the IBD consortium in a large replication study of 733 nuclear families (8). A metaanalysis of 10 published genome-wide scans showed that IBD3 was the only locus that had genome-wide significance (9). Although it is difficult to estimate the importance of this region in determining overall genetic susceptibility, calculations derived from studies of the sharing of HLA alleles within families suggest that it contributes between $10 \%$ and $33 \%$ of the total genetic risk of CD (10), and between $64 \%$ and $100 \%$ of the total genetic risk of UC (11). Since 1972, more than 100 association studies have investigated the role of HLA genes in determining susceptibility to both $\mathrm{UC}$ and CD. Interest has traditionally focused on the classical class II HLA alleles, but recent insights into the biological function of other genes encoded within this region have led investigators to a more comprehensive exploration of this region.

\section{Classical HLA class II genes and IBD}

HLA-DRB1 is the most extensively studied gene in IBD research. Convincing evidence of association has been described for a number of alleles, some of which confer risk, while others are protective. Many of these were highlighted in a 1999 meta-analysis (12) of 29 association studies published between 1966 and 1998. Since publication of this report, improvement in study design has enabled the study of accurately characterized, larger patient cohorts. Realization that a 
genetic basis might underlie disease heterogeneity has stimulated more detailed genotype-phenotype analyses of this locus.

\section{HLA class II associations with UC}

HLA-DRB1*0103 and severe, extensive UC: The most consistently replicated association of UC is with the HLADRB1*0103 allele. This is a rare allele that occurs in less than $2 \%$ of the European and North American Caucasian and Jewish populations, and is absent in the Japanese. Data from the 1999 meta-analysis (12) demonstrated a moderate disease association in unselected UC patients (OR 3.42), which has subsequently been confirmed in Spanish (13), North American (14), British (15) and Mexican cohorts (16). The association is observed for both the DRB1*0103-DQB1*0301 and DRB1*0103-DQB1*0501 haplotypes, strongly implicating DRB1*0103 in the pathogenesis of the disease. This association is particularly strong in patients with extensive (15-18) or severe disease, as defined by the need for colectomy for failed medical therapy $(15,16)$. Among patients who require colectomy, this allele is associated with a shorter mean time to surgery (15). The low frequency of this allele, however, limits its clinical value in predicting disease course.

HLA-DRB1*1502: HLA-DRB1*1502 is associated with UC in European (15), North American (14), Japanese $(19,20)$ and Korean (21) populations, with similar ORs of 2 to 4.5 despite variable background prevalence (allele carriage rates are 20\% to $25 \%$ in Japanese but less than $1 \%$ in northern European populations). This transracial concordance suggests that this allele, or a nearby one, is a true disease-causing variant. Association with HLA-DRB1*1502, rather than with HLADRB1*1501, explains the earlier reported association with the serological antigen DR2 (OR 2.00; 95\% CI 1.52 to 2.63) highlighted in the 1999 meta-analysis (12). Limited data suggest HLA-DRB1*1502 is associated with extensive and intractable UC among Japanese (22) but not Korean patients (21). In Japanese (23) and British (24) patients, UC has also been reportedly associated with $\mathrm{HLA}-\mathrm{B} * 52$, the class I allele in linkage disequilibrium with DRB1*1502. Interestingly HLA-B*52, but not HLA-DRB1*1502, has also been shown to be associated with colonic $\mathrm{CD}$ in these populations $(25,26)$, providing suggestive evidence of a shared genetic basis for $\mathrm{UC}$ and colonic CD.

HLA-DRB1*04 - UC protection: The HLA-DRB1*04 allele is negatively associated with UC (OR 0.54) (12) but positively associated with CD in northern Europeans and Japanese populations. In the United Kingdom population, the effect is confined to the most prevalent subtype DRB1*0401, and only when present on the two-locus haplotype DRB1*0401 DQB1*0301 (24). This probably indicates that the true protective polymorphism is found on the associated extended haplotype.

\section{HLA class II associations with CD}

HLA-DRB1*07 and NOD2/CARD15 variant-negative ileal CD: The most consistently replicated association of $\mathrm{CD}$ with a common HLA allele is with HLA-DRB1*07, which has an allele frequency between 5\% and 29\% in European and North American populations but less than $1 \%$ in Japanese. In the 1999 meta-analysis (12), a weak association was demonstrated in unselected patients with CD (OR 1.42), but three subsequent studies of well-characterized patients from the United Kingdom (25), Canada (27) and Spain (28) showed that the allele is specifically associated with ileal involvement (with or without colonic disease) with ORs of 1.5, 1.9 and 2.6, respectively. These figures are similar to those observed for possession of a single NOD2/CARD15 variant. Importantly, by demonstrating that the association with HLA-DRB1*07 is present only in patients who do not possess one of the three common NOD2/CARD15 variants associated with CD, the United Kingdom and Canadian studies provided evidence for genetic heterogeneity in ileal CD $(25,27)$. The Canadian study found that HLA-DRB1*07 was numerically more prevalent in Jewish patients with ileal CD, although this association did not achieve statistical significance, perhaps because of the small number of patients analyzed (27).

HLA-DRB1*0103 and colonic CD: The association between HLA-DRB1*0103 and CD was not demonstrated until 2000 (14), almost certainly because of the heterogeneity of CD and the low prevalence of this allele, but has now been widely replicated in North American and European patients. DRB1*0103 is strongly associated with colonic location, particularly isolated colonic disease (25,27-29), and the described association with perianal location and fistulizing behaviour appears not to be independent of colonic involvement $(25,28)$. The ORs for isolated colonic disease range from 5.1 to 18.5 in non-Jewish Caucasians $(25,27,28)$. Despite the strength of this association, this allele was present in no more than $32 \%$ of patients with isolated colonic disease, thereby limiting its clinical application.

HLA-DRB1*04 and NOD2/CARD15 variant-positive ileal CD?: The association between HLA-DRB1*04 and CD is particularly important in Japanese cohorts, in whom the strongest HLA associations are with DRB1*0405, *0410 and the linked DQB1*0401 - 0402 alleles $(20,30,31)$. This has not been widely observed in European and North American patients, but a weak association with DRB1*04 has recently been identified in Canadian patients with ileal disease (RR 1.7; 95\% CI 1.1 to 2.5 ) (27). This association was stronger in patients possessing one of the three common NOD2/CARD15 variants, which might indicate an epistatic interaction in ileal $\mathrm{CD}$ between HLA-DRB1 and NOD2/CARD15 (27). Genotypephenotype analysis of this allele in Japanese patients is awaited. HLA-DRB1*1501 - CD protection: HLA-DRB1*1501 is a common allele, with a frequency of $6 \%$ to $25 \%$ in European and North American Caucasian populations, and 6\% to $10 \%$ in the Japanese. It is negatively associated with overall CD susceptibility (12), and probably confers protection against CD in all ethnic groups. This allele is encompassed within the serologically defined antigen DR2, explaining the previously reported negative association between DR2 and CD described in the 1999 meta-analysis (12).

HLA-DRB3*0301 - HLA-DRB1*1302: The HLA-DRB3 gene is expressed in less than $50 \%$ of European and North American Caucasians, and has not been extensively studied. However, both a meta-analysis of three small studies (12) and a large United Kingdom study (25) support a positive association of CD with DRB3*0301, although it remains unclear whether this is due to linkage disequilibrium with another CDassociated DRB1 allele, DRB1*1302, or the HLA class I allele $\mathrm{Cw}^{*} 0802(12,25)$.

HLA class II associations with the extraintestinal manifestations of IBD: A number of HLA associations have been described with extraintestinal manifestations (EIMs) of IBD in small, mixed studies of UC and CD. Type I peripheral arthritis, 
a migratory pauciarticular arthritis involving large joints, has been shown to be associated with HLA-DRB1*0103 (as well as with the class I alleles found in linkage disequilibrium, B*27 and $B * 35)$ (32). In that study, HLA-DRB1*0103 was found in $35 \%$ of patients compared with $3 \%$ of controls. In contrast, type II peripheral arthritis, a chronic, small joint, symmetrical arthritis, is associated with HLA-B*44 (32). Uveitis has also been associated with DRB1*0103 and HLA-B*27, and erythema nodosum with the tumour necrosis factor (TNF) promoter single nucleotide polymorphism (SNP)-1031C (33). An increased prevalence of EIMs has previously been reported in patients with colonic CD (34), raising the possibility that the association with DRB1*0103 may merely reflect the documented association with colonic disease. Further work is required to clarify this issue.

A number of important observations should be noted from the reported associations with HLA class II alleles. First, the specific associations with CD and UC are different, with the notable exceptions of HLA-DRB1*0103 and HLA-B*52 with both UC and colonic CD. Second, it is clear that multiple alleles may be associated with any specific phenotype. This may suggest a shared disease-associated peptide motif, as seen in rheumatoid arthritis (35). However, only some disease-associated alleles share significant residue changes in the antigen-binding domain, indicating that this hypothesis cannot entirely explain these associations. Third, it is not known whether a gene-dose effect operates, such that possession of two high-risk HLA alleles confers additional risk. Fourth, while many of the associations appear to be robust, it is clear that the penetrance is low, and the presence of a risk allele is neither necessary nor sufficient for disease to occur. Finally, the reported associations vary with ethnicity and geographical location, reflecting genetic heterogeneity, prevalence of risk alleles in the background population, and population-specific patterns of linkage disequilibrium across the HLA complex.

A second HLA gene for UC and CD?: In IBD, as with a number of other HLA class II-associated diseases, there is increasing evidence for a second susceptibility locus within the HLA (36-40). Such a gene might act independently of the class II locus, or interact with disease-associated class II alleles in cis or trans positions. Specific additional associations in IBD have been identified with the HLA class I genes, HLA-B and Cw, the nonclassical major histocompatibility complex class Irelated (MIC) genes, MICA and MICB, and the three heat shock protein genes (HSPA1L, HSPA1A and HSPA1B). Recent interest has focused on a cluster of immunoregulatory genes centred around TNF in the HLA class III region, including TNF, lymphotoxin alpha, lymphotoxin beta, NFKBIL and BAT1. To date, most studies have investigated only a few SNPs in a single gene, chosen because of previously described associations or for ease of genotyping. Results have generally been inconsistent, even within phenotypically defined subgroups and, as with other HLA-associated diseases, very few studies have fully controlled for linkage disequilibrium with HLADRB1.

TNF: The most widely studied gene in the HLA class III region is TNF, which encodes a proinflammatory cytokine found in increased concentrations in the mucosa, serum and stool of patients with IBD. The $\triangle \mathrm{ARE}$ (deletion of AU-rich elements) (41) and TNF-/- mouse (42) models provide experimental evidence of the importance of TNF in IBD. This concept is supported by convincing clinical evidence of dramatic responses in both $\mathrm{CD}$ and $\mathrm{UC}$ to infusions of the anti-TNFalpha monoclonal antibody, infliximab. A large number of TNF promoter polymorphisms have been described, although the functional significance of individual variants remains uncertain. The -857 TNF polymorphism has been most widely studied. The C allele is extremely common: $99 \%$ of the healthy Caucasian population possess at least one copy and approximately $85 \%$ are homozygotes. A modest association with the $-857 \mathrm{C}$ allele was reported in transmission disequilibrium test and case-control analyses from the United Kingdom (43). RRs for the homozygote TNF-857CC genotype were 2.4 in both $\mathrm{UC}$ and in $\mathrm{CD}$ patients lacking the three CD-associated NOD2/CARD15 variants (43). This association was replicated in transmission disequilibrium test studies from Australia (44) and the IBD consortium (8). In contrast to the United Kingdom study, the association was stronger in families that carried high-risk NOD2/CARD15 variants. In the latter studies, no association was found with UC, possibly a consequence of the smaller number of UC families included. No specific phenotypic associations have been identified. Although not directly investigated by either of these studies, it should be noted that an important confounder is the linkage disequilibrium between the rare, protective $-857 \mathrm{~T}$ allele and DRB1*0301 (45), an allele shown by several studies to be protective against CD overall. Thus, the TNF-857C association may simply reflect linkage disequilibrium within this highly complex region.

Modest associations have also been reported with many other polymorphic sites in the TNF promoter. In CD, these include TNF-1031C (46), TNF-863A (47) and TNF-308A $(25,48,49)$. The association with TNF-308A appears to be specifically associated with colonic CD $(25,48,49)$; however, once again this finding is confounded by tight linkage disequilibrium across the A1-B8-DR3 ancestral haplotype, the only common haplotype to contain the TNF-308A allele. In small studies, TNF-308A has also been shown to be associated with UC $(50,51)$, providing further evidence of shared genetic susceptibility for UC and colonic CD.

Integrating HLA genotypes into a classification of IBD

The data reviewed in the present report demonstrate that genes in the HLA region are important in determining the susceptibility to and the phenotype of UC and CD. Although the specific disease-causing genes remain unidentified, the strength and consistency of these associations have confirmed the importance of classifying patients both by accurately defined clinical characteristics and by their possession of known genetic risk factors, such as NOD2/CARD15 diseaseassociated variants. For overall disease susceptibility and clinical phenotype of both CD and UC, the most consistently replicated associations are with the classical class II gene, HLA-DR. In CD, the strongest associations are observed with subgroups defined by the location of disease. No consistent associations have been reported with disease behaviour, which is a less stable phenotypic characteristic, age at diagnosis, disease complications (with the exception of EIMs) or response to treatment. In UC, the strongest associations are seen with overall disease susceptibility, which is consistently associated with DRB1*0103 and DRB1*1502. These alleles vary widely in prevalence across ethnic groups. Fewer subgroup associations have been identified than with $\mathrm{CD}$, but the association with DRB1*0103 is particularly strong in patients with extensive or severe disease. 
The low sensitivity and specificity of these associations currently preclude their use as a tool in diagnosis of either $\mathrm{CD}$ or UC. For the same reason, it is unlikely that the use of HLA markers alone will be useful in disease screening of asymptomatic individuals. Similarly, HLA markers cannot be reliably used for the discrimination of CD from UC. Indeed the shared association of DRB1*0103 and B*52 with UC and colonic CD suggests the presence of at least one shared HLA susceptibility factor, providing a tantalizing clue about the molecular basis of colonic inflammation. Such shared HLA factors may help to explain clustering of both forms of IBD in the same family. The apparent differential effect of HLA-DRB1*0401 in UC and CD, although unique within the HLA region, is weak, populationspecific, and neither sufficiently sensitive nor specific to be clinically useful.

In the near future, the greatest value of HLA genotyping is likely to be in the prediction of disease course in patients with an established diagnosis of $\mathrm{UC}$ or $\mathrm{CD}$, but it is currently not sensitive or specific enough to be clinically useful. Integration of an individual's HLA genotype into a panel of other genetic and serological markers may improve the sensitivity and specificity, although ultimately this is likely to require the identification of the primary IBD genes within this complex region.

In common with virtually all other diseases that have HLA associations, the HLA susceptibility genes for IBD remain elusive. Mapping of disease genes within this region is challenging because of the high gene density and degree of polymorphism; the complex haplotype structure and patterns of linkage disequilibrium; the relatively small RRs conferred by individual alleles; and the likely clustering of more than one IBD susceptibility gene either within the HLA complex or within the surrounding IBD3 locus.

The data in the present report indicate that the goal of an integrated classification of IBD would be more easily achieved if the following steps were taken in the design of future studies of the HLA region:

1. Patients need to be rigorously phenotyped, preferably according to the updated World Congress of

Gastroenterology 2005 classification guidelines. Further consensus is required regarding the minimum period of follow-up, and how to classify unstable phenotypic characteristics. This type of meticulous approach is likely to require complete case note review for patient inclusion, and would be a dynamic, iterative process. At present, there is debate as to whether disease location should include separate ileal, colonic and ileocolonic subgroups, or whether the last of these is redundant. Furthermore, it is unclear whether perianal and internal fistulizing disease should be classified as separate behavioural entities. Molecular information may help to resolve this issue.

2. Larger studies need be performed to address the problems associated with the low RRs of disease-associated HLA alleles, many of which occur at low frequency, and would also permit the dissection of potential gene-gene HLA interactions involved in the development of a specific phenotype. This might only be possible through multicentre studies, and consensus clinical phenotyping would obviate the problem of variable disease definition. Such studies would require particular attention to ethnic definition.
3. Specific consideration needs to be taken of the complex, variable patterns of linkage disequilibrium across the HLA region, which can currently be addressed only by detailed haplotype studies. Association data from various ethnic cohorts (transracial mapping) may be particularly useful.

4. Stratification of association data by known IBDassociated mutations, such as NOD2/CARD15 variants and specific HLA alleles, might further reduce genetic heterogeneity, facilitating the identification of other disease-associated polymorphisms and important genegene interactions.

\section{REFERENCES}

1. Complete sequence and gene map of a human major histocompatibility complex. The MHC sequencing consortium. Nature 1999;401:921-3.

2. Shiina T, Tamiya G, Oka A, et al. Molecular dynamics of MHC genesis unraveled by sequence analysis of the 1,796,938-bp HLA class I region. Proc Natl Acad Sci U S A 1999;96:13282-7.

3. Hampe J, Schreiber S, Shaw SH, et al. A genomewide analysis provides evidence for novel linkages in inflammatory bowel disease in a large European cohort. Am J Hum Genet 1999;64:808-16.

4. Dechairo B, Dimon C, van Heel D, et al. Replication and extension studies of inflammatory bowel disease susceptibility regions confirm linkage to chromosome 6p (IBD3). Eur J Hum Genet 2001;9:627-33.

5. Ma Y, Ohmen JD, Li Z, et al. A genome-wide search identifies potential new susceptibility loci for Crohn's disease. Inflamm Bowel Dis 1999;5:271-8.

6. Hampe J, Shaw SH, Saiz R, et al. Linkage of inflammatory bowel disease to human chromosome $6 \mathrm{p}$. Am J Hum Genet 1999;65:1647-55.

7. Rioux JD, Silverberg MS, Daly MJ, et al. Genomewide search in Canadian families with inflammatory bowel disease reveals two novel susceptibility loci. Am J Hum Genet 2000;66:1863-70.

8. Panhuysen CI Cavanaugh J, Yang H, et al. TNF -857 promoter polymorphism is a significant risk factor for IBD and shows epistasis with NOD2/ CARD15 Crohn's disease predisposing mutations. IBD in press 2005.

9. van Heel DA, Fisher SA, Kirby A, Daly MJ, Rioux JD, Lewis CM. Inflammatory bowel disease susceptibility loci defined by genome scan meta-analysis of 1952 affected relative pairs. Hum Mol Genet 2004;13:763-70.

10. Yang H, Plevy SE, Taylor K, et al. Linkage of Crohn's disease to the major histocompatibility complex region is detected by multiple non-parametric analyses. Gut 1999;44:519-26.

11. Satsangi J, Welsh KI, Bunce M, et al. Contribution of genes of the major histocompatibility complex to susceptibility and disease phenotype in inflammatory bowel disease. Lancet 1996;347:1212-7.

12. Stokkers PC, Reitsma PH, Tytgat GN, van Deventer SJ. HLA-DR and $-D Q$ phenotypes in inflammatory bowel disease: A metaanalysis. Gut 1999;45:395-401.

13. de la Concha EG, Fernandez-Arquero M, Martinez A, et al. Amino acid polymorphism at residue 71 in HLA-DR beta chain plays a critical role in susceptibility to ulcerative colitis. Dig Dis Sci 1999;44:2324-9.

14. Trachtenberg EA, Yang H, Hayes E, et al. HLA class II haplotype associations with inflammatory bowel disease in Jewish (Ashkenazi) and non-Jewish caucasian populations. Hum Immunol 2000;61:326-3.

15. Ahmad T, Armuzzi A, Neville M, et al. The contribution of human leucocyte antigen complex genes to disease phenotype in ulcerative colitis. Tissue Antigens 2003;62:527-35.

16. Yamamoto-Furusho JK, Uscanga LF, Vargas-Alarcon G, et al. Clinical and genetic heterogeneity in Mexican patients with ulcerative colitis. Hum Immunol 2003;64:119-23.

17. Roussomoustakaki M, Satsangi J, Welsh K, et al. Genetic markers may predict disease behavior in patients with ulcerative colitis. Gastroenterology 1997;112:1845-53.

18. Bouma G, Crusius JB, Garcia-Gonzalez MA, et al. Genetic markers in clinically well defined patients with ulcerative colitis (UC). Clin Exp Immunol 1999;115:294-300.

19. Futami S, Aoyama N, Honsako Y, et al. HLA-DRB1*1502 allele, subtype of DR15, is associated with susceptibility to ulcerative colitis and its progression. Dig Dis Sci 1995;40:814-8. 
20. Yoshitake S, Kimura A, Okada M, Yao T, Sasazuki T. HLA class II alleles in Japanese patients with inflammatory bowel disease. Tissue Antigens 1999;53:350-8.

21. Myung SJ, Yang SK, Jung HY, et al. HLA-DRB1*1502 confers susceptibility to ulcerative colitis, but is negatively associated with its intractability: A Korean study. Int J Colorectal Dis 2002;17:233-7.

22. Masuda H, Nakamura Y, Tanaka T, Hayakawa S. Distinct relationship between HLA-DR genes and intractability of ulcerative colitis. Am J Gastroenterol 1994;89:1957-62.

23. Seki SS, Sugimura K, Ota M, et al. Stratification analysis of MICA triplet repeat polymorphisms and HLA antigens associated with ulcerative colitis in Japanese. Tissue Antigens 2001;58:71-6.

24. Ahmad T, Armuzzi A, Neville M, et al. The contribution of human leucocyte antigen complex genes to disease phenotype in ulcerative colitis. Tissue Antigens 2003;62:527-35.

25. Ahmad T, Armuzzi A, Bunce M, et al. The molecular classification of the clinical manifestations of Crohn's disease. Gastroenterology 2002;122:854-66.

26. Kinouchi Y, Matsumoto K, Negoro K, et al. Hla-B genotype in Japanese patients with Crohn's disease. Dis Colon Rectum 2003;46(10 Suppl):S10-4.

27. Newman B, Silverberg MS, Gu X, et al. CARD15 and HLA DRB1 alleles influence susceptibility and disease localization in Crohn's disease. Am J Gastroenterol 2004;99:306-15.

28. Fernandez L, Mendoza JL, Martinez A, et al. IBD1 and IBD3 determine location of Crohn's disease in the Spanish population. Inflamm Bowel Dis 2004;10:715-22.

29. Silverberg MS, Mirea L, Bull SB, et al. A population-and familybased study of Canadian families reveals association of HLADRB1*0103 with colonic involvement in inflammatory bowel disease. Inflamm Bowel Dis 2003;9:1-9.

30. Matake H, Okabe N, Naito S, Yao T. An HLA study on 149 Japanese patients with Crohn's disease. Gastroenterol Jpn 1992;27:496-501.

31. Nakajima A, Matsuhashi N, Kodama T, Yazaki Y, Takazoe M, Kimura A. HLA-linked susceptibility and resistance genes in Crohn's disease. Gastroenterology 1995;109:1462-7.

32. Orchard TR, Thiyagaraja S, Welsh KI, Wordsworth BP, Hill Gaston JS, Jewell DP. Clinical phenotype is related to HLA genotype in the peripheral arthropathies of inflammatory bowel disease. Gastroenterology 2000;118:274-8.

33. Orchard TR, Chua CN, Ahmad T, Cheng H, Welsh KI, Jewell DP. Uveitis and erythema nodosum in inflammatory bowel disease: Clinical features and the role of HLA genes. Gastroenterology 2002;123:714-8.

34. Rankin GB, Watts HD, Melnyk CS, Kelley ML Jr. National Cooperative Crohn's Disease Study: Extraintestinal manifestations and perianal complications. Gastroenterology 1979;77:914-20.

35. Gregersen PK, Silver J, Winchester RJ. The shared epitope hypothesis. An approach to understanding the molecular genetics of susceptibility to rheumatoid arthritis. Arthr Rheum 1987;30:1205-13.

36. Newton J, Brown MA, Milicic A, et al. The effect of HLA-DR on susceptibility to rheumatoid arthritis is influenced by the associated lymphotoxin alpha-tumor necrosis factor haplotype. Arthr Rheum 2003;48:90-6.

37. de la Concha EG, Fernandez-Arquero M, Vigil P, et al. Celiac disease and TNF promoter polymorphisms. Hum Immunol 2000;61:513-7.

38. Fernandez-Arquero M, Arroyo R, Rubio A, et al. Primary association of a TNF gene polymorphism with susceptibility to multiple sclerosis. Neurology 1999;53:1361-3.

39. Degli-Esposti MA, Abraham LJ, McCann V, Spies T, Christiansen FT, Dawkins RL. Ancestral haplotypes reveal the role of the central $\mathrm{MHC}$ in the immunogenetics of IDDM. Immunogenetics 1992;36:345-56.

40. Nomura E, Kinouchi Y, Negoro K, et al. Mapping of a disease susceptibility locus in chromosome $6 \mathrm{p}$ in Japanese patients with ulcerative colitis. Genes Immun 2004;5:477-83.

41. Kontoyiannis D, Pasparakis M, Pizarro TT, Cominelli F, Kollias G. Impaired on/off regulation of TNF biosynthesis in mice lacking TNF AU-rich elements: Implications for joint and gut-associated immunopathologies. Immunity 1999;10:387-98.

42. Neurath MF, Fuss I, Pasparakis M, et al. Predominant pathogenic role of tumor necrosis factor in experimental colitis in mice. Eur J Immunol 1997;27:1743-50.
43. van Heel DA, Udalova IA, De Silva AP, et al. Inflammatory bowel disease is associated with a TNF polymorphism that affects an interaction between the OCT1 and NF-kappaB transcription factors. Hum Mol Genet 2002;11:1281-9.

44. O'Callaghan NJ, Adams KE, van Heel DA, Cavanaugh JA. Association of TNF- $\alpha-857 \mathrm{C}$ with inflammatory bowel disease in the Australian population. Scand J Gastroenterol 2003;38:533-4.

45. Ahmad T, Neville M, Marshall SE, et al. Haplotype-specific linkage disequilibrium patterns define the genetic topography of the human MHC. Hum Mol Genet 2003;12:647-56.

46. Negoro K, Kinouchi Y, Hiwatashi N, et al. Crohn's disease is associated with novel polymorphisms in the 5'-flanking region of the tumor necrosis factor gene. Gastroenterology 1999;117:1062-8.

47. Levine A, Karban A, Eliakim R, et al. A polymorphism in the TNFalpha promoter gene is associated with pediatric onset and colonic location of Crohn's disease. Am J Gastroenterol 2005;100:407-13.

48. Louis E, Peeters M, Franchimont D, et al. Tumour necrosis factor (TNF) gene polymorphism in Crohn's disease (CD): Influence on disease behaviour? Clin Exp Immunol 2000;119:64-8.

49. Ferreira AC, Almeida S, Tavares M, et al. NOD2/CARD15 and TNFA, but not IL1B and IL1RN, are associated with Crohn's disease. Inflamm Bowel Dis 2005;11(4):331-9.

50. Bouma G, Xia B, Crusius JB, et al. Distribution of four polymorphisms in the tumour necrosis factor (TNF) genes in patients with inflammatory bowel disease (IBD). Clin Exp Immunol 1996;103:391-6.

51. Sashio H, Tamura K, Ito R, et al. Polymorphisms of the TNF gene and the TNF receptor superfamily member $1 \mathrm{~B}$ gene are associated with susceptibility to ulcerative colitis and Crohn's disease, respectively. Immunogenetics 2002;53:1020-7.

\section{New genes for IBD - where are we now?}

\section{Key points}

- While the IBD5 locus plays an important role in IBD, the definitive gene within the region remains unproven.

- Multidrug resistance-1 (MDR1), Drosophila discs large homolog 5 (DLG5) and toll-like receptor 4 (TLR4) are excellent functional candidate genes with reported associations to IBD.

\section{Significant references}

Rioux JD, Daly MJ, Silverberg MS, et al. Genetic variation in the $5 \mathrm{q} 31$ cytokine gene cluster confers susceptibility to Crohn disease. Nat Genet 2001;29:223-8.

Panwala CM, Jones JC, Viney JL. A novel model of inflammatory bowel disease: Mice deficient for the multiple drug resistance gene, mdr1a, spontaneously develop colitis. J Immunol 1998;161:5733-44.

Stoll M, Corneliussen B, Costello CM, et al. Genetic variation in DLG5 is associated with inflammatory bowel disease. Nat Genet 2004;36:476-80.

\section{Progress towards gene identification}

The development of a linkage map of the human genome, involving informative microsatellite markers, has provided the basis for hypothesis-free scanning of the human genome for loci involved in susceptibility to simple monogenic and polygenic diseases (1). Thus far, numerous susceptibility loci have been implicated in IBD with varying degrees of replication and statistical support. Convincing replication of results has been demonstrated for nine such loci, termed IBD 1 to 9 (Table 11 and Figure 3) (2). While some loci appear specific to CD (eg, IBD1 on Ch16q- OMIM 266600) (3) or UC (eg, IBD2 on 
TABLE 11

Selected candidate genes with promising inflammatory bowel disease (IBD) genetic association evidence

\begin{tabular}{|c|c|c|c|c|c|}
\hline Gene & Disease & Polymorphisms & Chromosome & Populations & Additional phenotypic features \\
\hline CARD4/NOD1 & IBD & $32656 * 1 \mathrm{ins} / \mathrm{del}$ & $7 \mathrm{p} 14$ & British (47) & Early onset and extraintestinal disease (47) \\
\hline DLG5 & IBD & $113 \mathrm{G} / \mathrm{A}$ & $10 q 23$ & German (28) & \\
\hline $\begin{array}{l}\text { IBD5 locus haplotype and candidate gene } \\
\text { (SLC22A4-A5 or organic cation } \\
\text { transporter N1 and N2) }\end{array}$ & CD & $\begin{array}{l}600 \text { kb haplotype; } \\
\text { L503F and G-207C }\end{array}$ & $5 q 31-33$ & $\begin{array}{l}\text { Non-Jewish } \\
\text { Caucasians } \\
(7,9-17,32,48)\end{array}$ & $\begin{array}{l}\text { Perianal disease (14); } \\
\text { Severity/complications (11); lleal (10); UC } \\
\text { (NOD2+) (16); Infliximab-resistant (48) }\end{array}$ \\
\hline IL1 RA & UC & $\begin{array}{l}\text { Tandem repeat } \\
\text { allele } 2\end{array}$ & $2 q 14$ & $\begin{array}{l}\text { Caucasians }(49) \\
\text { Japanese }(52)\end{array}$ & $\begin{array}{l}\text { Pouchitis (50); Ankylosing spondylitis (51); } \\
\text { Early onset/pancolitis ( } 52 \text { ) }\end{array}$ \\
\hline NF-kB1 & UC & Promoter-94delATTG & G 4q24 & Caucasians $(53,54)$ & Gene maps to major mouse colitis locus (54) \\
\hline PPAR- $\gamma$ & $C D$ & $\begin{array}{l}\text { Intron } 2 \\
\text { polymorphisms }\end{array}$ & $3 p 25$ & Caucasians (55) & $\begin{array}{l}\text { Gene also implicated in SAMP1/YitFc mouse } \\
\text { model (55) }\end{array}$ \\
\hline
\end{tabular}

ABCB1 ATP-binding cassette, subfamily B, member 1; CARD4 Caspase recruitment domain-containing protein 4; CD Crohn's disease; DLG5 Drosophila discs large homologue 5; IL1 RA Interleukin 1 receptor antagonist; Ins/del Insertion/deletion; MDR1 Multidrug resistance gene 1; NF-кB1 Nuclear factor-kappaB subunit 1; NOD1 Nucleotide-binding oligomerization domain 1; PPAR- $\gamma$ Peroxisome proliferator-activated receptor-gamma; SAMP1 Senescence-accelerated mouse-prone 1; SLC22A4-A5 Solute carrier family 22 member 4 and member 5; TLR Toll-like receptor; UC Ulcerative colitis

Ch12q-OMIM 601458) (4), others seem to confer susceptibility to IBD overall (eg, IBD3 Ch6p- OMIM 604519) (5), supporting the notion that $\mathrm{CD}$ and $\mathrm{UC}$ are polygenic disorders sharing some, but not all, susceptibility loci.

\section{IBD5 locus}

The IBD5 region, on chromosome $5 \mathrm{q} 31-33$, is second only to the NOD2/CARD15 region in receiving the most attention in recent years. In Canada, Rioux et al (6) first demonstrated the association between this region and $\mathrm{CD}$, especially in patients diagnosed before the age of 16 years. The same investigators then subjected the IBD5 locus to painstaking analysis, and demonstrated the presence of a number of potentially important candidate genes, including a cytokine gene cluster (7). Progress in narrowing the linkage interval and identifying the primary locus of susceptibility was limited, however, by the extent of linkage disequilibrium within the region. Indeed, Daly et al (8) described in detail the haplotype structure of this region with eleven discrete haplotype blocks punctuated by areas of recombination, as well as the obstacles that these haplotype blocks provided in positional cloning.

The IBD5 locus has been recently re-examined, with particular attention to the contribution of polymorphic markers within the organic cation transporter OCTN1 (SCL22A4 $\mathrm{C} \rightarrow \mathrm{T}$, a missense substitution in exon 9) and OCTN2 (SCL22A5 $\mathrm{G} \rightarrow \mathrm{C}$, a transversion in the promoter region) genes in the IBD5 linkage interval (9). In the original study of the IBD5 region, these genes were initially considered potential candidate genes, but were thought to have little relevance to the pathobiology of CD (7). The OCTN1 and OCTN2 genes are adjacent to each other within a single haplotype block of the IBD5 locus, and Peltekova et al (9) suggest that a haplotype involving two functional OCTN1/2 variants (the TC haplotype) is associated with disease susceptibility. The authors further suggest that the contribution of the OCTN1/2 variants is stronger than, and independent of, the association

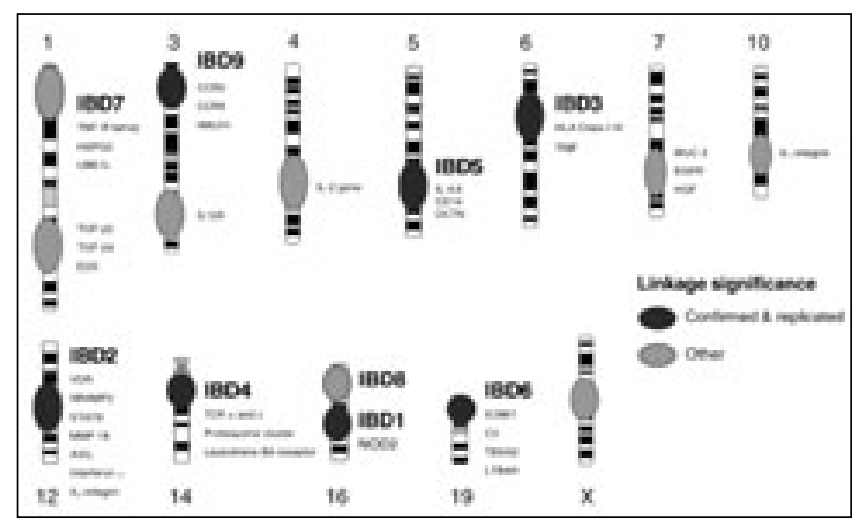

Figure 3) Susceptibility loci for inflammatory bowel disease (IBD) as identified on genome wide scanning (printed with permission, adapted from reference 58). CCR CC chemokine receptor; EGFR Epidermal growth factor receptor; HGF Hepatocyte growth factor; hMLH1 Human mismatch-repair protein MutL homologue 1; HSPG2 Heparan sulfate proteoglycan 2; ICAM1 Intercellular adhesion molecule 1; IL-12A Interleukin-12A; LTB4H Leukotriene $\mathrm{B}_{4}$ omega hydroxylase; MUC Mucin; NOD2 Nucleotide-binding oligomerization domain 2; OCTN Organic cation transporter; STAT6 Signal transducer and activator of transcription 6; TBXA Thromboxane A, TCR $T$ cell antigen receptor; TGF Transforming growth factor; TNF-R Tumour necrosis factor receptor; UBE1L Ubiquitin-activating enzyme E1-like; VDR Vitamin D receptor

with risk markers on the IBD5 haplotype. They also found that the TC haplotype interacts positively with the NOD2/CARD15 variants. A genotype-phenotype study from the same group has demonstrated an association between homozygosity for the TC haplotype and ileal disease, especially in the presence of NOD2/CARD15 mutations (10).

Yet a number of critical and unanswered questions remain. It appears somewhat implausible, on biological grounds, that 
two different variants involved in two adjacent genes are required for disease susceptibility. Given the extent of linkage disequilibrium across the region, are these simply markers for another critical variant? Moreover, no replication data, functional data or expression data in IBD are yet available to bolster the argument that Peltekova et al have identified the critical susceptibility genes. Our own data do demonstrate an association between OCTN1/2 and susceptibility to CD, but suggest that the effect is not independent of the IBD5 haplotype and that OCTN1/2 variants might simply be markers for the haplotype association (11). The latter finding has now been confirmed by several independent groups $(12,13)$. There is now real urgency to resolve this controversy by very large genotyping studies involving several thousand individuals with IBD together with expression and functional studies of OCTN1/2; until then, the causative role of OCTN1/2 variants must be regarded as unproven.

The phenotypic associations of the IBD5 locus with the HLA region and the NOD2/CARD15 gene have been explored in a number of populations, but no consistent pattern has emerged. One study (14) suggested an association with perianal disease, but this was not replicated in other datasets $(11,12)$. In the Edinburgh dataset, we noted an association with disease severity, manifested by progression of the disease and the need for surgery for CD (11). Whether the region has an important part to play in the pathogenesis of UC also remains debatable; the majority of positive studies have involved CD alone. Data from Germany and the United Kingdom have shown an association with UC and evidence for epistasis specifically with the CARD15 702Arg allele (15-17).

\section{MDR-1 gene}

The MDR-1 gene maps to chromosome 7q, and is located in a region that was associated with IBD susceptibility in a genomewide scan in the United Kingdom (18). This gene has generated considerable interest because of its relevance to the pathogenesis of disease susceptibility. The MDR $1^{-1-}$ mouse model develops spontaneous enterocolitis in specific pathogen-free, although not in germ-free, conditions (19). Decreased MDR1 expression has been noted in the colon in the interleukin $10^{-1-}$ model and the HLA-B27/beta2 microglobulin transgenic rat (20-22). Allelic association studies involving MDR1 variants have concentrated on two SNPs of putative functional significance: the C3435T exonic variant and the A2677G/T variant. To date, positive associations have been demonstrated in five independent datasets (23-27), and the most consistent association is with UC. In the Edinburgh dataset, specific haplotypes involving the two common single nucleotide polymorphisms appear to determine either disease susceptibility, or intriguingly, disease resistance in UC (27). Moreover, phenotypic associations with disease extent are reported. Although the physiological function of the MDR1 protein remains controversial, it appears most likely to play a role in protection of the epithelium against xenobiotics, which is entirely consistent with the involvement of gene-bacterial interactions in the pathogenesis of IBD. This hypothesis is consistent with our own data in the HLA-B27 transgenic model (20).

\section{DLG5}

Recent data from Stoll at al (28) in Germany has implicated that germline variation of the Drosophila discs large homolog 5 (DLG5) conveys susceptibility to CD and to IBD in general. The investigators pursued a positional cloning strategy for the 10q23 locus, which had been implicated in their own previous genome-wide scan, but failed to replicate the results in other datasets (29). Given the strength of initial observations, the authors followed the strategy of saturation genotyping and physical mapping, and have generated data implicating variation within this gene, which might have a practical role in maintenance of the epithelial structure or scaffold. DLG5 interacts with vinexin and beta-catenin in immunolocalization studies (30). As for the MDR1 gene, both risk-associated and protective haplotypes were described in the index population from Stoll's group (28). These data have been partially replicated in one study (31), but not in two others $(32,33)$. As with NOD2/CARD15, Japanese patients with CD do not display any of the SNPs of the DLG5 locus described in Caucasian patients, but SNPs unique to the Japanese population show weak associations with CD (34).

\section{TLR-4}

After the discovery of the NOD2/CARD15 gene and the realization of the significance of intraluminal bacteria in the pathogenesis of IBD, it was appropriate to look specifically for polymorphisms affecting the receptors of the innate immune system. Lipopolysaccharide, released by Gram-negative bacteria, is a ligand that binds with TLR4 expressed on intestinal epithelial cells. The TLR4 Asp299Gly polymorphism is associated with decreased bronchial responsiveness to lipopolysaccharide in humans, with reduced activation in transfection experiments, similar to some of the NOD2/CARD15 mutations (35). The TLR4 Asp299Gly polymorphism was associated with CD and UC in a Belgian study (36), and with CD in Greek and Dutch populations $(37,38)$. In a German cohort, an association was found between UC and the TLR4 Thr399Ile polymorphism (39). No association was found between the Asp299Gly polymorphism and IBD in German, Hungarian or Scottish datasets (39-41). Whether either of these two SNPs are the causal variants within the TLR4 gene remains controversial, and recent data imply they may simply be in linkage disequilibrium with the causal variants (42).

\section{Other IBD loci}

It is likely that a number of the other loci implicated by genome-wide screening will lead to the identification of other risk determinants for IBD. Some may be population-specific and be relevant to only a specific phenotype of disease; the lessons from the IBD1 locus are fresh in our minds. The IBD2 locus was first described in a United Kingdom dataset (18), and more recent data suggest that it is most strongly linked to colonic disease (43). The IBD4 locus (OMIM 606675) appears to be an important determinant of $\mathrm{CD}$ in the Flemish population in Belgium (44) and in populations in the United States (45). Most recently, these associations for the IBD4 locus have been replicated by the international genetics consortium (46). Although established criteria for definite linkage have not yet been met, the situation may change once fine mapping of the region and gene identification have been undertaken.

\section{CONCLUSIONS}

It is gratifying to consider how much progress has been made in genetic studies in IBD in the past decade. The application of molecular genetics has enhanced our understanding of disease pathobiology and has focused attention on the interaction 
between genetic factors and intestinal bacteria. Whether it be through intracellular (NOD2/CARD15) or cell surface (TLR) bacterial recognition, antigen processing (HLA molecules) or a breakdown in epithelial integrity (DLG5), the overwhelming swell of evidence supports the concept that IBD results from a genetic predisposition to excessive or abnormal interaction with an environmental stimulus, most likely part of the normal luminal bacterial flora which, in turn, leads to excessive immune activation and chronic inflammation.

The importance of germline variation of the NOD2/CARD15 gene provides proof of principle for studies of the molecular genetics in complex diseases, but it is still difficult to translate genetic findings to the clinical arena. It is hoped that, in the near future, discoveries in this field will yield a better understanding of the pathogenesis of IBD and lead to novel targeted therapies.

\section{REFERENCES}

1. Weissenbach J. The Human Genome Project: from mapping to sequencing. Clin Chem Lab Med 1998;36:511-4.

2. McKusick-Nathans Institute for Genetic Medicine, Johns Hopkins University Baltimore MD and National Center for Biotechnology Information National Library of Medicine Bethesda MD. Online Mendelian Inheritance in Man, OMIMTM.

<http://www.ncbi.nlm.nih.gov/omim/> (Version current at July 28, 2005)

3. Cavanaugh J, IBD International Genetics Consortium. International collaboration provides convincing linkage replication in complex disease through analysis of a large pooled data set: Crohn disease and chromosome 16. Am J Hum Genet 2001;68:1165-71.

4. Parkes M, Barmada MM, Satsangi J, Weeks DE, Jewell DP, Duerr RH. The IBD2 locus shows linkage heterogeneity between ulcerative colitis and Crohn disease. Am J Hum Genet 2000;67:1605-10.

5. Van Heel DA, Fisher SA, Kirby A, Daly MJ, Rioux JD, Lewis CM. Inflammatory bowel disease susceptibility loci defined by genome scan meta-analysis of 1952 affected relative pairs. Hum Mol Genet 2004;13:763-70.

6. Rioux JD, Silverberg MS, Daly MJ, et al. Genomewide search in Canadian families with inflammatory bowel disease reveals two novel susceptibility loci. Am J Hum Genet 2000;66:1863-70.

7. Rioux JD, Daly MJ, Silverberg MS, et al. Genetic variation in the 5 q31 cytokine gene cluster confers susceptibility to Crohn disease. Nat Genet 2001;29:223-8.

8. Daly MJ, Rioux JD, Schaffner SF, Hudson TJ, Lander ES. Highresolution haplotype structure in the human genome. Nat Genet 2001;29:229-32.

9. Peltekova VD, Wintle RF, Rubin LA, et al. Functional variants of OCTN cation transporter genes are associated with Crohn disease. Nat Genet 2004;36:471-5.

10. Newman B, Gu X, Wintle R, et al. A risk haplotype in the solute carrier family 22A4/22A5 gene cluster influences phenotypic expression of Crohn's disease. Gastroenterology 2005;128:260-9.

11. Noble CL, Nimmo E, Drummond H, Smith L, Arnott IDR, Satsangi J. OCTN $1 \& 2$ polymorphisms within the IBD5 locus predict susceptibility and severity in Crohn's disease. Aliment Pharmacol Ther 2005;21:199. (Abst)

12. Waller S, Tremelling M, Bredin F, et al. OCTN associated with Crohn's disease and ulcerative colitis but does it cause IBD? Gut 2005;54:062. (Abst)

13. Onnie C, Fisher S, Hampe J, et al. Multiple SNPs at the IBD5 locus contribute to the risk of Crohn's disease. Gut 2005;54:361. (Abst)

14. Armuzzi A, Ahmad T, Ling KL, et al. Genotype-phenotype analysis of the Crohn's disease susceptibility haplotype on chromosome $5 \mathrm{q} 31$. Gut 2003;52:1133-9.

15. Mirza MM, Fisher SA, King K, et al. Genetic evidence for interaction of the $5 \mathrm{q} 31$ cytokine locus and the CARD15 gene in Crohn disease. Am J Hum Genet 2003;72:1018-22.

16. Giallourakis C, Stoll M, Miller K, et al. IBD5 is a general risk factor for inflammatory bowel disease: Replication of association with Crohn disease and identification of a novel association with ulcerative colitis. Am J Hum Genet 2003;73:205-11.
17. McGovern DP, Van Heel DA, Negoro K, Ahmad T, Jewell DP. Further evidence of IBD5/CARD15 (NOD2) epistasis in the susceptibility to ulcerative colitis. Am J Hum Genet 2003;73:1465-6.

18. Satsangi J, Parkes M, Louis E, et al. Two stage genome-wide search in inflammatory bowel disease provides evidence for susceptibility loci on chromosomes 3, 7 and 12. Nat Genet 1996;14:199-202.

19. Panwala CM, Jones JC, Viney JL. A novel model of inflammatory bowel disease: Mice deficient for the multiple drug resistance gene, mdr1a, spontaneously develop colitis. J Immunol 1998;161:5733-44.

20. Moodie F, Lyons V, Satsangi J, Seckl JR. Effects of glucocorticoids on expression of $\mathrm{P}$-glycoprotein and glucocorticoid receptor in the intestinal epithelium. Gastroenterology 2004;126:A303. (Abst)

21. Mizoguchi E, Xavier RJ, Reinecker HC, et al. Colonic epithelial functional phenotype varies with type and phase of experimental colitis. Gastroenterology 2003;125:148-61.

22. Iizasa H, Genda N, Kitano T, et al. Altered expression and function of P-glycoprotein in dextran sodium sulfate-induced colitis in mice. J Pharmaceut Sci 2003;92:569-76.

23. Brant SR, Panhuysen CI Nicolae D, et al. MDR1 Ala893 polymorphism is associated with inflammatory bowel disease. Am J Hum Genet 2003;73:1282-92.

24. Schwab M, Schaeffeler E, Marx C, et al. Association between the C3435T MDR1 gene polymorphism and susceptibility for ulcerative colitis. Gastroenterology 2003;124:26-33.

25. Croucher PJ, Mascheretti S, Foelsch UR, Hampe J, Schreiber S. Lack of association between the C3435T MDR1 gene polymorphism and inflammatory bowel disease in two independent Northern European populations. Gastroenterology 2003;125:1919-20.

26. Glas J, Torok HP, Schiemann U, Folwaczny C. MDR1 gene polymorphism in ulcerative colitis. Gastroenterology 2004;126:367.

27. Ho GT, Nimmo ER, Tenesa A, et al. Allelic variations of the multidrug resistance gene determine susceptibility and disease behavior in ulcerative colitis. Gastroenterology 2005;128:288-96.

28. Stoll M, Corneliussen B, Costello CM, et al. Genetic variation in DLG5 is associated with inflammatory bowel disease. Nat Genet 2004;36:476-80.

29. Hampe J, Schreiber S, Shaw SH, et al. A genomewide analysis provides evidence for novel linkages in inflammatory bowel disease in a large European cohort. Am J Hum Genet 1999;64:808-16.

30. Wakabayashi M, Ito T, Mitsushima M, et al. Interaction of $\mathrm{lp}$-dlg/KIAA0583, a membrane-associated guanylate kinase family protein, with vinexin and beta-catenin at sites of cell-cell contact. J Biol Chem 2003;278:21709-14.

31. Daly MJ, Pearce AV, Farwell L, et al. Association of DLG5 R30Q variant with inflammatory bowel disease. Eur J Hum Genet 2005;13:835-9

32. Noble CL, Nimmo ER, Drummond H, Smith L, Arnott ID, Satsangi J. DLG5 variants do not influence susceptibility to inflammatory bowel disease in the Scottish population. Gut 2005, e-publication

33. Cummings JR, Herrlinger KR, Ahmad T, Jewell DP. Genotypephenotype analyses of the IBD susceptibility gene DLG5. Gut 2005;54:360. (Abst)

34. Yamazaki K, Takazoe M, Tanaka T, et al. Association analysis of SLC22A4, SLC22A5 and DLG5 in Japanese patients with Crohn disease. J Hum Genet 2004;49:664-8.

35. Arbour NC, Lorenz E, Schutte BC, et al. TLR4 mutations are associated with endotoxin hyporesponsiveness in humans. Nat Genet 2000;25:187-91.

36. Franchimont D, Vermeire S, El Housni H, et al. Deficient hostbacteria interactions in inflammatory bowel disease? The toll-like receptor (TLR)-4 Asp299gly polymorphism is associated with Crohn's disease and ulcerative colitis. Gut 2004;53:987-92.

37. Ouburg S, Mallant-Hent R, Crusius JBA, et al. The toll-like receptor 4 (TLR4) Asp299Gly polymorphism is associated with colonic localisation of Crohn's disease without a major role for the Saccharomyces cerevisiae mannan-LBP-CD14-TLR4 pathway. Gut 2005;54:439-40.

38. Gazouli M, Mantzaris G, Kotsinas A, et al. Association between polymorphisms in the Toll-like receptor 4, CD14, and CARD15/NOD2 and inflammatory bowel disease in the Greek population. World J Gastroenterol 2005;11:681-5.

39. Torok HP, Glas J, Tonenchi L, Mussack T, Folwaczny C. Polymorphisms of the lipopolysaccharide-signaling complex in inflammatory bowel disease: Association of a mutation in the Tolllike receptor 4 gene with ulcerative colitis. Clin Immunol 2004;112:85-91. 
40. Lakatos PL, Lakatos L, Szalay F, et al. Toll-like receptor 4 and NOD2/CARD15 mutations in Hungarian patients with Crohn's disease: Phenotype-genotype correlations. World J Gastroenterol 2005;11:1489-95.

41. Arnott ID, Nimmo ER, Drummond HE, et al. NOD2/CARD15, TLR4 and CD14 mutations in Scottish and Irish Crohn's disease patients: Evidence for genetic heterogeneity within Europe? Genes Immun 2004;5:417-25.

42. Oostenbrug LE, Drenth JP, de Jong DJ, et al. Association between toll-like receptor 4 and inflammatory bowel disease. Inflamm Bowel Dis 2005; 11:567-75.

43. Crawford N, Uthoff S, Eichenberger M, et al. Characterization of genotype-phenotype correlations show that the IBD2 susceptibility locus is associated with colonic Crohn's disease and ulcerative colitis. Gastroenterology 2003;124:A48. (Abst)

44. Vermeire S, Rutgeerts P, Van Steen K, et al. Genome wide scan in a Flemish inflammatory bowel disease population: Support for the IBD4 locus, population heterogeneity, and epistasis. Gut 2004;53:980-6

45. Duerr RH, Barmada MM, Zhang L, Pfutzer R, Weeks DE. Highdensity genome scan in Crohn disease shows confirmed linkage to chromosome 14q11-12. Am J Hum Genet 2000;66:1857-62.

46. Pierik M, Yang H, Barmada MM, et al. The IBD international genetics consortium provides further evidence for linkage to IBD4 and shows gene-environment interaction. Inflamm Bowel Dis 2005;11:1-7.

47. McGovern DP, Hysi P, Ahmade T et al. Association between a complex insertion/deletion polymorphism in NOD1 (CARD4) and susceptibility to inflammatory bowel disease. Hum Mol Genet 2005; 14:1245-50.

48. Urcelay E, Mendoza JL, Martinez A, et al. IBD5 polymorphisms in inflammatory bowel disease: Association with response to infliximab. World J Gastroenterol 2005;11:1187-92.

49. Carter MJ, di Giovine FS, Jones S, et al. Association of the interleukin 1 receptor antagonist gene with ulcerative colitis in Northern European Caucasians. Gut 2001;48:461-7.

50. Carter MJ, di Giovine FS, Cox A et al. The interleukin 1 receptor antagonist gene allele 2 as a predictor of pouchitis following colectomy and IPAA in ulcerative colitis. Gastroenterology 2001;121:805-11.

51. van der Paardt M, Crusius JB, Garcia-Gonzalez MA, et al. Interleukin-1beta and interleukin-1 receptor antagonist gene polymorphisms in ankylosing spondylitis. Rheumatology (Oxford) 2002:41:1419-23

52. Nohara $\mathrm{H}$, Inoue $\mathrm{N}$, Hibi $\mathrm{T}$, et al. Association between the interleukin-1 receptor antagonist polymorphism and ulcerative colitis with younger age at diagnosis. Immunol Lett 2003;90:53-7.

53. Karban AS, Okazaki T, Panhuysen CI, et al. Functional annotation of a novel NFKB1 promoter polymorphism that increases risk for ulcerative colitis. Hum Mol Genet 2004;13:35-45.

54. Borm MEA, He J, Kelsall B, et al. A major quantitative trait locus on mouse chromosome 3 is involved in disease susceptibility in different colitis models. Gastroenterology 2005;128:74-85.

55. Sugawara K, Olson TS, Moskaluk CA, et al. Linkage to peroxisome proliferator-activated receptor-gamma in SAMP1/YitFc mice and in human Crohn's disease. Gastroenterology 2005;128:351-60.

56. Gazouli M, Mantzaris G, Kotsinas A, et al. Association between polymorphisms in the Toll-like receptor 4, CD14, and CARD15/NOD2 and inflammatory bowel disease in the Greek population. World J Gastroenterol 2005;11:681-5.

57. Torok HP, Glas J, Tonenchi L, et al. Crohn's disease is associated with a toll-like receptor-9 polymorphism. Gastroenterology 2004;127:365-6.

58. Ahmad T, Tamboli CP, Jewell D, Colombel JF. Clinical relevance of advances in genetics and pharmacogenetics of IBD. Gastroenterology 2004;126:1533-49.

\section{Discussion - Progress and prospects for an integrated classification system}

\section{Crohn's disease}

Classification of CD is a difficult task because of the significant heterogeneity in disease presentation and course. In developing a classification system one must consider its purpose. Prior classification schemes have been developed mainly for the purposes of having a simple and practical clinical tool that can be easily recalled and implemented. Indeed, this was the rationale for the revision of the Rome classification to the Vienna classification - to reduce the number of possible classification categories from several hundred to 64. Beyond clinical use, however, a classification scheme is important in standardizing definitions and in developing consistency for research studies. In this case, comprehensiveness is more important than simplicity. It cannot be predicted a priori which genetic, serological or other future biomarkers will be pathophysiologically linked to a particular variation in disease expressivity. Data emerging from molecular and serological studies would suggest that a 'simplified' clinical proposal may not be sufficient to provide adequate information for classification based on genetic and serological markers. To identify the strongest pathophysiological association of a potential biomarker and IBD, the observed variations in phenotypes must be analyzed for the association. Furthermore, to have maximum power to make associations, potential sources of heterogeneity in disease etiology and/or pathogenesis should be reduced.

In the classification described in this Working Party report, the authors have addressed the difficulties and unresolved questions that evolved from the Vienna classification. Specifically, there are data from numerous sources that age of diagnosis is an important factor in disease course. The subclassification by age of diagnosis of 40 years was thought to be insufficient to capture some of these differences and, therefore, the updated classification scheme proposed here further subdivides earlier age of diagnosis into an A1 category to define age of diagnosis of 16 and younger, with A2 now describing age of diagnosis from age 17 to 40 years of age and A3 reserved for diagnosis older than 40 years of age. While this is thought to be a reasonable advance for the clinical classification, it is worthwhile noting that even further subdivisions may be required to address real differences in CD based on age of diagnosis. Some authors have reported unique clinical features for CD diagnosed earlier than eight years of age. More limited data also suggest that late age of diagnosis (ie, over the age of 60 years) may predict a different disease course. Accordingly, as part of a minimal data set that would be useful for studies evaluating the contribution of genetic and serological markers, it is recommended to record the exact age of diagnosis.

The currently proposed classification has also amended the Vienna classification with respect to disease location and behaviour by allowing for the co-classification of L4 with other disease location categories so this site can be examined in isolation and not be confounded by the cooccurrence of upper GI involvement and disease more distally. In addition, an independently documented variable known as the 'p' variable would be added to designate the presence or absence of perianal disease, allowing B3 to be defined as intra-abdominal penetrating disease. Both issues will allow improved accuracy of genotype/serotype correlation with disease phenotype.

While these are significant changes to the clinical classification system, it is worthwhile pointing out that using specific disease location sites as present or absent is an important feature of analysis by genetic and serological typing. For example, association of markers may occur with involvement of the upper GI tract or jejunum or with perianal disease alone. Therefore, it is recommended that a minimal dataset 
defining disease location for such studies should be as specific as possible as to the site of disease and presence or absence of inflammation (where absence implies that the site has been examined and found to be free of involvement). For a given site, 'unknown' needs to be recorded when an appropriate examination has not been performed. Areas of difficulty that require further investigation with respect to disease location include how to interpret the presence of microscopic involvement in the absence of gross evidence of disease by endoscopy or diagnostic imaging studies and the utility of recent advances in imaging, such as wireless capsule endoscopy.

Another area of critical importance is the issue of disease severity or disease progression, particularly in view of evolving data implicating genetic and serological markers that predict rapid progression and severe disease. Both in UC, and to a lesser extent in $\mathrm{CD}$, there are good measurements of disease severity for a given 'point-in-time'; however, it has been very difficult to define measurable parameters of what constitutes an overall severe disease course. Need for surgery or disease progression over time have both been used as surrogates in recent studies, but each has limitations. Indications for surgery may vary greatly and, in many centres, there has not been prospective data collection at regular intervals to determine disease progression. While our Working Party has not reached a consensus on an addition of this type of measure to the Montreal classification, it is suggested that future studies in large data sets with access to information about disease course over time be evaluated to arrive at definitions of severe disease and rapid progression.

Areas that have not been included in the clinical classification but are recommended as part of a minimal CD dataset for genetic and serological studies include presence or absence of extraintestinal manifestations and documentation of additional disease features such as ethnicity and country of birth, place of residence, smoking history and family history. All of these are related to some factors that affect the phenotype of $\mathrm{CD}$ or the course of disease.

The discovery of the NOD2/CARD15 gene and its involvement in the pathophysiology of $\mathrm{CD}$ has provided a paradigm for the integration of genetic markers into clinical classification. As discussed, however, the data currently available with respect to disease heterogeneity and gene penetrance argue against its use in clinical practice or decision making. Future studies will require that detailed phenotypic classification systems be used consistently by investigators throughout the world.

\section{Ulcerative colitis}

Many of the issues regarding $\mathrm{CD}$ are relevant to UC, in particular, the differing requirements of a purely clinical classification system and of one that allows assessment of integrated serotype/genotype-phenotype relationships. Even from a clinical viewpoint, however, there are several unique aspects to UC that deserve comment. Although UC is arguably a less heterogeneous disorder, it has been somewhat difficult to create a universally acceptable clinical classification scheme that takes into account all of the important aspects of the disease. The authors have developed the Montreal clinical classification for UC, which incorporates the maximal extent of colitis at the most recent assessment. The difficulty inherent in this approach, however, is the need for information on progression, or even regression, of disease over time. As with disease behaviour in $\mathrm{CD}$, extent in UC is clearly a dynamic process whose further elucidation may be required for meaningful correlation with genetic or serum markers.

The severity parameters for UC relate to acute relapses, instead of to changes in severity over time. The latter may be more relevant to molecular and serological markers in UC. Using surrogate measures like the need for surgery, a number of markers have already been implicated, notably HLADRB $1 * 0103$ and variants of the MDR1 gene. The historical data from Oxford from Edwards and Truelove (1) strongly suggested that there are distinct patterns of disease activity over time. We see the need to move towards the development of an acceptable classification system that addresses this facet of disease phenotype before the next World Congress. Based on the data from Langholz et al (2), a system that includes the number of flares over time or the time to colectomy might be most useful in this context.

Other areas of critical importance are the occurrence of dysplasia or cancer and the presence of PSC with UC. Some distinct molecular and serological associations have been described in relation to these phenotypes and therefore their presence should be documented as part of a minimal research data set. While somewhat rare, these concurrent diseases result in substantial morbidity and mortality in UC and are important targets for molecular and serological studies using large, collaborative datasets.

We have also discussed a number of other pertinent issues, including age at diagnosis, microscopic versus gross disease extent, and extraintestinal manifestations. As with CD, these parameters might not warrant inclusion as separate entities in an essentially clinically based system, but should be part of the minimal dataset for a research-based analysis of genetic and serological markers. The concept of age-related heterogeneity in UC is supported by data regarding smoking cessation and some preliminary genetic data, while there is strong genetic and epidemiological evidence that extraintestinal manifestations have a distinct genetic basis.

\section{Indeterminate colitis}

IC is a confusing entity that is inconsistently understood by clinicians and the IBD pathologists alike. The members of the Working Party strongly contend that definitions should be improved and standardized so that emerging molecular and serological markers could be optimally utilized. Future studies should then enable us to determine whether this disease eventually evolves into $\mathrm{CD}$ or $\mathrm{UC}$, is its own unique entity or perhaps is something in between.

The authors of this section of our report have proposed reverting to the original definition for IC in cases of chronic IBD without characteristic features of either UC or CD in a colectomy specimen. The novel term 'colonic IBDU' should be applied to patients who have not undergone surgery, in whom the diagnosis depends on clinical and endoscopic features together with histopathological findings from mucosal biopsies. Use of this term recognizes that IBD has been diagnosed but that additional clinical, imaging, serological and genetic information might be of value in further characterizing the condition. Serological markers promise to identify patients who would eventually progress to definite $\mathrm{CD}$ or $\mathrm{UC}$, as well as those who would not (the 'seronegative' group).

In summary, the need for a classification system for IBD has evolved in recent years from the requirement for a simple clinically based scheme to one that allows the integration of the 
rapidly evolving data on serotypes and genotypes. Indeed, these data may in turn lead to a transformation of the classification of IBD. At present, the data with respect to serotypes and genotypes are not sufficiently robust for use in clinical practice or in the recommended clinical classification systems for $\mathrm{CD}, \mathrm{UC}$ or IC. However, any future integrated classification system will depend on standardization of research-related and clinical diagnostic criteria. In turn, minimal datasets must include sufficient relevant clinical data to allow exploration and confirmation of genotype/serotype-phenotype relationships in diverse populations. Our goal for the next five years will be to facilitate this process and move toward an integrated system for the classification of IBD.

\section{REFERENCES}

1. Edwards FC, Truelove SC. The course and prognosis of ulcerative colitis. Gut 1963;4:299-308.

2. Langholz E, Munkholm P, Davidsen M, Binder V. Course of ulcerative colitis: Analysis of changes in disease activity over years. Gastroenterology 1994;107:3-11.
ACKNOWLEDGEMENTS: The Working Party Chairs would like to acknowledge the work of the individual chapter authors as well as of the Writing Committee (WC): Chairs - Mark Silverberg, Jack Satsangi; WC - Mark Silverberg, Jack Satsangi, Ian Arnott, Steven Brant, Jean-Frédéric Colombel, Bryan Warren; Introduction - WC; Crohn's disease clinical classification - A Hillary Steinhart, Christoph Gasche, David Sachar; Ulcerative colitis clinical classification - Edward Loftus, Renzo Caprilli, Derek Jewell; Indeterminate colitis - Severine Vermeire, Karel Geboes, Bryan Warren, Robert Riddell; Geography and ethnicity - Ian Arnott, Amir Karban, Charles Bernstein; Serology - Jean-Frédéric Colombel, Stephan Targan; NOD2/CARD15 - Steven Brant; Human leukocyte antigen Tariq Ahmad, Sara Marshall, A Salvador Peña; New genes Daniel Gaya, Richard Russell, Elaine Nimmo, Steven Brant, Jack Satsangi; Discussion - WC. 


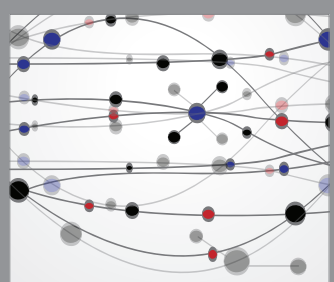

The Scientific World Journal
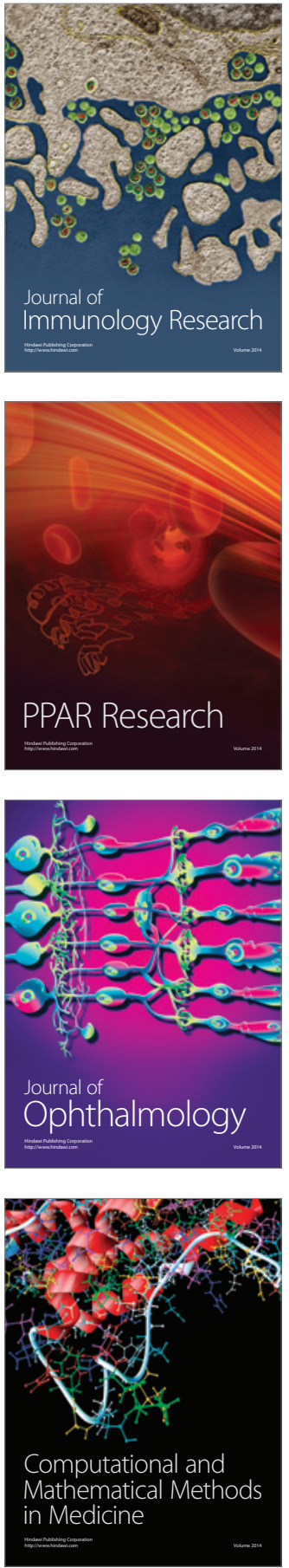

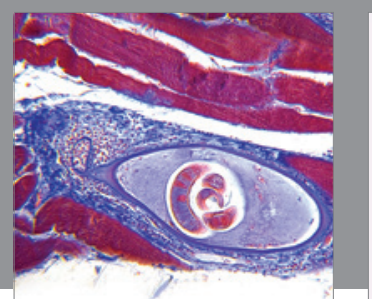

Gastroenterology Research and Practice

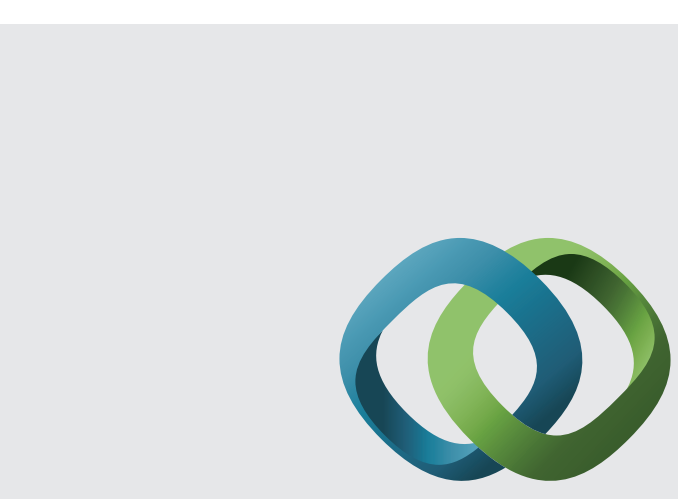

\section{Hindawi}

Submit your manuscripts at

http://www.hindawi.com
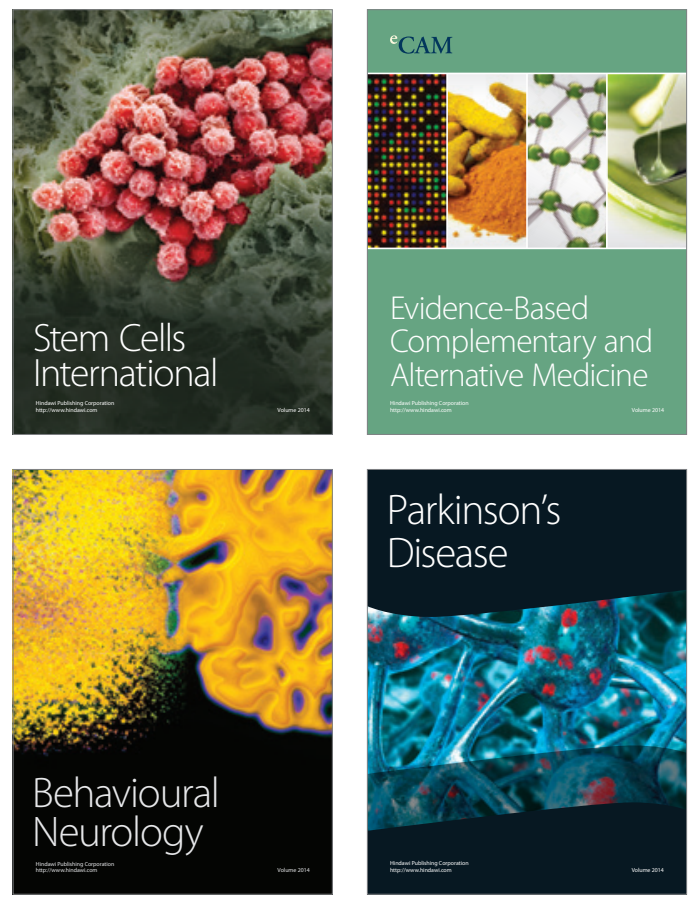
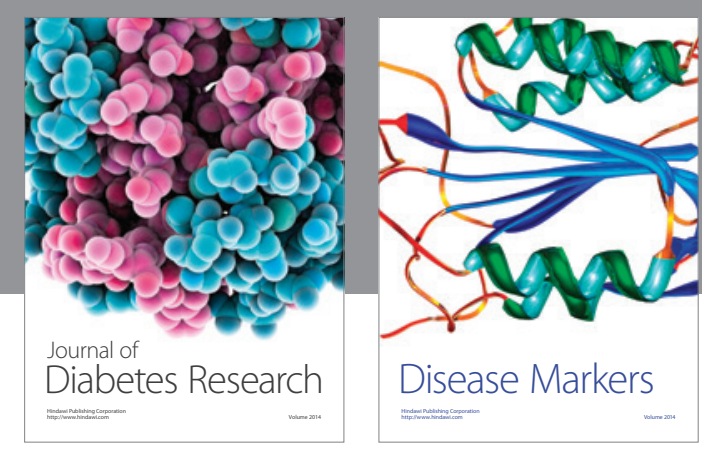

Disease Markers
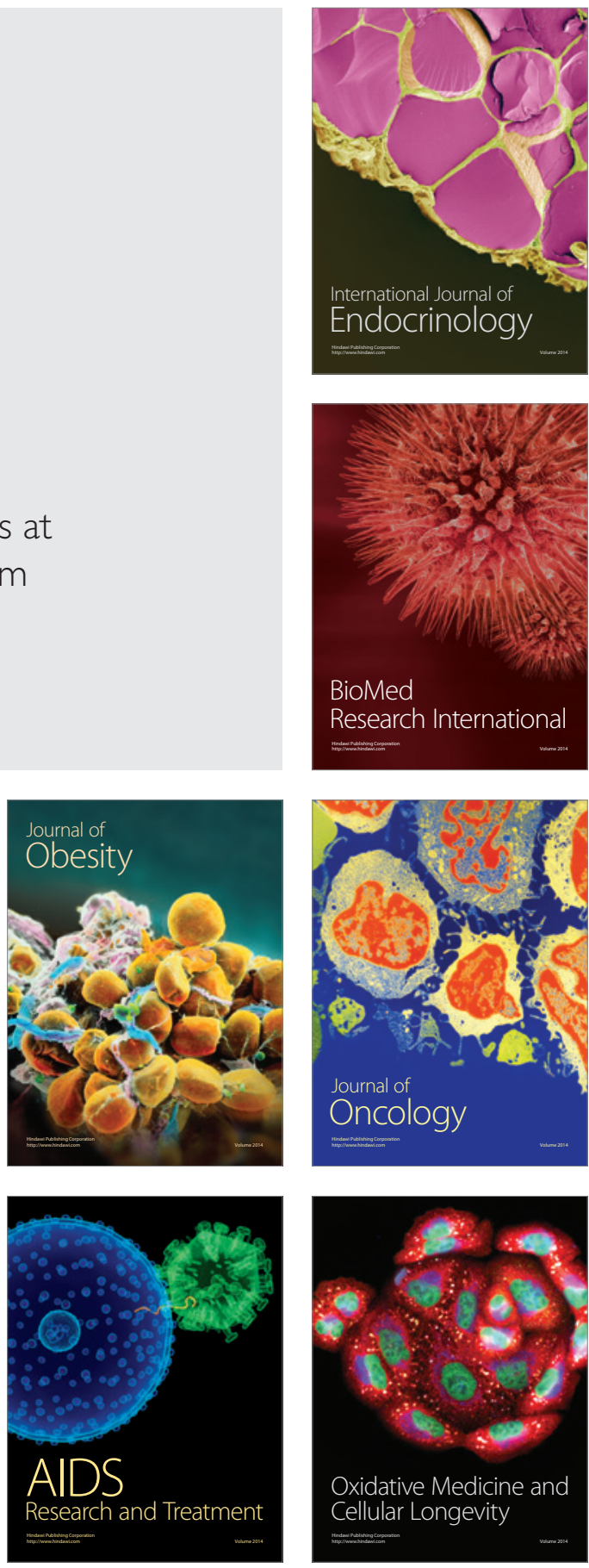